\title{
Men Faculty Engagement in Gender Equity Work in STEM: The Radicalization of "Doing the Right Thing"
}

Amena Oliver Anderson

Follow this and additional works at: https://researchrepository.wvu.edu/etd

\section{Recommended Citation}

Anderson, Amena Oliver, "Men Faculty Engagement in Gender Equity Work in STEM: The Radicalization of "Doing the Right Thing"'" (2017). Graduate Theses, Dissertations, and Problem Reports. 5103.

https://researchrepository.wvu.edu/etd/5103

This Dissertation is protected by copyright and/or related rights. It has been brought to you by the The Research Repository @ WVU with permission from the rights-holder(s). You are free to use this Dissertation in any way that is permitted by the copyright and related rights legislation that applies to your use. For other uses you must obtain permission from the rights-holder(s) directly, unless additional rights are indicated by a Creative Commons license in the record and/ or on the work itself. This Dissertation has been accepted for inclusion in WVU Graduate Theses, Dissertations, and Problem Reports collection by an authorized administrator of The Research Repository @ WVU.

For more information, please contact researchrepository@mail.wvu.edu. 
Men Faculty Engagement in Gender Equity Work in STEM:

The Radicalization of "Doing the Right Thing"

Amena Oliver Anderson

Dissertation submitted

to the College of Education and Human Services

at West Virginia University

in partial fulfillment of the requirements for the degree of

Doctor of Philosophy in

Education

Erin McHenry-Sorber, Ph.D., Chair

S. Melissa Latimer, Ph.D.

Nathaniel M. Sorber, Ph.D.

Scott A. Myers, Ph.D.

Samuel F. Stack, Ph.D.

Department of Curriculum and Instruction/Literacy Studies

Morgantown, West Virginia

2017

Keywords: men faculty, ally identity, gender equity, allies, advocates, NSF ADVANCE, STEM

Copyright 2017 Amena Oliver Anderson 


\section{ABSTRACT \\ Men Faculty Engagement in Gender Equity Work in STEM}

\section{Amena Oliver Anderson}

This grounded theory study explores the sparsely examined phenomenon of men faculty engagement in gender equity work through the National Science Foundation's (NSF) ADVANCE project and one of its program innovations, Men Faculty Advocates and Allies (A \& A). The A \& A initiative recruits two categories of men faculty - advocates and allies - to engage in a program of work designed to heighten awareness about gender inequity and redress it through strategic efforts at the individual, departmental, and institutional level. Advocates are usually senior faculty or program administrators from within and outside of STEM fields. They assume the greater part of the program work which includes self-initiated education and awareness as well as facilitating educational workshops and dialogues for various contingents of faculty men across their campuses. Men targeted to serve as allies are typically junior faculty who are encouraged to participate in ongoing educational awareness activities and to attend or support A \& A program initiatives but are not expected to take on additional work as they focus on attaining tenure. Of interest in this study were the drivers of men faculty's initial and continuous engagement in this work, the work itself - that is, the activities described as gender equity work, men faculty perceptions of their personal ally identity development, and the implications of academic and institutional context on men faculty's experiences of engagement in this work. A rigorous analysis of data generated during 35 interviews with 29 men and 6 women faculty at six ADVANCE program sites with formal A \& A programs revealed four initial drivers of men faculty engagement in gender equity work. These include: prior interest or involvement in equity work, recognition of and desire to solve the problem, belief in ability to help solve the problem, and sense of duty. Four continuous drivers of engagement were also revealed. These include: belief in the importance of the work undertaken by ADVANCE/A \&A, a continued sense of duty, satisfaction with the engagement experience, and positive feedback from significant others. Additionally, data revealed that men talk about their ally identity in two primary ways: as an "ever-evolving" process, and as ally-indicative actions. Participants perceived gender equity work as encompassing an array of activities including micro-actions like challenging another colleague's biased comment, and macro-actions like revamping search committee policies and practices to ensure more diverse pools of candidates. Institutional dynamics including: disposition toward sharing data, shifting priorities from teaching to research, perceived levels of support for faculty engagement in gender equity work, and the quality of the pre-existing ADVANCE initiative all emerged as variables which may influence the continuous engagement of men faculty in this work. A theory of academic men's continuous engagement in gender equity work is proposed. To accomplish the goal of diversity, equity, and inclusion, academic and administrative leaders must consider a portfolio of empirically-tested social justice-oriented change strategies that promote desired outcomes and mitigate wellintended program failure. Given that a key indicator of program demise is member disengagement. The extent to which members remain continuously engaged is likely to positively impact program sustainability. In the case of ADVANCE/A \& A, there appears to be a strong chance of program survival. 


\section{ACKNOWLEDGEMENTS}

This is for the little girl within me who learned early on how to project strength, confidence and know-how even when she felt vulnerable, insecure, and clumsy. This is for every little girl like her who may question if they have what it takes-yes, dear ones you do! This is for my mother who could care less how old I am, or how long this journey has been. She has never put away her pompoms. Even when it looked as if I was going to lose, she was on the sidelines cheering me on, running alongside me — reminding me I'm still in the game - there is still time on the clock. This is for my three-heartbeats, my Malcolm, my Noah, my McKinley. As awesome as earning my $\mathrm{PhD}$ is, the three of you are my greatest accomplishments. Thank you for all the ways each of you have supported mommy on this journey. To my funders-THANK YOU! I can’t express enough how grateful I am for the opportunity I was given to make this pursuit a full-time endeavor. VP Fryson and Dr. C your faith in me continues to be a sustaining force. To Erin and Melissa and Maja, thank you for the incredible sister-scholar-friends and mentors you have been to me during this journey — although uncompromising in your standards of excellence, you were always considerate and generous of spirit in your guidance and encouragement. To Nate and Scott and Sam — thank you for agreeing to serve on my dissertation committee but especially for the lessons I learned and skills I developed in your classrooms that have been instrumental in getting me to this culminating point. To my institution, my home among the hills, I am so proud to be a Mountaineer! I pray that in moving forward, I always find ways to reflect the exceptionalism that is WVU. 
"Radicalization involves increased commitment to the position one has chosen, and thus ever greater engagement in the effort to transform concrete, objective reality"

Paulo Freire (1970) 


\section{Table of Contents}

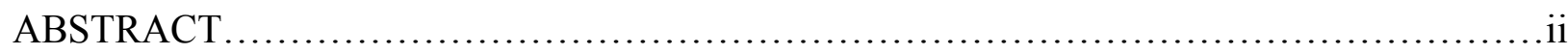

ACKNOWLEDGEMENTS...............................................................ii

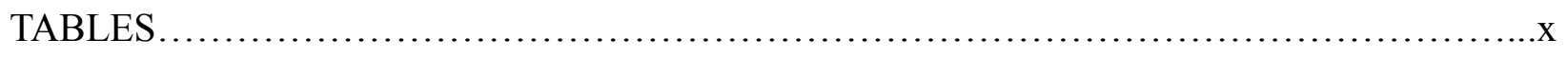

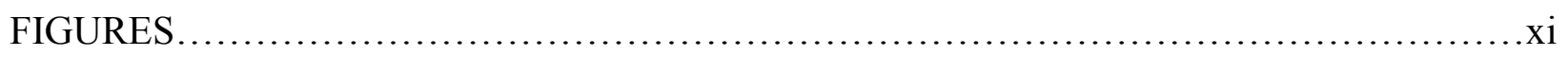

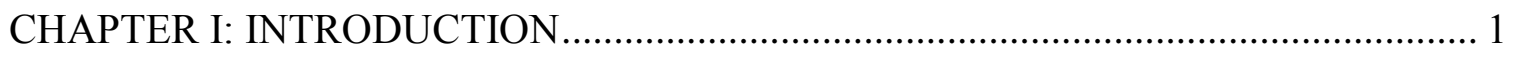

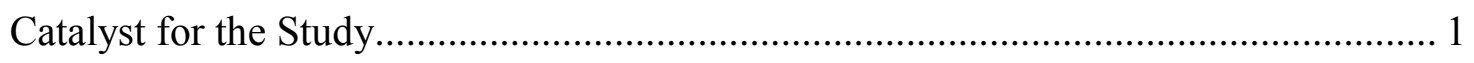

Explanations of Key Terms/Concepts ..................................................................... 3

Pilot Study of Men Faculty Advocates …………………………………………....... 3

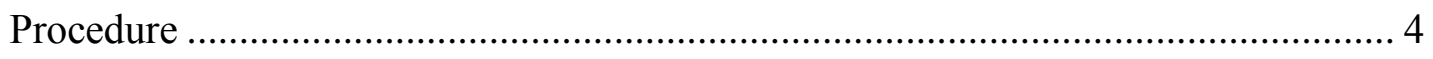

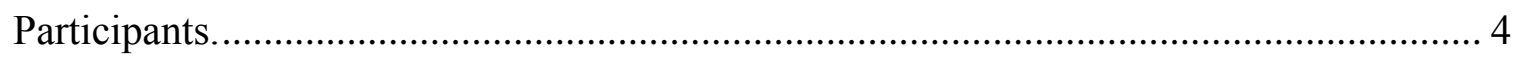

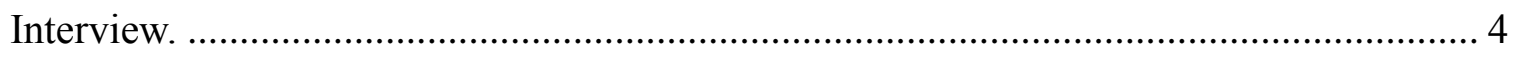

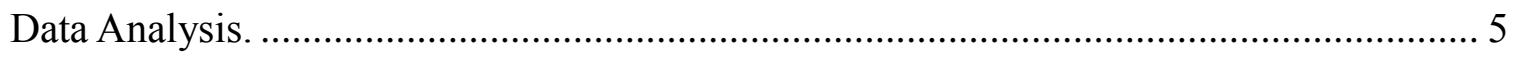

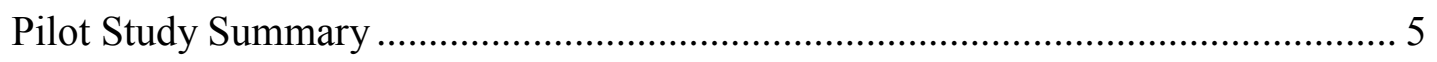

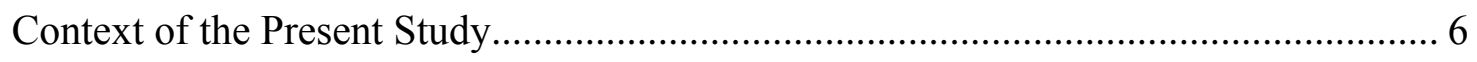

Synopsis of the Gender Inequity Problem in STEM …………................................ 6

The NSF ADVANCE Project ....................................................................... 10

The Men Faculty Advocates \& Allies (A \& A) Program ........................................... 12

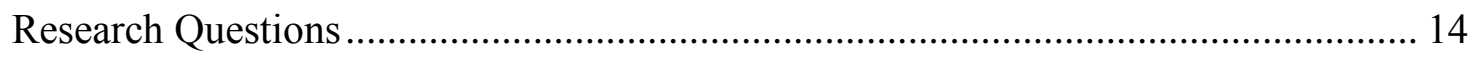

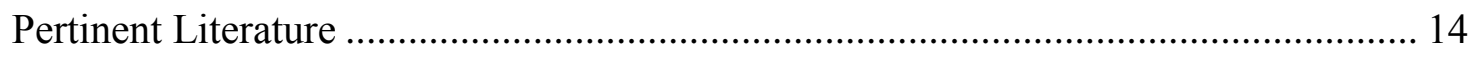

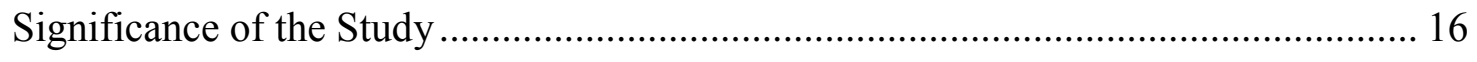


CHAPTER II: LITERATURE REVIEW

Daily Practices \& Meaning: Expanding Conceptualizations of Faculty Work......... 22

Faculty Work as In-Role \& Extra-Role Behavior ............................................. 23

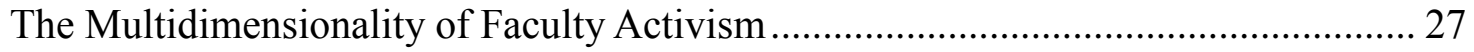

Faculty Activism as Engaged Scholarship ..................................................... 29

Faculty Activism as Protest..................................................................... 34

Faculty Activism as Leadership for a Just Institution (LJI) ................................ 38

The Peculiarity of Dominant Group Member Social Justice Activism........................ 42

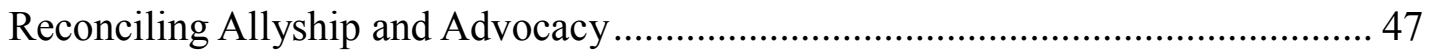

Key Issues Addressed in the Literature on Social Justice Allyship and Advocacy .. 48

Pertinent Theories and Research on Men Allyship \& Advocacy............................. 51

Men as a Specific Dominant Identity Group .................................................... 52

Barriers to, Antecedents, and Consequences of Men Allyship .............................. 58

The Gendered Academic Organization ............................................................... 79

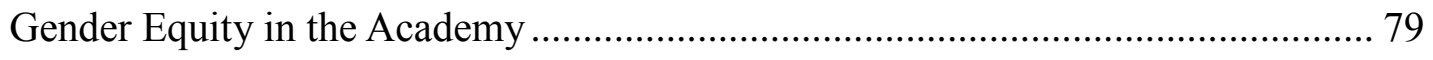

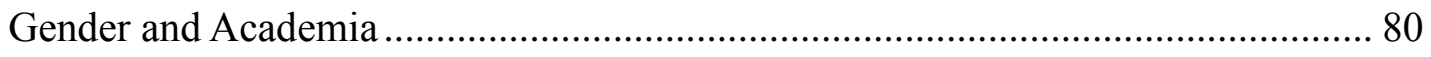

Roles of Faculty Actors in Gender Equity Work ................................................. 83 
Summary

Research Questions ................................................................................... 94

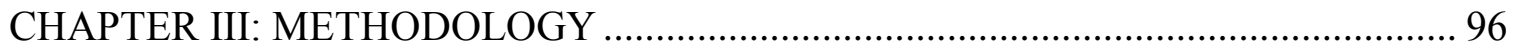

Phenomenology as Philosophy Underlying Grounded Theory (GT) ........................ 96

Grounded Theory as a Research Methodology..................................................... 98

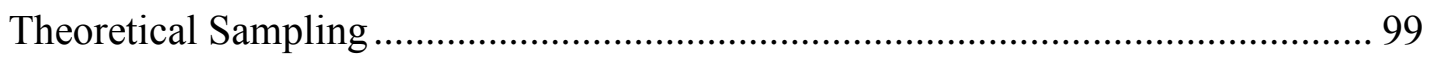

Constant Comparative Analysis ............................................................... 100

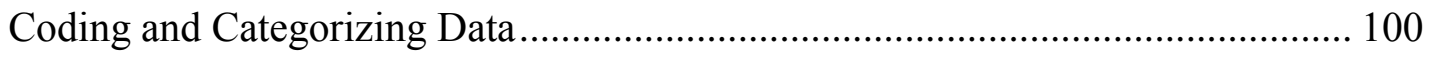

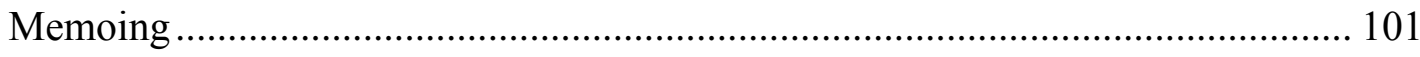

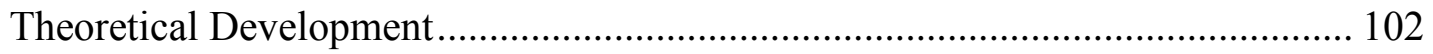

Presenting Grounded Theory at the End of the Study ......................................... 102

Research Procedure.................................................................................. 102

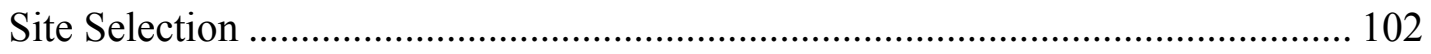

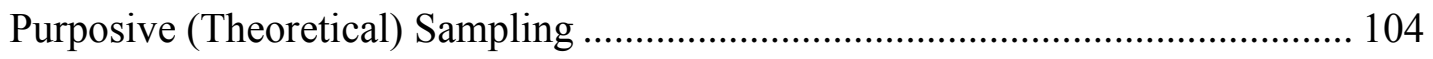

Participant Recruitment Strategy ................................................................. 105

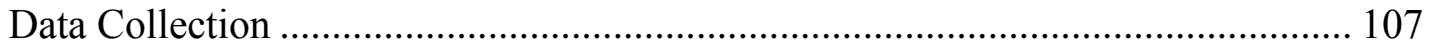

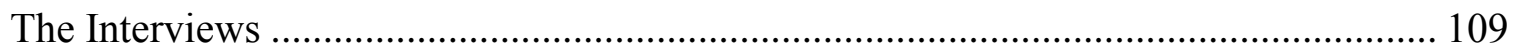

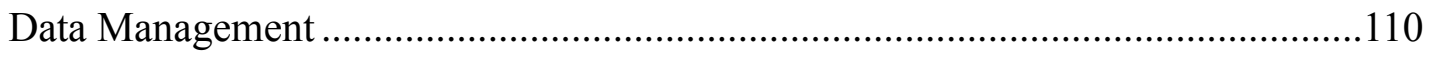

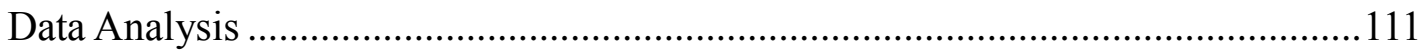

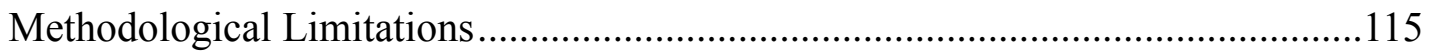


Recognition of and Desire to Solve the Gender Inequity Problem.

Drivers of Continuous Engagement.

Belief in Importance of ADVANCE/ A \& A Work.

Implications.

How Do Men Faculty Talk About Their Ally Identity Development? ..................... 132

Seasoned Social Justice Allies ...

The Appropriate Role of Men Allies in 'Women-Centered' Initiatives 138

The Intersectionality of Allies 140

Wearing an Advocate/Ally or Feminist Label..... 142 


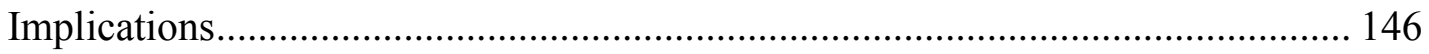

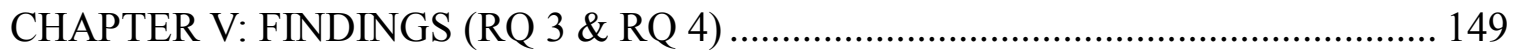

What are Men Faculty Perceptions of Gender Equity Work? …………………….... 149

Academic Leader Perceptions of In-Role Behavior (IRB) ..................................... 154

Gender Equity Work \& Traditional Faculty Work Fit............................................. 156

Time Spent on Gender Equity Work …………………….............................. 157

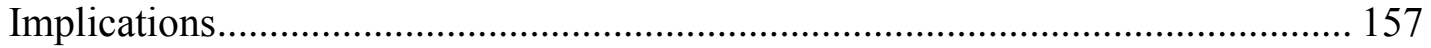

What are the Implications of Institutional Context/Site Dynamics on the Work? ...... 158

Institutional Disposition Toward Data \& New Research Mission ............................ 159

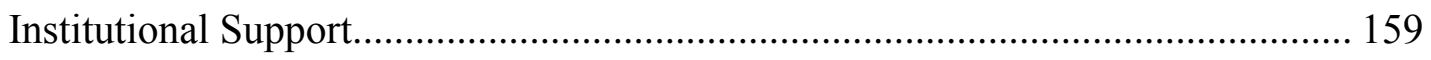

Perceptions of the Pre-existing ADVANCE-IT Project ........................................... 163

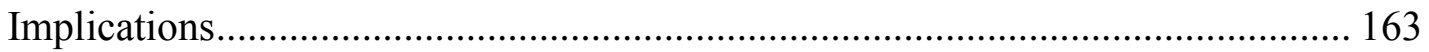

CHAPTER VI: GROUNDED THEORY \& CONCLUSIONS ........................................ 166

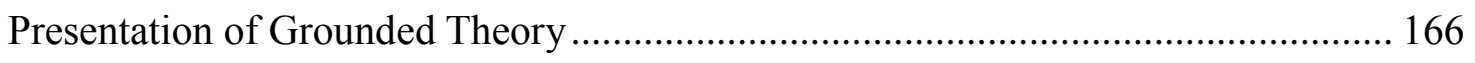

Explanation of the Theoretical Model ............................................................... 166

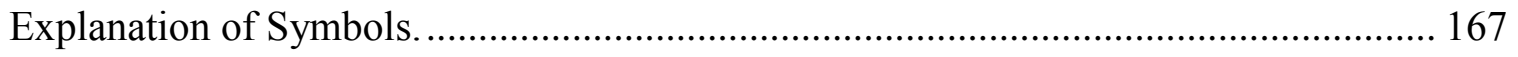

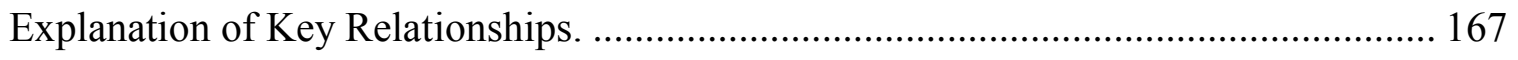

Intervening Factors \& Alternate Pathways. ............................................................... 168

The Continuous Nature of the Model. ..................................................................... 169

The Complexity of the Model................................................................................ 170 


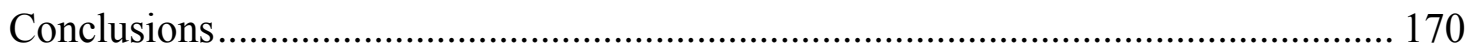

Future Directions for Research .................................................................. 171

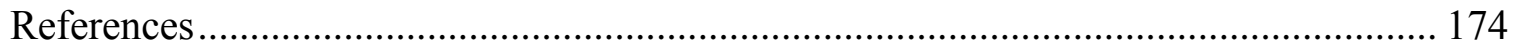

APPENDIX A--Letter to ADVANCE Women Leaders .............................................. 204

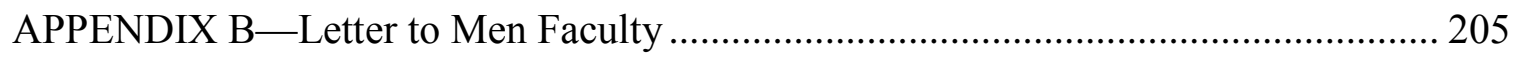

APPENDIX C_Demographic Questionnaire .................................................... 206

APPENDIX D_-Interview Protocol (Men) ........................................................... 208

APPENDIX E-Interview Protocol (Women) .................................................. 210 


\section{List of Tables}

Table 1. Themes from Pilot: Components of Men Faculty Advocacy for Gender Equity............. 5

Table 2. Key Factors Contributing to Gender Inequity Problem (...) .................................... 10

Table 3. Boulding's (2014) Abridged Theory of Protest .................................................... 37

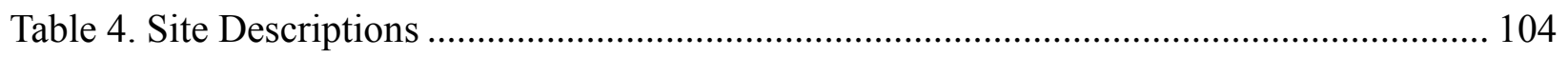

Table 5. Men Faculty Participant Descriptions ............................................................... 106

Table 6. Women Leader Participant Descriptions ........................................................... 107

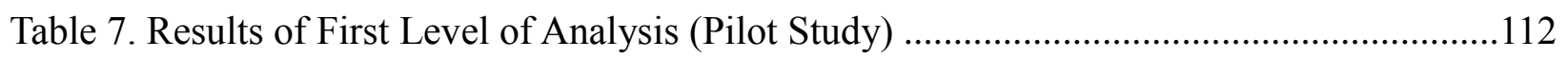

Table 8. Results of Second-Level Analysis "Conceptualizing" .............................................113

Table 9. Theoretical Relationships between Emergent Analytic Categories ............................115

Table 10. Initial \& Continuous Drivers of Engagement in Gender Equity Work ......................117

Table 11. Men Faculty Conceptualizations of Ally Identity Development............................. 137

Table 12. Key Objectives of Gender Equity Work \& Strategies Used to Accomplish Them ..... 158

Table 13. Site Dynamics \& Their Implications................................................................. 164 


\section{List of Figures}

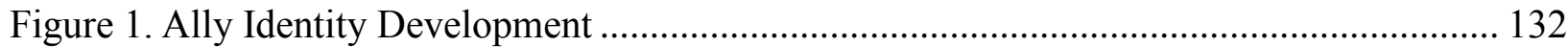

Figure 2. Presentation of Theory of Academic Men's Significant \& Continuous Engagement . 166 


\section{CHAPTER I: INTRODUCTION}

This chapter begins with the catalyst for the study, followed by a report of a pilot study conducted to learn more about the topic of the study, a section explicating study context, a statement of the significance of the study, a brief description of pertinent extant literature related to the study, a problem statement and a list of the major research questions guiding the inquiry. It concludes with a short summary of subsequent dissertation chapter content.

\section{Catalyst for the Study}

As a seasoned higher education leader with specific responsibilities and expertise in diversity education and programming, I have been intrigued by the extent to which my colleagues in the faculty and staff who are members of dominant groups engage in activities that might be characterized as social justice activism. My informal observation has been that there is significant variation in both the type of social justice activism in which majority group faculty/staff engage, and the levels of their engagement in social justice activism. That is, some majority group faculty/staff would be described as having no level of engagement in any sort of social justice activism, while others might be described as having a moderate to high level of engagement in such activities. In my exploration of the literature on dominant group member engagement in social justice work within academia, I discovered that extant research centers on the experiences and/or perspectives of (mostly White) students (see Broido, 2000; Hong, 2000; Munin \& Speight, 2010; Rice, 2009). In fact, while I found two studies which examined faculty engagement in social justice work, only one, Patton and Bondi (2015), targeted faculty who belonged to a dominant social identity group — men. The other, Messinger (2011) targeted faculty engaged in LGBTQ work irrespective of their social group identity. The scant research on the experiences and perspectives of dominant group member faculty who engage in social 
justice work is not only alarming, but an oversight that may have serious implications for the success of social justice initiatives. As Manning (2013) points out, faculty (and administrators) on most college campuses wield considerable decision-making power. Therefore, the extent to which those who are members of dominant groups engage in social justice work can be expected to have significant implications on the success of those initiatives. During the fall of 2014, I learned about a new, men faculty-only gender-equity advocacy group called Advocates \& Allies (A \&A) formed under the umbrella of a larger National Science Foundation (NSF) initiative called ADVANCE. The broader ADVANCE initiative aims to improve the climate for and support the advancement of academic women in the sciences. The A \& A initiative was “designed to train and support men faculty working alongside women faculty (STEM and nonSTEM) to advocate for gender equity on campus" (Anicha, Burnett, Bilen-Green, 2015, p. 22). Given their objectives ADVANCE and the A \& A program provide a viable context for the exploration of dominant group social justice-related activism (in this case, gender equity) among men faculty. As Patton and Bondi (2015) explain in their study of White men in academia identified by their colleagues as allies, "Focusing on white men, is relevant because they occupy significant spaces in the academy as college presidents, senior administrators, and faculty (especially full professors), hence, their ability to wield power not experienced by non-dominant populations" (p. 491). Acker (2012) echoes this sentiment, "white men are still clearly the dominant category in the top positions in almost all organizations" (p. 2014). To learn more about the A \& A, I conducted a pilot study with the new group during the spring of 2015 . Before I discuss the pilot study and its pertinent findings, I clarify key terms and concepts used throughout this study. 


\section{Explanations of Key Terms/Concepts}

Men Faculty Engagement: As a construct in the education and learning science literature, engagement has been problematized for its lack of definitional clarity and its inconsistent theoretical underpinnings (Azevedo, 2015; Sinatra, Heddy, \& Lombardi, 2015). In this study, engagement is not operationalized as a construct to be measured quantitatively, but as a concept which explains the type, level, and significance (or impact) of men faculty involvement in activities described as gender equity work.

Gender Equity Work: In this study, gender equity work is conceptualized as an intentional pattern of activities enacted to promote equitable and inclusive interpersonal and organizational experiences and climates for women and other marginalized persons.

Men Faculty Advocacy: In this study, men faculty advocacy refers to activities men faculty undertake to intentionally support gender equity work.

\section{Pilot Study of Men Faculty Advocates}

Although scholars have espoused the benefits of pilot studies to broader research projects (DeVaus, 1993; Frankland \& Bloor, 1999; Nunes, Martins, Zhou, Alajamy, \& Al-Mamari, 2010; Polit, Beck, \& Hungler, 2001; Prescott \& Soeken, 1989; Simon, 2011; van Teijlingen \& Hundley, 2001), as Prescott and Soeken (1989) point out, pilot studies are mostly "underdiscussed, underused and underreported" (p. 60). van Teijlingen and Hundley (2001) point out that the experiences and issues arising during the pilot should be included in the larger study to make explicit the researcher's holistic experience. In addition to this benefit, Frankland and Bloor (1999) add that pilot studies can help provide a "clear definition of the focus of the study" (p. $154)$. 


\section{Procedure}

After securing IRB approval, I reached out to the director of the ADVANCE project at the public, land-grant institution where the newly formed men faculty advocate group I had learned about exists to arrange a focus group like interview with the groups' members. The director introduced me by email to the group's chair. After explaining the subject of my research, the chair complied with my request and sent an email to group members which included my invitation to participate in the project, and a plan to conduct the focus group interview during the group's next regularly scheduled meeting. According to Krueger and Casey (2009),

The purpose of conducting a focus group is to listen and gather information...to better understand how people feel or think about an issue...Participants are selected because they have certain characteristics in common that relate to the topic of the focus group (p. 2).

Although focus groups typically consist of 5-10 members, on the appointed date for the focus group interview only 3 of the group's 7 members showed up and I conducted the interview with them.

Participants. The three pilot participants were straight White men whose average age was 46. All the men were married to women and each had more than 2 children. Two of the men were tenured faculty members, the other a program administrator. Combined, their average years at the institution was 12 . To protect their identities, I eliminated, to the extent possible, all personal and institutional identifying data and used pseudonyms to report their responses.

Interview. The 48-minute-long, focus group interview took place in a classroom with ushaped seating in the academic department of the group's chair (one of the three participants). I 
recorded the entire interview — which I later transcribed — using a voice recorder application I downloaded on my iPad.

Data Analysis. The data generated from this study came from participant responses to 10 semi-structured interview questions designed to explore the phenomenon of men faculty advocacy as it pertains to advocate identity and advocacy work. Citing Adler and Adler (1987), Saldana (2013) explains that interview questions act as a "filter" for "how you perceive, document, and thus code your data..." (p. 7). In the context of the pilot, this filter resulted in an initial round of codes that fit into one of three main themes, under the subheading, Components of Men Faculty Advocacy for Gender Equity. The three themes are: Raising One's

Consciousness, Developing an Advocate/Ally Identity, and Taking-Action. Subsequent coding revealed emergent categories of data under these themes. These are depicted below in Table 1.

Table 1. Themes from Pilot: Components of Men Faculty Advocacy for Gender Equity

\begin{tabular}{|c|c|c|}
\hline $\begin{array}{l}\text { Raising One's } \\
\text { Consciousness }\end{array}$ & $\begin{array}{l}\text { Ally Identity } \\
\text { Development }\end{array}$ & Taking-Action \\
\hline $\begin{array}{l}\text { Heighten Awareness of } \\
\text { Issues } \\
\text { Self-Initiated Education } \\
\text { Reflect on Role in Inequity }\end{array}$ & $\begin{array}{l}\text { Engage } \\
\text { Continual Learning } \\
\text { Confront Injustice } \\
\text { Seek Feedback \& Reflect } \\
\text { Repeat }\end{array}$ & $\begin{array}{l}\text { Keep Learning } \\
\text { Support \& Affirm } \\
\text { marginalized others } \\
\text { Making inequities visible to } \\
\text { others } \\
\text { Recruit other allies } \\
\text { Don't overshadow women }\end{array}$ \\
\hline
\end{tabular}

\section{Pilot Study Summary}

The emergence of three salient themes and several categories of data under those themes affirmed the viability of pursuing this topic for the dissertation study. However, textual factors 
such as the single data collection strategy at a single site, the size of the focus group, the newness of the men faculty advocate initiative, the absence of the voices of women from the study, and the researcher's novice skill in conducting focus group interviews limited the extent to which findings from the pilot could be used to develop or extend theories about men faculty advocacy for gender equity. Nevertheless, pilot study findings did serve the purpose of "sensitizing concepts," that is, "[providing] initial ideas to pursue and sensitiz[ing] [the researcher] to ask particular kinds of questions about [the] topic" (Blumer, 1969, as cited by Charmaz, 2006, p. 16), including those the pilot study failed to raise.

\section{Context of the Present Study}

To contextualize the present study, the following sections include a synopsis of the gender inequity problem in STEM, an explanation of the broader NSF ADVANCE project, and a description of the Men Faculty Advocates \& Allies (A \& A) Program.

\section{Synopsis of the Gender Inequity Problem in STEM}

The primary indicator of gender inequity in academic STEM is the disparity between the percentage of women in the U.S. earning PhDs in STEM fields and the percentage of women PhDs in STEM tenure-track faculty positions (Latimer, Jackson, Dilks, Nolan, \& Tower, 2014). The fact is that the number of doctoral degrees awarded in science and engineering fields is growing across the board. Between the years 2000-2011, the largest increases were in the fields of engineering (58\%) and in the biological sciences (52\%). The number of women earning terminal degrees in science and engineering has also increased remarkably since 1993, but still lags significantly behind the number of men earning terminal degrees in science and engineering fields (National Center for Science and Engineering, 2015). Per Women in the Sciences (2013), $\mathrm{PhD}$ holding women in the academic sciences (whether they have been in their field less/ more 
than ten years) are primarily located in the health sciences $(70.1 \%$--less than 10 years/62.5\%-more than 10 years) followed by psychology $(66.4 \% / 47.1 \%)$, social sciences $(47.0 \% / 31.5 \%)$, and the biological, agricultural, and environmental life sciences $(45 \% / 30.2 \%)$. The lowest percentage of $\mathrm{PhD}$ holding women is in mathematics/statistics (33.3\%/16.9\%) and engineering $(22.9 \% / 7.2 \%)$. The concerns about these disparities and key factors contributing to them are discussed next.

Concerns about the underrepresentation of women in academic STEM vary. A major concern has to do with the belief that woman scientists, like their men colleagues, have the potential to make invaluable contributions to their fields (Blickenstaff, 2005; Maher \& Thompson Tetreault, 2007). Arguing this point, Blickenstaff (2005) asserts that "[a]s scientists construct understandings of the world, the ability to see questions and answers from many perspectives will help make scientific explanations more robust and complete" (p. 370). Williams and Norton (2008) frame another concern in terms of the ways in which the underrepresentation of women faculty decreases an institution's competitive edge as well as its ability to attract female students to the most demanding STEM fields. Churchill (2011) makes the point that STEM faculty are awarded more grants, are paid higher salaries, and have "more social and financial cache" (Burnett, Bilen-Green, McGeorge, \& Anicha, 2012, p. 15) than other faculty on campus raising yet another concern about the ways in which the underrepresentation of women in STEM further disenfranchises women, while augmenting the privilege of men. The concerns I have discussed here are not exhaustive, but capture some of the forces driving gender equity efforts.

In the section below, I address some of the factors contributing to the underrepresentation of women in the highest STEM faculty and leadership ranks. 
While an attempt to pinpoint all the factors which contribute to the underrepresentation of women in the highest STEM faculty and leadership ranks would be more ambitious than the immediate goals of this study, I have identified four factors which seem to shape gender equity efforts in higher education. The first is negative perceptions generated from underrepresentation. The presence or absence of women in the highest STEM faculty and leadership ranks has an important impact on perceptions. In their study of factors contributing to a "chilly climate" for women faculty, Maranto and Griffin (2011) found that "women are less likely to feel a part of the collegial environment of their department as the percentage of female colleagues declines" ( $p$. 152). In an analysis of the effects of gender composition on the perceptions of women faculty in STEM, one set of researchers found that "a greater proportion of women in a department is related to increased perceptions that the department advances women" (Hillard, Schneider, Jackson, \& LaHuis p. 356). In other words, these findings suggest that the presence (or lack thereof) of women faculty can either boost or depress the morale of aspirant women faculty. Morale is important to consider because of its relationship to job satisfaction and intent to leave. As Burnett et al. (2012) point out, "[w]hen morale is high, faculty are engaged, have regard for their institution....maintain a sense of well-being, [and]... are less likely to intend to leave" (p. 3). However, when the work environment is perceived to be 'chilly' job dissatisfaction can lead to attrition (Maranto \& Griffin, 2011). A chilly climate for academic women is the second factor I identified. Sandler (1986) describes chilly climates as those where women are excluded from the informal networks within which key networking opportunities unfold, and are further marginalized by institutional/departmental policies, practices, and intellectual traditions which deprioritize family commitments and devalue feminist perspectives (Blickenstaff, 2005). The third factor I identified is the pressure to conform to the image of the ideal academic. According 
to Bailyn (2003), the ideal academic is "someone who gives total priority to work and has no outside interests and responsibilities." In a scathing critique of senior women faculty in the academic sciences at MIT, Bailyn (2003) admonishes, "They cannot conceive of any other way to be a first-rate scientist, which may explain why most of them are not married and have no children" (p. 139). She calls for more progressive conceptualizations of gender equity that acknowledge "an academic's outside life." In her estimation, an "ideal image of gender equity" legitimates "the private sphere of family, community and other personal involvements, but would equalize the value placed on economic and noneconomic activity" (p. 140). The fourth factor I identified is powerful leader-perceptions-and practices. In their study of organizational determinants of gender diversity strategies in STEM departments, Su, Johnson, \& Bozeman (2015) found that the extent to which an academic department demonstrated a commitment to gender diversity strategies was related to the chair's administrative power and his/her perception that gender equity is indeed a problem. In a separate study of academic leaders, researchers found that when leaders felt personally responsible for creating diversity change, they not only reflected on the personal ways in which they needed to change, but encouraged their subordinates (men) to do the same as they worked collectively toward more equitable policies and practices. On the other hand, when leaders expressed low personal responsibility for increasing gender diversity, they did not initiate meaningful change and perceived that the onus of responsibility for such changes lied with women faculty (McClelland \& Holland, 2014). Underscoring the above factors, summarized in Table 2, as some which not only contribute to the gender inequity problem, but help shape efforts to resolve it is an important precursory step in the study of men faculty engaged in gender equity work. 
Table 2. Key Factors Contributing to Gender Inequity Problem (...)

\section{Key Factors Contributing to the Gender Inequity Problem and Helping to Shape Efforts to Resolve It}

1. Negative perceptions generated from the underrepresentation of women in STEM.

2. A chilly climate for academic women.

3. Pressure to conform to the image of the ideal academic

4. Powerful leader perceptions and practices

To further contextualize the study, and to provide additional insights into the process endured by sites selected for participation in the dissertation study, a description of the NSF ADVANCE project, including the parameters for receipt of funding for the Institutional Transformation (IT) grant is discussed next.

\section{The NSF ADVANCE Project}

The NSF ADVANCE project was founded in 2001. According to its website, it has “...invested over $\$ 130 \mathrm{M}$ to support ADVANCE projects at more than one-hundred institutions of higher education and STEM-related not-for-profit organizations in forty-one states, the District of Columbia, and Puerto Rico...” Per NSF,

...[t]he ADVANCE program is designed to foster gender equity through a focus on the identification and elimination of organizational barriers that impede the full participation and advancement of all women faculty in academic institutions. Organizational barriers that inhibit equity may exist in areas such as policy, practice, culture, and organizational climate. For example, practices in academic departments that result in the inequitable allocation of service or teaching assignments may impede research productivity, delay advancement and create a culture of differential treatment and rewards. Policies and 
procedures that do not mitigate implicit bias in hiring, tenure, and promotion decisions could mean that women and underrepresented minorities are evaluated less favorably, perpetuating their underrepresentation and contributing to a climate that is not inclusive. Three main objectives drive the ADVANCE project. The first is to “...develop systemic approaches to increase the representation and advancement of women in academic STEM careers." The second is to "...develop innovative and sustainable ways to promote gender equity that involve both men and women in the STEM academic workforce..." The third is to “...contribute to the research knowledge base on gender equity and the intersection of gender and other identities in STEM academic careers."

Project administration. The ADVANCE project is administered at the institutional level through one of three program tracks: partnership, adaptation, or institutional transformation (IT). The partnership track supports “...partnerships of two or more academic institutions and/or STEM organizations to increase gender equity in STEM academic careers through systemic change strategies." The adaptation track “...supports the adaptation and implementation of proven organizational change strategies within a non-profit two-year or four-year academic institution..." And, the IT track “...supports the development of innovative organizational change strategies to produce comprehensive change within one non-profit two-year or four-year academic institution across all STEM disciplines." In addition to this core objective, IT “...projects are expected to contribute new research on gender equity in STEM academics...” Of the three tracks, the IT track is not only the track funded at the highest dollar amount and over the longest period (five years), but it is the most internally-focused track as it requires an institution to draw on its own unique resources as a primary resource for innovative ideas and change strategies that promote gender equity. 
Main Award Criteria for ADVANCE IT funding. Institutions awarded an IT grant receive up to $\$ 3,000,000$ over the course of five years. Awardees must be U.S. accredited public or private, two-and/or four year institutions with a campus located in the U.S. Two main criteria determine the success of program proposals. They are the extent to which the proposed project has the potential to advance knowledge (intellectual merit); and, the extent to which the proposed project demonstrates the potential to benefit society (broader impacts).

Given the internally-focused and comprehensive thrust of the IT track, this study is conducted at U.S. higher education sites that have been awarded the ADVANCE-IT grant, and have also implemented a formal men faculty advocates/allies program. A demographic profile of the study sites is included in the methods section (Chapter 3).

\section{The Men Faculty Advocates \& Allies (A \& A) Program}

The signature ADVANCE Advocates and Allies (A \&A) program that has been adopted by other ADVANCE programs is an innovation of an ADVANCE-IT site which perceived the need for a program that would constructively engage men faculty in efforts to address gender inequity in academia. The A \& A program aims to:

- provide men faculty with data about gender inequities nationally and locally,

- $\quad$ educate men on critical issues like implicit bias and male privilege.

- equip men to use that knowledge to build a supportive network of men colleagues who are advocates and allies for women.

Within the context of the A \& A program, the role of men faculty 'advocates' and men faculty 'allies' are differentiated:

Advocates are faculty men with a record of and strong commitment to supporting faculty 
Women. . They are expected to be active and effective proponents of gender diversity and equality specifically in terms of increasing the number of female faculty, encouraging the hiring and promotion of female faculty in administrative positions, and ensuring the fair and equitable treatment of women within their units. . Advocates also develop and regularly administer Ally training [initial and follow-up].

Distinguishably, men faculty identified as allies carry out another role. These men are willing to identify themselves as allies of faculty women, they participate in the Ally trainings and sign an "Ally Agreement"-a statement formalizing their commitment to gender equity allyship ... They are expected to take action primarily within their departments: speaking up at a meeting, inviting a female colleague to collaborate on research... serving on a committee so their female colleague does not have to ... It might also mean making sure that coffee runs, lunches, or after-work social events are open and inclusive. (Bilen-Green, Green, McGeorge, Anicha, \& Burnett, 2013, pp. 5-6)

In addition to being an ADVANCE-IT awardee, all sites included in this study adopted a formal A \& A program following training and tutelage from members of the originating site.

Subsequently, while there are differences in the administration of A \& A programs, they have in common the aforementioned principles. It is important to note that in addition to men faculty formally engaged in A \& A, this study includes the voices of men who were engaged in ADVANCE pre-A \& A. For this reason, the terms 'allies' and 'advocates' continue to be used interchangeably throughout this paper, except when making specific reference to the division of duties as prescribed by the formal A \& A program. 


\section{Research Questions}

Having considered the catalyst for this research, the perceptible problem, context and viability of an investigation, the central focus of this study are the factors contributing to men faculty engagement in gender equity work. Of central importance are those which lead to an ongoing commitment to or engagement in this work. To further this analysis, I pose the following research questions:

1. What drives men faculty to engage in gender equity work?

2. Given the centrality of the adapted concepts of allies and advocates in the A \& A program, how do men faculty talk about their ally identity development?

3. What are men faculty's perceptions of gender equity work? What counts as gender equity work and what doesn't?

4. What are the implications of institutional context on the work?

\section{Pertinent Literature}

The complexity of faculty work is a theme which dominates literature on the subject. One of the most prevalent aspects of this literature is the ongoing debate about the primacy of research and publication over teaching and service activities in the evaluation process for promotion and tenure (Blackburn \& Lawrence, 1995; Park, 1996). While the present study is not primarily concerned with this debate, it is concerned, in part, with how faculty activities such as engagement in gender equity initiatives challenge and/or support perceptions of traditional faculty work.

Faculty activities which promote social justice are frequently referred to in the literature as faculty engagement (see Boyer, 1996; Coles \& Scarnati, 2015) or faculty activism (see Messinger, 2011). Faculty activism is a multidimensional concept. That is, there are various 
types of faculty activism and in some instances faculty activism describes activities which align with a faculty member's role, while in other instances faculty activism describes activities that are not considered to be part of a faculty member's role (see Flood, Martin, \& Dreher, 2013; Kezar, Lester, Carducci, Gallant, \& McGavin, 2007; Kuntz, 2007). The precarious nature of faculty activism and its inextricable link to traditional conceptualizations of faculty work means that there are subjectivities at play when it comes to the analysis and evaluation of faculty work and the faculty role. Exploring how men faculty engaged in gender equity work make sense of it in the broader context of traditional faculty work provides useful insight into why some men faculty engage and others do not.

Dominant group members who engage in social justice work have been described in the literature as allies (Broido, 2000). Allyship is a specific type of social justice activism enacted by members of dominant social identity groups who may work alongside who Hardiman, Jackson, and Griffin (2013) refer to as "empowered target group members" (p. 33; that is, activists who belong to marginalized groups), to challenge, disrupt, and transform oppressive, discriminatory structures, systems, policies, and practices within organizations and larger society (Bishop, 2002). Much of the literature on social justice allyship within higher education settings emerges from the field of student affairs and is focused on the development of student allies for social justice (Broido, 2000; Broido \& Reason, 2005; Edwards, 2006; Munin \& Speight, 2010). However, two studies in higher education contexts focused on the engagement and experiences of faculty/administrators who serve as social justice allies. One, by Messinger (2011), explored the factors which led faculty to engage as advocates for LGBTQ students. The other, by Patton and Bondi (2015), examined how White men faculty/administrators, identified by their peers as allies, described the multifaceted aspects of their social justice work. This study helps to fill this 
pronounced gap in the extant literature by operationalizing the tenets of Grounded Theory (GT) to explore data-rich cases of men faculty engaged in gender equity work via ADVANCE/A \& A program.

\section{Significance of the Study}

Research on men faculty engagement in gender equity work is "virtually nonexistent" (NSF Award Abstract \#1500604). This study draws upon cross-disciplinary literature on faculty work; faculty activism; allyship and gender equity in academia to frame a conversation about the experiences of men faculty engaged in this work and the implications of their efforts. The need for research on men faculty engagement in gender equity work in academia is important because men typically dominate the most powerful positions in higher education's leadership and faculty ranks (Acker, 2012; Patton \& Bondi, 2015). Therefore, to achieve gender equity, men must not only be supportive but critically engaged in this effort (Prime \& Moss-Racusin, 2009). Findings from this GT study led to the proposition of a theory of continuous engagement that may be useful for subsequent investigations of this and similar topics.

\section{Summary of Dissertation Chapters' Content}

This dissertation is divided into two parts. Part I includes: Chapter One-Introduction; Chapter Two-Literature Review; and Chapter Three-Method. Chapter two begins with a discussion of methodological considerations pertinent to the placement of the literature review in a grounded theory study. It is followed by a section explaining the choice of literature given the sparse research on the dissertation topic. The literature reviewed addresses faculty work, faculty activism, dominant group member social justice activism, men allyship, the gendered academic organization, and the role of faculty in gender equity work. The chapter concludes with a summary of the literature and the emergent research questions. Chapter three details the research 
methodology. It includes justification for a qualitative study, an explanation of grounded theory (GT) - that is, why GT was appropriate for this investigation, its components, challenges, and methods of evaluation, and a description of the selected sites. It further details the research procedure, outlining the tenets of purposive sampling, the participant recruitment strategy, the data collection strategy, the data analysis process, and methodological issues. Part II includes: Chapter Four-Research Findings I; Chapter five-_Research Findings II; and Chapter 6: The Summary of Findings, Future Directions, and The Proposed Theory 


\section{CHAPTER II: LITERATURE REVIEW}

\section{Methodological Considerations}

The appropriate location for the review of literature in grounded theory $(\mathrm{GT})$ research is a debated topic (Dunne, 2011; Giles, King, \& deLacey, 2013; Yarwood-Ross \& Jack, 2015). The classic or purist view dictates that a review of literature commence after data analysis to prevent extant theories from governing the development of new concepts from the data (Gibson \& Hartman, 2014; Glaser, 1998). GT classists advocate a process wherein "researchers integrate existing literature on the substantive topic into their thinking as the theoretical categories and framework stabilize" (Locke, 2001, p. 122). In this way, researchers "adopt a respectful yet critical stance" towards the literature (Dunne, 2011, p. 115). That is, rather than privilege preexisting theories, "extant concepts...earn their way into your narrative" (Charmaz, 2006, p. 126) based on their relevance to concepts emerging from the current data. As Yarwood-Ross and Jack (2015) explain there are essentially three approaches to the use of literature in GT. In addition to the classic approach already discussed, the constructivist approach, simultaneously acknowledges the benefit of delaying the review of literature so as not to mute the researchers voice (Charmaz, 2006), but also the practicality or “...the expectation of a literature review in the research" (p. 20; particularly for PhD students, see also Dunne, 2011; Hallberg, 2010). Nevertheless, constructivists are not resolved that a GT study is necessarily undermined by an early review of the literature and argue that done strategically an early review of the literature "...can help the researcher clarify ideas and make comparisons..." Similarly, the Straussian (Stern, 1994) approach, sees ways in which an early review of the literature can benefit a grounded study as "... a secondary source of data or for comparisons with the data," and advocates an early review of the literature because of its potential to "... direct theoretical 
sampling, and help with concept development and defining properties and dimensions."

Researchers who embrace the Straussian or constructivist approach argue that an early review of the literature gives the researcher a sense of topic coverage (Chiovitti \& Piran, 2003; Hallberg, 2010), sensitizes the researcher to extant theories (Coffey \& Atkinson, 1996; McCann \& Clark, 2003), promotes clarity in thinking about concepts and theory development (Henwood \& Pidgeon, 2006, p. 350), and contextualizes the study (McCann \& Clark, 2003) by underscoring contexts and situations within which the phenomena under question have occurred, helping to establish the significance of the study (McGhee, Marland, \& Atkinson, 2007; Coyne \& Cowley, 2006) and signaling gaps in the research the current research project may fill. Having delineated these perceived benefits, it must also be noted that all three approaches agree that a review of the extant literature should be included somewhere in a grounded study and that “...theoretical development should be guided by the concepts emerging from the empirical data rather than the concepts in the literature" (Heath \& Cowley, 2004, as cited in Yarwood-Ross \& Jack, 2015, p. 20). Furthermore, as Dunne (2011) insists,

the argument in favour of an early literature review does not refute the point that a researcher should try to approach each new project with a mind that is sufficiently open so as to allow new, perhaps contradictory, findings to emerge from the raw data. (p. 117) Having considered this ongoing debate and the subject of my research, I determined that an integration of both the Straussian and constructivist perspectives regarding the review of literature is appropriate for my study. That is, given my prior awareness of men faculty engagement in gender equity work as a new, and only recently developing research topic, I perceive that an "early" review of literature closely related to this subject would not only serve as a useful "secondary source of data," but as a resource that would help me clarify and compare relevant 
extant concepts and theories, contextualize the study, and get a sense of what has already been covered on the specific topic and topics closely related, thereby indicating where gaps in the research remain. Furthermore, an "early" review of the literature would help to refine my research questions and serve as an initial source of data for subsequent theoretical sampling.

In keeping with the tenets of grounded theory, I also depart from traditional conventions in dissertation research which proffer a theoretical framework for a study before the analysis of data and align with Dunne's (2011) reasoning and disciplined approach as explicated below:

I deliberately avoided imposing a specific theoretical framework on the study at the outset. This approach to extant theories is what Henwood and Pidgeon (2006, p. 350) term 'theoretical agnosticism', which they argue 'is a better watchword than theoretical ignorance to sum up the ways of using the literature at the early stages of the flow of work in grounded theory'. This approach does not advocate that the researcher ignore existing theories, but rather avoid the imposition of specific theoretical frameworks, as this may cause the researcher to analyze the data through a specific theoretical lens. In practice, this meant that as the data collection and analysis progressed, and ideas and tentative hypotheses began to emerge, I began to consider how theories with which I was already familiar could perhaps be used to progress the analysis. Simultaneously, I also sought to identify new theories which could help explain or even contradict the multiple and diverse ideas emerging from the data analysis, in order to improve the quality, rigour and profundity of the analysis. (p. 119)

Deciding on which literature to review for a new and emerging topic is challenging. While the terms I used to articulate the topic I wanted to investigate derived from my current understanding of what it is I want to know, those terms did not always lead to the concepts and extant research 
most relevant to my topic. Subsequently, it took a good bit of preliminary parsing of concepts to design a review of literature that made sense for this study. Eventually, six pertinent concepts from the extant literature prevailed: (1) faculty work, (2) faculty activism, (3) dominant group member activism, (4) men allyship and advocacy, (5) the gendered academic organization, and (6) faculty roles in gender equity work. These concepts became the themes of the subsequent sixsectioned review of the literature.

Given that men faculty are the subject of my study, the first section of the literature review describes the complexity of faculty work, including a discussion of the particular challenge faculty activities that may not be considered in-role behavior may present in faculty evaluations. In the second section, the multidimensionality of faculty activism is explored as an umbrella concept encompassing such faculty activities as men faculty engagement in gender equity work. Additionally, three categories of faculty activism are proposed for future analyses. Because men continue to dominate the most powerful positions in academia, the third section of the review examines dominant group members' social justice activism, generally, creating a logical segue to a closer analysis of pertinent theories and research addressing men allyship and advocacy in the fourth section. In the fifth section, the gendered nature of the post-secondary academic organization is reviewed, followed by a discussion of the roles faculty play in gender equity related initiatives in the sixth section. The review of literature concludes with a summary that synthesizes key concepts and findings, underscores prevalent gaps in the extant research, and delineates the emergent research questions.

\section{The Complexity of Faculty Work}

Faculty work is a slippery construct. Scholars have described it as complex, conflicting and rather than complimentary — a triune of competing priorities (Bellas \& Toutkoushian, 1999; 
Blackburn \& Lawrence, 1995; Boyer, 1990; Fairweather, 2002, 2005; Fairweather \& Beach, 2002; Gappa, Austin, Trice, 2007; Houston, Meyer, Paewais, 2006; Porter \& Umbach, 2001; Schuster \& Finkelstein, 2006). Researchers have documented the ways in which faculty responsibility for teaching, research, and service create conflict which is reinforced by reward structures within academic departments and institutions which emphasize "the discreteness, not the mutuality" of these work components (Fairweather, 1993, p.44). As Boyer (1990) pointed out, "colleges pay lip service to the trilogy of teaching, research, and service, but when it comes to making judgments about professional performance, the three rarely are assigned equal merit" (p. 14). In fact, several studies of faculty work indicate that research continues to be the most significant measure of faculty work (Blackburn \& Lawrence, 1995; Fairweather, 1997), while teaching, which continues to be viewed as fundamental (Boyer, 1990) is less rewarded (Blackburn \& Lawrence, 1995; Park, 1996), and at some institutions, service - though a faculty work requirement - is omitted from the promotion and tenure decision process altogether (Mamiseishvili \& Rosser, 2011).

\section{Daily Practices \& Meaning: Expanding Conceptualizations of Faculty Work}

Drawing on Foucault's conceptualization of regimes of practice (1991), Kuntz (2007) posits that faculty work can be interpreted by a close analysis of the daily practices undertaken by faculty to fulfill their faculty role. According to Kuntz, understanding what is done- the activities carried out - in the name of faculty work is more important than attempting to strictly define faculty work (p. 28). These daily practices he suggests, not only reveal the specific tasks faculty do, but their meaning, and the relationship of their meaning to faculty identity (p. 185). In his study, Kuntz examines the "material and social micromovements" that make up faculty work in order to uncover activities that contradict assumptions about who faculty are and what faculty 
do (p. 9). He concludes that faculty work is encompassing-inclusive of activities within contexts that may or may not fit neatly into traditional conceptualizations of faculty work, but from case to case help to clarify it.

\section{Faculty Work as In-Role \& Extra-Role Behavior}

Traditional conceptualizations of faculty work and the suggestion that faculty work is complex and subsequently open to myriad interpretations underscores the tension between work that is considered to align with a faculty member's role within the institution and work that is not. Bess and Dee (2012) describe two approaches to role analysis in organizations. In the first, the focus is on function - that is, how a given role, in relation to those around it, helps an organization achieve its objectives. For example, Bolman and Gallos (2011) assert that "Higher education's mission requires that many of its key employees be teachers and scholars whose contributions depend on their unique expertise, dedication, and capacity for professional judgement" (p. 7). Their assertion illuminates the function of faculty within tertiary education. In the second approach, the focus is on expected behaviors from an individual in each role. Katz and Kahn (1978) assert that individuals occupy "offices" within organizations and each office is defined by "a set of activities or expected behaviors" (p. 188). Expected behaviors are determined by "role senders, who create and/or interpret roles and corresponding formal job descriptions, and then transmit them to others with varying degrees of accuracy and clarity" (Bess \& Dee, 2012, p. 249). In the case of the "office" of faculty member, the role senders would typically include, broadly, the higher education field, the academic discipline, and, narrowly, the academic department, the dean, the chair, and irrefutably the students. Behaviors that organizations expect from their members have been described as in-role behavior (IRB; Van Dyne, Cummings, and McLean-Parks, 1995, p. 222). The theoretical antipodal of IRB are 
"positive discretionary behaviors which go beyond delineated role expectations and also benefit the organization" (Van Dyne et al., 1995, p. 217). Van Dyne et al. describe 'positive discretionary behaviors' as extra-role behavior (ERB). ERB is defined as behavior which benefits the organization and/or is intended to benefit the organization, which is discretionary and which goes beyond existing role expectations. (p. 218) To further clarify the construct, the authors insist that ERB must be

(1) voluntary (not role-prescribed, nor part of formal job duties, not formally-rewarded and failing to perform the behavior cannot be formally penalized), (2) intentional—she or he must make an active decision to engage in the behavior, (3) positive-either the behavior is intended positively by the actor or is perceived positively by an observer, and (4) primarily disinterested from the perspective of the employee (the actor). This means that the employee must engage in the behavior primarily to benefit someone or something other than him/herself. It is important to note, however, that disinterest does not require an absence of interest on the employee's part. (p. 218)

In an effort to establish a nomological network for ERB, Van Dyne and colleagues identify four types of ERB. These include: organizational citizenship behavior (OCB; see Bateman \& Organ, 1983; Organ, 1988, 1990; Smith, Organ, and Near, 1983; Van Dyne, Graham, \& Dienesch, 1994), prosocial organizational behavior (PSOB; see Brief \& Motowildo, 1986; George, 1990, 1991; O’Reilly \& Chatman, 1986), whistle-blowing (WB; see Dozier \& Miceli, 1985; Near \& Miceli, 1987), and principled organizational dissent (POD; see Graham, 1983, 1986). In the next sections, attention is given to prosocial organizational behavior (PSOB), and principled organizational dissent (POD) because either of these may characterize faculty activities that are also described as social justice efforts--such as gender equity work. 
Prosocial Organization Behavior (PSOB). Brief and Motowildo (1986) define PSOB as behaviors directed toward individuals, groups, or the organization itself with the "intention of promoting the welfare of the individual, group, or organization" (p. 711). According to their conceptualization, some forms of PSOB may be considered organizationally-functional, while other forms of PSOB may be considered organizationally-dysfunctional. PSOB is considered functional when it is perceived to directly or indirectly benefit the organization. PSOB is considered dysfunctional when the behavior, which may benefit an individual or group, in some way, comprises the integrity of the organization. A housing director's decision to expunge the inroom alcohol violation of a wealthy donor's daughter to avoid a potentially contentious encounter with the donor may be perceived by the administration as an organizationallyfunctional application of PSOB. However, the impact of the housing director's decision on the resident assistant who issued the sanction, the housing staff and residents who were aware of the violation, and arguably the donor's daughter, could prove to be a dysfunctional application of PSOB. Another distinguishing feature of PSOB is that it can be either an IRB or an ERB. For example, a faculty member who maintains regular office hours may be perceived as enacting an in-role PSOB, whereas a faculty member who comes into the office on a Saturday to advise a student whose hectic work schedule will not accommodate an advising meeting during the work week may be perceived as enacting an extra-role PSOB. These examples underscore another important dimension of ERB which is the subjectiveness of label application. According to Van Dyne et al. (1995), labeling a behavior ERB depends upon the point of view of the observer of the behavior, the characteristics of the individual being observed, and the point in time the behavior is observed (p. 220). In the latter example, above, the faculty member and the studentboth organizational members - could perceive the faculty member's behavior, differently. The 
faculty member may consider coming in on a Saturday 'positive discretionary behavior' (or ERB). However, her student may perceive the same behavior as the faculty member simply doing her job (IRB).

Principled Organizational Dissent (POD). PSOB and POD occupy separate categories of ERB which Van Dyne and colleagues describe as "affiliative and promotive" and "challenging and prohibitive." PSOB is categorized as "affiliative and promotive" and refers to helping behaviors described as "altruistic" (personal—directed toward individual, e.g. courteous) or “conscientious" (impersonal— directed toward organization, e.g. obedience). POD, on the other hand, is categorized as "challenging and prohibitive" and refers to behaviors that "attempt to modify the status quo by prohibiting illegal...or unprincipled...behavior" (pp. 235-237). Graham (1986) defined POD as

[A] protest and/or effort to change the organizational status quo because of a conscientious objection to current policy or practice" (p. 1). She added, "[t]he term principled [emphasis in original] applies to the issue at stake, e.g. one which violates a standard of justice, honesty, or economy; it does not necessarily describe the ultimate motive of the person who raises it. (p. 2)

She further described three forms of POD:

[C]onflict among people or units (individual level), disagreement on how best to achieve organization goals (organizational level), and policies or practices that violate legal or ethical principles. (super-organizational level; as cited in, Van Dyne et al., 1995, p. 249) Neither the moral conviction which drives POD, nor the altruistic motivation that drives PSOB undermine their common objective which is to enact behavior intended to improve the organization. Within higher education organizations there are faculty who demonstrate PSOB 
and/or POD. As Van Dyne and colleagues have indicated depending on the observer, these behaviors may or may not be perceived as activities that align with a faculty members' expected role. When faculty engage in activities that are considered to be beyond the scope of their faculty role a number of issues may arise. In this study, the academic unit/institution represents the organization; and, the behaviors in question are those reflected in activities that may be described separately or jointly as faculty work and/or faculty activism and their relationship to the goals and objectives of the academic organization.

Having drawn attention to the complexities of faculty work, the next section will examine faculty activism which includes activities that may be described as in-role behavior (IRB), or one of two forms of extra-role behavior (ERB) - prosocial organizational behavior (PSOB) or principled organizational dissent (POD).

\section{The Multidimensionality of Faculty Activism}

Like faculty work, the literature revealed faculty activism as an equally slick construct. Aside from the fact that some forms of faculty activism may be interpreted as faculty work (see Boyer, 1990; Flood, et al., 2013; Kezar, et al., 2007; Kuntz, 2007), as a topic of investigation, faculty activism is not only cross-disciplinary, but multidimensional and chronically multinominal. Subsequently, attempting to distinguish between the many terms used to refer to faculty activism is an exercise in futility. Therefore, a more productive endeavor is to find a meaningful way to categorize the various forms of faculty activism, so that its multidimensionality is clear and important aspects of its dimensions are highlighted.

This section of the literature review examines a range of faculty activities which align with a definition of activism rooted in the notion of praxis, popularized by Paulo Freire (1970), and embraced by countless others including Kuecker (2010) who offers the following definition: 
Praxis is the product of agency, the conscious and willed attempt by humans to transform the structures that conspire to undermine humanity's perfectibility. It is the transformation of theory through a deliberate application of theory to social reality, or what is termed "practice ... it also causes societal change as well as the transformation of those who practice it. (p. 53)

In their investigation of factors which influenced faculty preparation for teaching diversity, Landreman, Rasmussen, King, \& Xinquan (2007) summarized key elements of Freire's "conscientizacao" (the development of critical consciousness) — an indispensable, ongoing reflective process which precedes, informs, and sustains praxis: According to Freire, a critically conscious person is aware of:

(a) the historical, political, and social implications of a situation (i.e., the context);

(b) his or her own social location in the context;

(c) the intersectionality of his or her multiple identities (e.g., race, socio economic class, gender, sexual orientation); and

(d) the inherent tensions that exist between a vision of social justice and the current societal conditions for all people. (p. 276)

Building on the preceding discussion, faculty activism is operationalized as a category of faculty activities which (1) reflect faculty members' ongoing development of criticalconsciousness, (2) aim toward transformation within and/or beyond their institutions, (3) may or may not be considered faculty work, and (4) may or may not be considered in-role or extra-role behavior. 
The scope of this definition permits consideration of a range of faculty activities that can be organized under three main headings: Faculty Activism as Engaged Scholarship; Faculty Activism as Protest; and Faculty Activism as Leadership for a Just Institution (LJI).

\section{Faculty Activism as Engaged Scholarship}

Consideration of faculty activism is necessarily framed within the broad field of tertiary education. Given this reality, the internal and external mechanisms which produce, reproduce, define, and sustain tertiary education at institutional, organizational, group and individual levels may certainly be indicted in the emergence of such organizational phenomena as faculty activism. That is, the conditions which bring the perceived need for faculty activism to bear are manifestations of complex dynamics that influence and are influenced by forces outside and within the tertiary education field. In response, to what institutional scholars term "disruptions," (DiMaggio, 1988; Jepperson, 1991; Seo \& Creed, 2002) a field will seek ways to destabilize and restabilize itself through adaptation or change (Jepperson, 1991).

American higher education in the 1980s and 1990s began to be admonished for a "professoriate [that] had grown self-satisfied and self-indulgent, producing esoteric scholarship and ignoring the pressing concerns of society" (Sykes, 1989; Smith, 1990; as cited in Hartley, 2009, p. 323). In response to this unanimous allegation-if in some instances, only philosophically — the higher education sector expressed a renewed interest and commitment to community service and civic engagement (Hartley, 2009). One of the most prolific voices validating this charge and offering a paradigmatic shift in how academia might more effectively carry out its work was the late Ernest Boyer, former president of the Carnegie Foundation for the Advancement of Teaching, and former Chancellor of the State University of New York system. In his preeminent work, Scholarship Reconsidered: Priorities of the Professoriate, Boyer (1990) 
proposed a re-envisioning of scholarship which demonstrates the interconnectedness of academia and society as well as academia's commitment to and valuing of society as a critical resource with whom a reciprocal relationship is not only desirable, but essential. His proposed scholarships of discovery, integration, application, and teaching, collectively referred to as Engaged Scholarship, have also been described as a "reframing of academic work to link teaching, research, and service purposefully to the public good" (Wade \& Demb, 2009, p. 6). The notion of "reframing" faculty work continues to resonate with activist-minded academics "who want to do work that both sustains their academic careers and supports social movement efforts" (Croteau, Haynes, Ryan, 2005, p. 20). Engaged Scholarship provides a category under which these academics can herald their cause without stepping too far outside of scholarly conventions. In 1999, the Kellogg Commission on the Future of State and Land Grant Institutions defined the engaged university this way:

By engagement, we refer to redesigned teaching, research, and extension and service functions that are sympathetically and productively involved with the communities universities serve. ... The engagement ideal is profoundly different: embedded in it is a commitment to sharing and reciprocity ... two way streets defined by mutual respect among the partners for what each brings to the table. (p. 27)

Similarly Wade and Demb (2009) defined engagement as "how colleges and universities address important social issues while preparing an educated citizenry for active civic, economic and cultural participation" (p. 5). It is important to note here that the emphasis on community in the definitions of engagement in both the Kellogg Commission on State and Land Grant Institution's statement (1999) and in Wade and Demb (2009) appear to conceptualize "community" primarily 
at the local level, whereas the Carnegie Community Engagement Classification (2015) for colleges and universities, defines community engagement as a collaboration between institutions of higher education and their larger communities (local, regional/state, national, global) for the mutually beneficial exchange of knowledge and resources in a context of partnership and reciprocity. (Kellogg Commission Website)

The Carnegie definition of community engagement seems to capture Boyer's (1990) sentiments in Scholarship Reconsidered:

Now is the time, we conclude, to build bridges across the disciplines, and connect the campus to the larger world... If the nation's colleges and universities cannot help students see beyond themselves and better understand the interdependent nature of our world, each new generation's capacity to live responsibly will be dangerously diminished. (p. 77)

Birk (2014) argues that

there can be many different rationales for global learning . . . vocational and marketfriendly ends...the cultivation of cross-cultural awareness and competencies . . . selfenrichment. [However] none provides a focused attention to global learning as a critical citizenship project. (p. 1)

To address this void, Birk and her colleagues at Otterbein College have embraced an approach called critical cosmopolitan teaching and learning:

critical cosmopolitan teaching and learning works to complicate—and, ideally, unseatthis binary logic. It does so by investing in thinking relationally about the local and the global. As a framework for global learning, critical cosmopolitan education is committed 
to unsettling the traditional and highly reified opposition of local and global to imagining a more dialogic and dynamic relationship between these terms. (p. 3)

How engaged institutions conceptualize community can be expected to have important implications for the interpretation of faculty activities described as activism. Institutions like Otterbein that embrace a global perspective of engagement (see also "The Global Imperative"University of Buffalo; "Liberal Education for Global Citizenship"-Macalester College, in Birk, 2014) are likely to interpret globally-focused faculty activism work as related to the faculty role. Whereas institutions that strictly adhere to local definitions of community may interpret globallyfocused faculty activism work as beyond the scope of the faculty role.

A comprehensive view of engaged scholarship not only embraces civic participation in the local and global community through professional outreach and engagement on the part of engaged faculty or service-learning on the part of students (Demb \& Wade, 2012), but also through within-the-classroom experiences taught by faculty who

create a common ground of intellectual commitment . . stimulate active, not passive learning and encourage students to be critical, creative thinkers, with the capacity to go on learning after their college days are over. (Boyer, 1990, p. 24)

Many engaged scholars who embrace this sentiment, define themselves as activists and their classroom practices as forms of critical pedagogy (see scholar-activist—Collins, 2005; intellectual activist —Collins, 2013; feminist, activist, engaged pedagogue-hooks, 1994; teacher-activist-Picower, 2015). Reflecting on Paulo Freire's contribution to educational practice, Giroux (2010) asserts:

It is imperative for educators to acknowledge Freire's understanding of the empowering and democratic potential of education. Critical pedagogy offers the best, perhaps the only, 
chance for young people to develop and assert a sense of their rights and responsibilities to participate in governing, and not simply to be governed. (p. B15)

Giroux's reflection underscores the inextricable link between engaged scholarship and critical pedagogy — as well as the logic behind labeling one of the three categories of faculty activism examined in this review engaged scholarship.

In addition to local and global service activities, and critical pedagogy, the other activity of engaged scholarship is research. A defining feature of engaged research whether occurring in local or international settings is that it aims to provide practical solutions to real problems by collaborating with members of the communities it targets (Boyer, 1990; Dempsey \& Barge, 2014). Faculty who participate in this form of research have been variously described as academic-activists (Kuecker, 2010; Maxey, 1999), scholar-activists (Collins, 2005), activistethnographers, activist-researchers (Checker, 2005, 2014; Schuller, 2014), and feminist-activist (Davis, 2014). Some of these activist (Checker, 2005, 2014; Davis, 2014; Maxey, 1999; Schuller, 2014) have described what Dempsey and Barge (2014) refer to as the "tensional activity" which characterizes engaged scholarship. In the case of engaged research, these tensions are: (1) the tension of distance and empathy — this tension has to do with the researcher stance and whether or not it is objective and distant, or empathetic to the cause and people it seeks to address, (2) the tension of representation-intervention - this tension has to do with research outcomes and whether they will represent a research problem through description, or suggest interventions to address a research problem, and (3) the tension of scholar-practitioner versus practitionerscholar - this tension has to do with the researcher's self-perception as either primarily a scholar whose objective is to produce knowledge or a practitioner-scholar who perceives "their primary contribution as a practitioner but is also attracted to academic scholarship" (p. 675). 
While some scholars question the extent to which engaged scholarship can meaningfully impact the causes it targets due to the inherent constraints placed on faculty by an academy more interested in maintaining the status quo than supporting radical change (see Croteau et al., 2005, p. 20), others argue that the collective, consistent action of faculty committed to these endeavors can, in fact, make a meaningful difference (also see Croteau et al., 2005, pp. 46-49).

Another category of faculty activism that aims to make a meaningful difference, but does not meet the criteria for engaged scholarship is protest.

\section{Faculty Activism as Protest}

Whereas faculty activism as engaged scholarship aims to mobilize university resources in service to the local and/or global community, faculty activism as protest aims to capture the attention and incite the desirable action or support of powerful societal and/or educational entities on behalf of those perceived to be disenfranchised. Building on the definition of faculty activism operationalized for this study, Turner's (1969), definition of protest, “as an expression or declaration of objection, disapproval, or dissent often in opposition to something a person is powerless to prevent or avoid" (as cited in Altheide \& Gilmore 1972, p. 100), and a summation of the literature, faculty activism as protest is operationalized as the use of principled dissent (Graham, 1986) to object to, confront, or take a stand against an action, decision, or process that is perceived to be unjust or to contradict the moral and/or ethical position of the institution with the goal of effecting positive change (see Boulding, 2014).

Just as there are various forms of engaged scholarship, there are variations in the method of protest as well as the purpose of protest. The review of literature suggests that most faculty protests challenge institutional policies, practices, and/or decisions perceived as unjust or inequitable. Some examples include: faculty at the City University of New York (CUNY) 
blocking the entrance to the institution's central administration offices to protest low salaries and the lack of a contract (Taylor, 2015); faculty and student creation of the Ad Hoc Committee against the militarization of CUNY to protest the recent hire of former Central Intelligence Agency (CIA) director, General David Petraeus and the reinstatement of the Reserve Officers' Training Corps (ROTC) on the system's junior colleges which are predominantly minorityserving institutions (Johnson, 2013; Paye, 2013); faculty formation of the national Campaign for the Future of Higher Education to protest the widespread relaxation of academic standards in order to bolster graduation rates (Pratt, 2014); a two-day walkout planned by University of Missouri faculty to join their students in protest against the handling of racial incidents on campus (Frizell, 2015); calls-for-dismissal and votes of no confidence which targeted the Chancellor of the University of Missouri issued by two separate faculty groups and a collective of nine deans alleging — among other things — that he "created a toxic environment through threat, fear and intimidation" (Tribune, 2015); strikes, rallies, and petitions organized by unionized faculty in Ohio to repeal SB5 which would not only limit union power, but disqualify faculty who take on service roles within the institution (e.g. participating on committees, in the faculty senate) by reclassifying them as managers (Schmidt, 2011).

The literature also revealed examples of faculty activism as protest which were not directly related to institutional concerns, but matters of justice in larger society. For example, June (2013) describes the activities of two faculty protestors: an assistant professor of law, Justin Hanford, who served as legal observer during the Black Lives Matter Movement and was a key organizer of \#FergusonToGeneva— " "a delegation that frames police violence in the United States as a human-rights issue worthy of global attention" and David Graeber, an anthropologist who helped set up the Occupy Wall Street Movement whose contract was not renewed at Yale. In 
another example, in an act of defiance, open-access faculty proponents posted free online copies of their published works following the suicide of a 26 -year-old open-access advocate believed to be distressed by what proponents considered excessive federal indictment charges for illegally downloading "nearly five million scholarly articles" from JSTOR "with the intention of uploading the documents to the Internet and making them freely available” (New, 2013). The aforementioned examples — whether their purpose was directed toward institutional policies and practices or perceived societal ills; whether their method involved sit-ins, strikes, or votes-of-noconfidence — provide substantial evidence that protest is a salient category of faculty activism.

Boulding (2014), a former economics professor at the University of Michigan, and a former activist in the peace movement against the Vietnam War, asserts that it is important ... for protestors to have some theory of protest, and to be sensitive to those circumstances in which protest is effective in achieving its intended consequences, and those circumstances in which it is not. (p. 166)

He goes on to describe the development of the first "teach-in" at the University of Michigan:

The method of protest first suggested by the original group at University of Michigan was a work moratorium and a one-day suspension of classes. . . [I]t immediately aroused a large counter-protest over the means, as well as over the object of protest, and it was very strongly on the protest side of the spectrum and away from education. The teach-in, which was adopted as a substitute, was much more successful. It at least edged toward the education end of the spectrum, even though it still retained a good many of the qualities of protest, and it was appropriate to the situation (pp. 170-171). 
Boulding proposes a seven-part theory of protest which explicates the origin of protest, factors effecting the success of protest, and when alternatives to traditional forms of protest are warranted. In abridged form, Boulding's theory of protest proposes that:

Table 3. Boulding's (2014) Abridged Theory of Protest

\section{Summary of Boulding's (2014) Proposed Theory of Protest}

1. protestors are dissatisfied, disenfranchised individuals within a system who feel entitled to voice;

2. for protest to be successful, a critical amount of societal consensus on an issue is needed;

3. when there is a lack of consensus, education should precede protest to build consensus;

4. the more system/institutional readiness-for-change, the more impactful the protest;

5. confrontational methods are appropriate in protest, but more conventional approaches are appropriate in educational movements;

6. congruency between the methods and objects of protest is necessary to mitigate the likelihood of counter-protests; and,

7. lack of issue clarity can compromise protest support

An application of Boulding's proposed theory is useful in hypothetical analyses of two of the aforementioned examples of faculty protests. First, what if there was no general consensus among faculty in the CUNY system that salaries were low and that the lack of contracts compromised job security (Taylor, 2015)? Then, according to Boulding, it would be likely that the protestors' sit-in and blocking of the entrance to the central administration building would be perceived by some as too confrontational and perhaps something along the lines of an awareness campaign which highlighted the discrepancies between faculty salaries/contracts at CUNY versus other public institutions might have been a more appropriate consensus-building 
approach. However, if critical consensus was there, then the protest may be considered a success as most—including the institution-would agree it was justified. In another application, what if faculty protestors at CUNY were perceived to have convoluted the protest against the militarization of CUNY? While one complaint was the institution hiring former CIA director General David Petraeus to teach two classes in one semester for $\$ 150,000$, another complaint was the reinstitution of the ROTC program. Although the issues are related, faculty protestors may have found that there were different degrees of consensus around the issue of paying Petraeus an exorbitant salary, and the related, but separate issue of providing ROTC as an opportunity for low income college students. These brief hypothetical analyses suggest that Boulding's proposed theory may also be useful in other analyses of faculty activism as protest.

Faculty activism as engaged scholarship and faculty activism as protest are two categories of faculty activism revealed in the literature. The third and final category of faculty activism revealed in the literature focuses on faculty activities which complement the image of the academic institution as just and equity-seeking.

\section{Faculty Activism as Leadership for a Just Institution (LJI)}

The literature revealed that some forms of faculty activism portray the college or university as a just institution or system. Faculty may act individually or in concert as agents of the institution to make it a fairer space and place. However, this type of engagement may or may not be considered part of a faculty member's expected job duties and thus, it may or may not be counted as service in the tenure and promotion process. Given the possibility that some of these activities could be seen as in-role behavior (IRB), classifying them as (principled organizational dissent (POD, which is an ERB) is inappropriate. Therefore, I named this category of activities 
faculty activism as LJI with the understanding that some of these activities may qualify as POD, while others may not.

Some of the examples of faculty activism as engaged scholarship (Collins, 2013; hooks, 1994; Picower, 2015) and faculty activism as protest (Frizell, 2015; Tribune, 2015) in the previous sections may resemble faculty activism as LJI. However, while the similarities between activities are intermittent, the distinctions are persistent enough to justify a third stand-alone category. Some examples of faculty activism as LJI that are neither engaged scholarship nor protest include: The work of the Internal Faculty Advisory Committee at Princeton which recommended key revisions (which were eventually approved by the larger faculty body) to campus policies on sexual assault_-i.e., lowering the burden of proof by replacing the "clear and persuasive" evidence standard with a "preponderance" of the evidence standard; replacing faculty and student disciplinary committees with a "panel of professionally trained investigators"; creating a more equitable appeal process for both the complainant and respondent which includes allowing both parties to be represented by outside advisors including lawyers in all meetings (Neel, 2014); Harvard Law faculty and staff expressing support for students in an official letter in which they commit to participating in change efforts, "Complacency is not an option. We are ready to work with students and staff in an immediate, concrete and informed process of assessment and reform" (Duehren, 2015); and, within the field of disability and education a contingent of faculty working collectively to reframe "the master narrative of deficiency" in disability studies (Connor \& Gabel, 2013, p. 100).

Using a social movement framework, Guckenheimer (2009) describes faculty diversity work within academic institutions as insider activism. She argues that activism does not always target organizations from the outside, but is sometimes enacted by individuals on the inside ( $\mathrm{p}$. 
xiii). Collective action is a criteria of social movement theory. According to Meyer and Whittier (1994),

Social movements are not self-contained and narrowly focused unitary actors, but rather are a collection of formal organizations, informational networks, and unaffiliated individuals engaged in a more or less coherent struggle for change. (p. 277)

While the examples of faculty activism as LJI above fit fairly well with Meyer and Whittier's (1997) description of social movements. Some types of faculty activism as LJI may not meet the criterion of collective action as easily. That is, in some instances, faculty activism as LJI may be reflected in individual efforts to make a difference (see Few, Piercy, \& Stremmel, 2007; Messinger, 2011; Patton \& Bondi, 2015). In a reflective piece, co-authored with her department chair and the chair of her tenure and promotion committee, April L. Few, an AfricanAmerican, assistant professor on a predominantly White campus reflects on balancing her "commitment to diversity and social justice with the demands of tenure." Her reflection includes descriptions of her service work which may be categorized as faculty activism as LJI, however, not all of it meets the collective action criterion as described in social movement theory. For example, her service as co-chair of the college's diversity committee; and as the organizer of a Women's Studies faculty development workshop as well as a regional conference on domestic violence, could be construed as forms of "collective" social movement activism in that it may be presumed that she worked alongside others in these efforts. However, her service as a mentor to minority graduate and undergraduate students on campus reflects her individual effort to make a difference (see Few, et al., 2007).

In her study of faculty advocacy for Lesbian, Gay, Bisexual, and Transgender (LGBT) students, Messinger (2011) describes forms of faculty activism as LJI that may reflect both 
collective and individual action. She notes that "through their work on faculty senates and university committees, serving as LGBT student group advisors, and participating in individual advocacy, informal outreach, organizing protests and lawsuits" (p. 1282) faculty have played a critical role in changing policies which positively affect the lives of LGBT individuals in the campus community. In their study of White male faculty who identify as allies, some of Patton and Bondi's (2015) participants describe their engagement in justice-seeking activities which reflect primarily individual, rather than collective effort. For example, one of their participants described advocating for the continuation of a position at his institution that was designed to provide leadership opportunities for "scholars of color." Two other participants described separate efforts to have colleagues re-evaluate the use of standardized test scores like the GRE as a determining criterion for admission. Another participant described how his service on hiring committees has enabled him to advocate for candidates of color by offering alternate hiring rationales for fellow committee members as well as his own initiative to recruit for diversity outside "traditional networks" (p. 499).

The categories of faculty activism revealed through the review of literatureengaged scholarship, protest, and LJI—do three major things: (1) they explain critical distinctions between faculty activities which aim to promote justice within and beyond academia, (2) they support the proposition that some forms of faculty activism may be considered in role behavior, extra-role behavior (especially POD), or neither, and (3) they underscore the multidimensionality of faculty activism helping to simplify analyses of faculty activities which may qualify as faculty activism.

In the next section of the literature review, social justice activism enacted by members of social dominant groups is considered, as the faculty who dominate U.S. higher education 
institutions typically represent two privileged social dominant group identities: White and/or male. A broad analysis of dominant group membership is followed by a distinction between dominant and target group membership, the implications of identity, and dominant group members' cultivation of ally identities.

\section{The Peculiarity of Dominant Group Member Social Justice Activism}

Kirk and Okazawa-Rey (2013) contend that, Classifying and labeling human beings, often according to real or assumed physical, biological, or genetic differences, is a way to distinguish who is included and who is excluded from a group, to ascribe particular characteristics, to prescribe social roles, and to assign status, power, and privilege ... In each category there is one group of people deemed superior, legitimate, dominant, and privileged while others are relegated—whether explicitly or implicitly — to the position of inferior, illegitimate, subordinate, and disadvantaged. (p. 12)

Dominant groups are made up of individuals in advantaged/privileged categories. Whereas targeted/subordinate groups are made up of individuals from disadvantaged categories (Tatum, 2013). According to Kirk and Okazawa-Rey (2013), within the U.S. the following dominantsubordinate group identities exist within the categories gender, race, class, nation, ethnicity, sexual orientation, religion, physical ability, age, and language, respectively: menwomen/transgender; White - person of color; middle class and upper class - poor and working class; U.S./first world—second/third world; European—any other non-European ethnic heritage; heterosexual—-lesbian, gay, bisexual, or transgender; able-bodied — person with a disability; youth—elderly person; and, English speaker-non-English speaker (p. 12). Hardiman, et al. (2013) describe "dominants" as members of oppressor groups and contend that 
Oppression is an interlocking, multi-leveled system that consolidates social power to the benefit of members of privileged groups and is maintained and operationalized on three dimensions [context, consciousness, and application]. (p. 26)

The contextual dimension refers to the level of oppression — individual, institutional, or societal. The consciousness dimension refers to intentionality—-that is, whether the oppression is a conscious or unconscious act. The applied dimension refers to whether oppression is manifested through an individual's attitudes and behaviors, an institution's policies, practices and norms, or a society's values, beliefs and norms (p. 27).

It is important to note the differences between certain concepts that are frequently conflated and confused in discussions which center on dominant or oppressor groups. For example, the dominant or oppressor group is often presumed to be the numerical majority when, in fact, they may not be. Recent demographic data indicate that Whites in U.S. society are now outnumbered by non-Whites. Nevertheless, the prevailing culture in U.S. society remains White or Eurocentric and is experienced as oppressive by members of targeted groups whether the dimension of oppression is individual, institutional, or societal, intended or unintended. Relatedly, the patriarchal socio-political system which sustains a male-privileged gender hierarchy persists (Johnson, 2006), despite the fact that the numbers of women in society are on par with men. Other terms that are frequently conflated and confused are minority, marginalized, underrepresented, and underserved. While a numerical minority group may also be marginalized (or discriminated against), underserved, and underrepresented (e.g. Blacks and Chicanos), this is not always the case. For example, although Asians are a minority in the U.S., they are overrepresented in tertiary education, meaning that their percentage in the academy is higher than their percentage in the U.S. population. Therefore, not only are they not underserved in 
tertiary education, whatever forms of oppression they may experience as a group have not negatively impacted their access to and success within academia. Failure to highlight the important differences between these concepts can draw attention away from key factors that affect the experiences and trajectories of all social groups—-singularly and in terms of their relationship to one another.

Given the various social categories which exist and the range of identities within each of them, Tatum (2013) asserts that most of us will discover that we have both dominant and targeted identities. For example, I am a cisgendered, able-bodied, heterosexual, Black woman with an advanced degree. While my identities as a racialized minority and a woman, assign me to historically "targeted" groups, my identities as a cisgendered, able-bodied, heterosexual, graduate-degree educated individual, simultaneously assign me to historically privileged dominant groups. Tatum further contends that a common characteristic of dominant group members is a tendency to take their dominant status for granted. Whereas a common characteristic of targeted group members is a heightened awareness of their targeted identity due to its distinctiveness from the dominant group (p. 7). In their study of the multiple dimensions of identity using a sample of college women, Jones and McEwen (2000) found that the salience of identity varies depending on whether the identity in question is dominant or targeted, as well as the context in which a given identity is being considered. Overwhelmingly, these researchers found that dominant group member identity was less salient for privileged members of these groups because it is not scrutinized based on difference, whereas dominant group identity as well as their own targeted group identity is salient for members of disadvantaged groups because they are scrutinized based on their difference from the dominant norm. As the authors point out, when the experience of difference based on a given identity is absent or minimal in one context, the 
salience of that identity may be less than it is in other contexts. For example, decades ago, as a Black undergraduate attending the historically and predominantly Black, Hampton University, at the time considered one of the preferred destinations for the children of the Black elite, day-today, I thought less about my identity as a racialized minority in larger U. S. society and more about the realities of the economic and social class to which I belonged. Although my family's values and aspirations were consistent with those of the Black upper class, our economic situation and social-positioning, at the time, were not. While many of my contemporaries were the children, grandchildren, and great-grandchildren of well-to-do Hampton alumni who vacationed on Martha's Vineyard, held membership in the great eight (historically Black fraternities and sororities), the Boules and the Links (highly-selective social societies), there was a contingent of us who descended from working class U.S. and immigrant Blacks who aspired toward upper class status, but had not yet acquired the material and cultural trappings which characterized members of this group. Jones and McEwen also found that the ways in which an individual's identities intersect indicate that the ability to understand one aspect of an identity is impossible without considering its relationship to other aspects of an individual's identity. They describe this dynamic in the following finding from their study:

[F]or all participants, gender was an identity dimension to which they related. However, the description of what being female meant to them was quickly connected with other dimensions. (e.g. Jewish woman, Black woman, lesbian, Indian woman; p. 410) Kirk and Okazawa-Rey (2013) assert that Identity formation is the result of a complex interplay among individual decisions and choices, particular life events, community recognition and expectations, and societal categorization, classification, and socialization. (p. 9) 
That is, our identity is not only the result of who we think we are, but how others in society see and react to us. Therefore, how we identify or the groups with whom we affiliate are partly determined by who we perceive ourselves to be and how we are "recognized by others" (p. 10). Subsequently, dominant and target group identities are not solely determined by our individual perception of self, but by how our multiply-identified selves are perceived and interpreted within larger societal contexts.

According to Hardiman et al. (2013), efforts to reverse the effects of dominant group oppression may be undertaken by targeted and dominant group individuals who perceive themselves as agents of change (p. 32). The authors describe members of targeted groups who "reject the inferior status assigned to them in a system of oppression" and fight against it as “empowered targeted group members.” Examples of empowered targeted group members are women fighting for gender justice and Blacks and Latinos opposing racial/ethnic discrimination. Hardiman and colleagues describe dominant group members who decide to act as change agents as allies. "Allies are members of the advantaged group who act against the oppression(s) from which they derive power, privilege, and acceptance" (p. 33). The most frequently cited definition of allies in the literature is from Broido (2000):

Social justice allies are members of dominant social groups (e.g. men, Whites, heterosexuals) who are working to end the system of oppression that gives them greater privilege and power based on their social-group membership. (p. 3)

Owney (2010) defines allyship as “using one's position, influence and relationships to combat stereotypes and dispel myths" (p. 2). 


\section{Reconciling Allyship and Advocacy}

While allyship is the term used most frequently in the literature to describe dominant group member activism in social justice issues, advocacy is another term used in the literature to describe this category of work. Drawing on an earlier definition of advocacy proposed by Williams (1989), Welp (1998) adapted the following definition of advocates and advocacy work for his study of white men's learning experiences “on the path to advocating for inclusion and equity":

[Taking] a stand to support inclusion and equity in the face of resistance; Being one of a small group who brings attention to these issues; Recognized by women, people-of-color, gay, lesbian, bisexual, disabled, and other marginalized groups as an advocate, as well as by other white males; Demonstrated commitment of significant time and resources. (p. 40) While Welp operationalizes advocacy in a way that depicts advocates as dominant group members, other scholars do not impose this qualifier. That is, advocates may be both allies and “empowered targeted group members" (see Hardiman et al, 2013). London (2010) defines advocacy as

the act of supporting an idea, need, person, or group. Advocates use cognitive, emotional, and behavioral strategies to influence others' attitudes, behaviors, and/or decisions for the benefit of specific individuals (oneself or others) or groups. Advocates speak out and take action to effect change. (London, 2010, p. 225)

Given the similarities between allyship and advocacy, allies and advocates, these terms are often used interchangeably in the literature. They are also used interchangeably in this paper, but as terms which describe the social justice activism of dominant group members. 


\section{Key Issues Addressed in the Literature on Social Justice Allyship and Advocacy}

Predominant themes in the literature on allyship and advocacy center on the impetus behind engagement in the work (Bishop, 2002; Broido \& Reason, 2005; Edwards, 2006; Goodman, 2011; Hardiman et al., 2013; Messinger, 2011; Munin \& Speight, 2010) and the challenges faced by allies and advocates in their performance of the work (Broido \& Reason, 2005; Crowfoot \& Chesler, 2003; Freire, 1993; Hytten \& Warren, 2003; Patton \& Bondi, 2015; Reason \& Broido, 2005). In her study of six traditionally aged White heterosexual college students, Broido (2000) found that precollege egalitarian values, increased knowledge of social justice issues, engagement in meaning making processes, self-confidence, and the opportunity to act contributed to participants' ally development. Drawing on Astin's (1993) input-experienceoutput (IEO) model, Broido and Reason (2005) examine how social justice attitudes and actions are influenced by college students' experiences within and beyond the classroom and their precollege characteristics (p. 18). Bishop (2002) proposes a six part framework for social justice ally development which begins with (1) understanding oppression; (2) recognizing the interdependent nature of oppressions, (3) acknowledging one's part in oppression and confronting and working through the pain associated with it; (4) taking action to undo oppressive systems; (5) embracing an ally identity; and, (6) staying the course of allyship which means understanding the primary role of an ally is to support rather than to lead movements. Munin and Speight (2010) found that in addition to personal qualities, family, and awareness of diverse others, their college participants' faith beliefs played a critical role in their ally development. Hardiman et al. (2013) point to three factors which motivate allyship. The first is an awareness of the ways in which "working against oppression can be in one's self-interest." The second is "altruistic feelings or by a moral or spiritual belief that oppression is wrong." The third is "one's 
experience as a person who is 'disadvantaged by association' with people who are targeted" (p. 33). Goodman (2011) identifies three main motivators which lead members of dominant/privileged groups to support social justice: empathy — the ability to put one's self in the shoes of another; moral and spiritual underpinnings - deeply rooted beliefs which convict moral action; and, self-interest — the perception that injustice not only hurts members of marginalized groups, but members of dominant groups as well. Edwards (2006) proposes an aspiring social justice ally development model which describes the motivations of three types of allies: (1) the ally for self-interest who wishes to protect those for whom they care from harm/ridicule; (2) the ally for altruism who perceives their efforts as doing good for others; and (3) the ally for social justice who perceives the ways in which oppression of one group ultimately oppresses all groups (p. 47). In her study of faculty advocates of LGBT issues on campus, Messinger (2011) proposes a model of individual and situational characteristics which lead to faculty participation in advocacy. Individual characteristics include: perceptions of injustice, perceptions of efficacy or one's ability to make a difference, and one's social identity. Situational characteristics include: the resources available to the faculty agent, perceptions of institutional and social network support, the opportunity to be heard, activist role models, and the institution's disposition toward change (p. 1284).

Scholars have identified specific challenges White allies must overcome as they work with marginalized persons to fight injustice, "White allies tend to direct others, take leadership and focus on self, rather than listening to and partnering with nondominant populations" (Crowfoot \& Chesler, 2003; Hytten \& Warren, 2003; as cited in Patton \& Bondi, 2015, p. 490). According to Crowfoot and Chesler (2003), this mitigates their ability to serve the people they are attempting to help. Freire (1970) elaborates on this sentiment: 
certain members of the oppressor class join the oppressed in their struggle for liberation, thus moving from one pole of the contradiction to the other. Theirs is a fundamental role, and has been so throughout the history of this struggle...however... as they cease to be exploiters or indifferent spectators...they almost always bring with them the marks of their origins... which include a lack of confidence in the people's ability to think, to want, and to know... They talk about the people, but they do not trust them; and trusting the people is the indispensable precondition for revolutionary change. (p. 60)

Other scholars recognize the fundamental role of White allies in social justice efforts.

Kivel (2002), for example, perceives their ability to talk to or educate other Whites in ways that members of targeted groups simply cannot as their most valuable contribution. Reason and Broido (2005) outline three main aspects of ally work: inspiring and educating dominant group members; creating institutional and cultural change; and supporting target group members ( $\mathrm{pp}$. $83,85)$. They also discuss the challenges of engaging in ally work. These include: being ostracized from the dominant group; overstepping target group member boundaries by cooptation; maintaining commitment to the ally role, finding and sustaining supportive relationships with other committed allies and; remembering to be compassionate to oneself and others as one works toward social justice transformation (p. 87). According to Reason and Broido,

[A]llies must find a precarious balance between knowing when to take a seat at the table of social justice advocacy, joining those who are oppressed at combating oppression; when to speak up; when to be silent in order to listen to the experiences of others; and when to leave the table altogether, so as not to infringe on or usurp the role of target group members in advocating for their own liberation. (p. 88) 
Having examined dominant group member activism, the implications of social group identity in activism, and the factors which lead to, challenge, and sustain social justice allyship and advocacy, the next section of the literature review more closely examines the intricacies of men allyship and advocacy.

\section{Pertinent Theories and Research on Men Allyship \& Advocacy}

As a new and emerging topic, extant research that specifically addresses men faculty engagement in gender equity initiatives is scant. However, there is a substantive body of literature on what Flood (2005) describes as “....male political and intellectual endeavors sympathetic to feminism" that is referred to as "antisexist," "antipatriarchal," and/or "profeminist." Within this general body of literature is antiviolence activism-a subcategory Flood (2005) contends, “is the most visible and well-developed aspect of [men's gender equality] efforts" (p. 458). Subsequently, the theories and research discussed in this section primarily derive from literature on men's antiviolence activism in communities (see Berkowitz, 2002), and higher education contexts (Hong, 2000; Rice, 2009). However, pertinent theories and research from literature addressing men's involvement in other forms of gender and social justice-related activism in other contexts (Moss-Racusin, 2014; Prime \& Moss-Racusin, 2009; Welp, 1998), including academia (Anicha, Burnett, \& Bilen-Green, 2015, 2015; Patton \& Bondi, 2015) are also reviewed.

Intersecting discussions related to men allyship and advocacy follow in four subtopic categories addressing: men as a specific dominant identity group; patriarchy and hegemonic masculinities; context, structural positioning, and agency; as well as, barriers to, antecedents and consequences of men allyship and advocacy. 


\section{Men as a Specific Dominant Identity Group}

As was discussed in the section on dominant group member activism, the salience of identity is influenced by whether a given identity is targeted or dominant (Jones \& McEwen, 2000). Davis (2002) found that the college men in his study did not think a great deal about what it meant to be men. Instead being a man was so normative, these men did not feel compelled to consider the meaning of their gender in relation to others (as cited in Davis \& Wagner, 2005, p. 31). The tendency for men to overlook their dominant group status is compounded by the tendency for men to deny its associated privileges (Davis \& Wagner, 2005). However, not all men are unaware of their membership in a gender dominant group, nor the associated privileges they experience as a result of it. These men include many who intentionally take action intended to fight against gender inequity, destructive constructions of masculinity, and patriarchy (see Anicha, et al., 2015; Casey \& Ohler, 2012; Flood, 2005; Hong, 2000; Johnson, 2006/2013a/2013b/2013c; Neely, 2013; Prime \& Moss-Racusin, 2009; Welp, 1998).

Patriarchy, hegemonic masculinities, and gender egalitarianism. Johnson (1997/2005) defines patriarchy as "a kind of society in which men and women participate." He adds,

A society is patriarchal to the degree that it promotes male privilege by being male dominated, male identified, and male centered. It is also organized around an obsession with control and involves as one of its key aspects the oppression of women. (p. 5)

Patriarchy has been similarly defined as a political-social system that insists that males are inherently dominating, superior to everything and everyone deemed weak, especially females, and endowed with the right to 
dominate and rule over the weak and to maintain that dominance through various forms of psychological terrorism and violence. (hooks, 2004, p. 18)

Patriarchy, like any other system, is maintained by the individuals who participate in it (Johnson, 2013a). Terrence Real, a family therapist and author cited in hooks (2004) uses the phrase "psychological patriarchy" to describe a way of thinking "common to females and males." As hooks (2004) contends, "Women can be as wedded to patriarchal thinking and action as men" (p. 23). Johnson (2013a) insists, patriarchy is so "woven into the fabric of everyday life" that men and women both participate in it as "normal" (p. 336).

As Anicha et al. (2015) point out, "The construct of hegemonic masculinities offers a lens through which to understand the grip of gendered norms" (p. 24). Hong (2000) asserts that Although men exhibit a multitude of masculinities [Connell, 1987; Laberge \& Albert, 1999], one ideal of masculinity becomes dominant and marginalizes other definitions. This hegemony is reinforced by such societal institutions as political power, mass media, and corporate culture. (p. 271)

Brannon and David (1976), proffer four metaphors which collectively reflect the major tenets of hegemonic masculinity or the making of real men: The first, "No sissy stuff," has to do with the notion that real men avoid all forms and expressions of femininity. The second, "Be a big wheel," has to do with the messaging men receive to be competitive, dominant, in control, powerful, wealthy, and successful. The third, "Be a sturdy oak," conveys the principle that real men should be strong, solid, reliable, independent, unemotional, providers, protectors, and defenders of weaker others, especially women and children. The fourth metaphor, "Give 'em hell," depicts men as aggressive, fearless, risk-takers, who do not walk away from challenges or 
confrontation but instead welcome them. Citing Berkowitz (2002), Wagner, Yates, and Walcott (2012) assert,

Defining masculine behavior in this myopic and idealized way, leads men to experience masculinity through their relationships and expectations of each other, making it difficult for them to act outside gender norms while maintaining a sense of masculine identity. (p. 108)

This has important implications for men interested in allyship. Rudman, Mescher, and Moss-Racusin (2013) examine how both men and women react to men who the authors describe as "gender egalitarian." They point out that these men may or may not embrace the "feminist" label but "endorse gender equality." Citing Prime and Moss-Racusin’s (2009) study, they underscore their finding that despite gender equality attitudes among professional men, "few were willing to champion women's causes in their organization." Shedding insight into the reason for this discrepancy, a male study participant explains:

What are men who are identified with "women's issues" or men who are, publicly or privately, seen as supporting equality? It's always their manhood is undermined. They're a wimp. Their heterosexuality is questioned. These are ... powerful policing mechanisms that keep men silent ... if it was understood that men who are supportive of women's efforts for equality are strong men-[that] it actually takes more strength as a man — that changes the conversation. (Prime \& Moss-Racusin, 2009, p. 15; as cited by Rudman et al., 2013, p. 573)

The effects of patriarchy and hegemonic masculinity are a recurring theme throughout this discussion, so too are efforts on the part of women and men to resist these forces. The ways 
in which gender differentially shapes men's and women's experiences and expressions of resistance is also a theme that appears multiply throughout this section.

Context, structural positioning, and agency. In their study of the theories and practices which informed a newly developed, all men faculty gender equity advocates program, Anicha et al. (2015) claim that, "when men attempt to interrupt sexism and gender injustice ... they face the same [emphasis added] social and institutional pressures as do their women colleagues" ( $\mathrm{p}$. 24). Several findings on the backlash men suffer when they participate in activities perceived to be feminine (including allyship) seem to lend support to this claim (Brescoll et al., 2012; Burke \& Black, 1997; Carlson, 2008; Casey \& Ohler, 2012; Heilman \& Wallen, 2010; Moss-Racusin, 2014; Moss-Racusin et al, 2010; Rudman, et al., 2013). However, other research appears to contradict this supposition (see Drury, 2013; Drury \& Kaiser, 2014; Eliezer \& Major, 2012; Flood, 2005; Patton \& Bondi, 2015; Rasinski \& Czopp, 2010). As Flood (2005) asserts, very often "men acting for gender justice receive praise and credit (especially from women) that is often out of proportion to their efforts" (p. 464). Participant reflections in Patton and Bondi's (2015) study of White academic male allies for social justice indicated overwhelmingly that they did not suffer any penalties for their engagement in ally work, but instead found that within their fields - higher education and student affairs — they were rewarded for their social justice efforts. Drury (2013) found that men perceived other men who confront sexism as more credible antisexist advocates than women advocates and further indicated that confrontations of sexism were more warranted when enacted by men rather than women confronters. Eliezer and Major's (2012) research findings further support this sentiment. In their study, women were more likely than their men counterparts to be perceived as whiners when they confronted sexism. Based on their review of literature on men who become allies against sexism, Drury and Kaiser (2014) 
surmise that "[non-ally] men may have viewed [men] allies who confronted [sexism] as more legitimate than women because confronting sexism seems not to directly benefit men" (p. 643). That is, "Compared to women, it is difficult for men to detect sexism; however, when they do detect and confront sexism, men experience more positive reactions from others and their actions are taken more seriously as appropriate condemnations of sexism" (p. 645). Research findings on allies confronting discrimination, in general, support this proposition (Czopp, Monteith, \& Mark, 2006; DeTurk, 2011; Rasinski \& Czopp, 2010).

The differential experiences of men and women demonstrated in these findings suggests that while men's gender justice advocacy in some contexts may be severely penalized, in other contexts, it may be disproportionately rewarded. Interestingly, the findings supporting Anicha et al.'s (2015) claim that men who support gender equity efforts in workplace settings may experience the same degree of retribution that gender equity supporting women face were all generated from non-academic, corporate-like settings. Conversely, all but one of the findings which seem to dispute this claim were generated from research studies which analyzed the responses of collegiate men and women. Only Patton and Bondi's (2015) research reflected the experiences of men faculty who enacted allyship behavior in a workplace setting. The seemingly distinct effects due to organizational context indicate that far more research on the experiences of men in various settings is warranted. It also raises unexamined questions about how men's gender equity advocacy efforts are likely influenced by their positioning and agency within an organization. For example, might college-affiliated men, in general, experience more agency, than men in nonacademic settings, or, are there other contextual factors about specific men in these settings that seems to mitigate their actual (rather than anticipated) experiences of backlash for engaging in gender justice work? Furthermore, given that most college-affiliated men in the 
studies referenced were White, could it be the case that despite some of these men's expressed fears that they might experience backlash, their actual experience of gender equity advocacy, irrespective of their institutional affiliation (i.e. student, administrator, faculty member) was mitigated by their combined gender and racial status? Anicha et al.'s (2015) findings are derived from analyses of documents and archival data pertaining to an all-men gender equity advocacy program implemented at a university. Their actual findings indicate that men allies are concerned about backlash, but they do not provide any evidence that men allies have experienced backlash in response to their gender equity efforts. Conversely, Patton and Bondi's (2015) findings provide more convincing evidence that academic men engaged in allyship work may not experience backlash in response to these efforts, however, the fact that the men in their study were affiliated with academic units that tend to be friendly toward issues of social justice and diversity, suggests another potentially significant contextual factor which deserves further investigation.

Evidence suggesting that some men are in fact better-positioned to enact agency for gender equity related change, while other men and women are not may reflect a reality that can be subverted to further the cause of gender equity (Flood, 2005). As Prime and Moss-Racusin (2009) insist, "Without the avid support of men, who are arguably the most powerful stakeholder group in most large corporations, significant progress toward ending gender disparities is unlikely" (p. 2). Patton and Bondi (2015) acknowledge that,

Focusing on white men [as allies] is relevant because they occupy significant spaces in the academy as college presidents, senior administrators, and faculty (especially full professors), hence, their ability to wield power not experienced by nondominant populations...While some white men may certainly experience temporary oppression (e.g. 
having a low socioeconomic status or being gay or bisexual), their whiteness and maleness affords latitude to negotiate and transcend oppressive terrains. (p. 491) Neely (2013) contends that while "women and trans* . . folks must lead and guide [gender equity] work" men, given their predominance in the culture, must assume their "responsibility to work for gender liberation" (p. 357).

Despite indications that some men may not only be more effective advocates for gender justice, but suffer penalties far less than some other men and women has not translated into a significant increase in the numbers of men working alongside women as gender justice allies. Factors contributing to this reality must be more closely explored.

\section{Barriers to, Antecedents, and Consequences of Men Allyship}

While the literature reviewed in the section on allyship reveals a substantial body of research on the general topic, research examining the intricacies of men allyship is sparse. That which exists, however, centers on barriers to allyship (Davis \& Wagner, 2005; Prime \& MossRacusin, 2009; Welp, 1998), antecedents of allyship (Anicha et al., 2015; Casey \& Ohler, 2012; Drury \& Kaiser, 2014; Fabiano, Perkins, Berkowitz, Linkenbach, \& Stark, 2003; Prime \& MossRacusin, 2009; Prime, Moss-Racusin, \& Foust-Cummings, 2009; Welp, 1998), and the consequences (costs/benefits) of men's allyship/non-gender conforming social behavior that may be associated with men who ally (Berdahl, 2007; Burn \& Ward, 2005; Czopp, Monteith, \& Mark, 2006; Davis \& Wagner, 2005; Eliezer \& Major, 2012; Heilman \& Wallen, 2010; Levant \& Pollack, 1995; Moss-Racusin, 2014; Moss-Racusin et al., 2010; Owen, 2009; Prime \& MossRacusin, 2009; Rudman \& Fairchild, 2004; Rudman \& Mescher, 2013; Rudman \& Phelan, 2008; Welp, 1998). Given the critical role many believe men must play if gender equity is to become a 
reality (Hackman, 2013, p. 321; hooks, 2004), understanding the barriers to, antecedents, and consequences of men allyship is an absolute necessity.

Barriers. In their research, Davis and Wagner (2005) identify three barriers to men's development of social justice attitudes and actions: (1) privilege, (2) men's adherence to hegemonic masculinity, and (3) men's contradictory experiences of power. As was discussed in an earlier section, the first barrier — privilege — is not only an accoutrement of dominant group membership, but a mechanism of institutionalized systems like patriarchy and racism that is so ingrained in the societal psyche that its manifestations are often accepted as "the norm" or "the way things are" (Davis \& Wagner, 2005; Johnson, 2006). While the negative effects of these systems make privilege salient for members of oppressed groups (e.g. minorities and women), members of privileged groups tend to bathe in what Johnson (2006) refers to as "the luxury of obliviousness" (p. 22). Davis and Wagner (2005) assert that "[s]ubordination permeates the experience of women, but male privilege often goes unacknowledged by men... essentially [allowing] men to go about their lives without having to think about the impact of sexism on women” (p. 31). As Bishop (2002) points out, this lack of awareness prohibits ally development which requires that allies not only understand how oppression operates, but one's own social positioning in oppressive structures. Davis and Wagner also point out that individuals from privileged groups lack first-hand experiences with discrimination or what Landreman et al. (2007) describe as critical incidents:

Critical Incidents are the significant events, interactions, and experiences that served as catalysts for self-reflection and subsequent meaning-making, as well as for the decision by individuals to seek continued or additional engagement in diverse experiences or environments. (p. 283) 
Davis and Wagner argue that "a purely or even predominantly intellectualized experience ... with oppression may not fully [enable men] to see oppression for what it is" (p. 31). Subsequently, privilege remains a blinder/barrier to men's ability to think and act as social justice allies. The second barrier to men acting as allies identified by Davis and Wagner has to do with men's adherence to traditional gender scripts or "hegemonic masculinity." According to these researchers, hegemonic masculinity is characterized by "restrictive emotionality ... socialized control, power, and competition ... restrictive sexual and affectionate behavior among men; and obsession with achievement, work, and success" (p. 32). Catlett, Toews, and Walilko, (2010) have described hegemonic masculinity "as the form of masculinity that embodies the hallmarks of successful manhood in Western capitalist culture" (p. 110). Hegemonic masculinity equates notions of manhood with power, "with being successful, capable, reliable, in control... The very definitions of manhood we have developed in our culture maintain the power that some men have over other men" (Kimmel, 1994, p. 125). Ely and Meyerson (2010) describe the enactment of hegemonic masculinity as "men 'doing' gender" (p. 5). This "doing" of gender legitimizes men's men and reinforces the standard against which traditional notions of manhood are judged (Carrigan, Connell, \& Lee, 1985; Ridgeway, 1991; Ridgeway \& Correll, 2000; Schrock \& Schwalbe, 2009). Further supporting, Davis and Wagner's (2005) proposition that adherence to hegemonic masculinity scripts impedes men's allyship behavior are findings from ethnographic research conducted by Hong (2000) on eight college students (including himself, a doctoral student) who made up the executive board of a campus-based, all-men antiviolence advocacy group. Hong's research revealed that despite the apparent positive influence of the group on participants' efforts to reject or reform destructive constructions of manhood and masculinity, a reliance on these gendered norms persisted, leaving him to conclude that the 
primary force driving these men participants' commitment to ending gender-based violence stemmed from patriarchal musings of the role men are expected to play as protectors and defenders of women. The third and final barrier Davis and Wagner (2005) identified to men's development of social justice attitudes and actions has to do with "men's contradictory experience of power" (Kaufman, 1999, p. 59). In his essay, Kimmel (2013) draws attention to the discrepancy between what feminist experience as the power and domination of men and men's experiences in their daily lives. He argues that men do not (as he claims some feminist suggest) necessarily feel powerful.

Men's feelings are not the feelings of the powerful, but of those who see themselves as powerless. These are the feelings that come inevitably from the discontinuity between the social and the psychological, between the aggregate analysis that reveals how men are in power as a group and the psychological fact that they do not feel powerful as individuals. (p. 333)

In a radical departure from Kimmel's profeminist perspective that despite being powerful as a group, men do not feel powerful, Farrell (1993) argues that the idea that men as a group are powerful and privileged is actually a myth. He points out the many ways in which men are disadvantaged by societal institutions which favor the well-being of women over men. For example, Farrell describes the overrepresentation of men in what he calls "the death professions." That is, the military (in which men are required to register) and other high-risk occupations. He also describes the ways in which men are psychologically conditioned to feel the need to sacrifice their lives in the interest of women and children (pp. 105-107). Aligning with this view is Asa Baber (1992) who challenges women's exemption from military service, the favor he perceives they are shown in divorce and child custody agreements, and argues that 
men should have a say in whether a woman terminates a pregnancy. Offering what some might describe as a more balanced analysis of men in relation to women is Murphy (1995) who promotes embracing the differences between men and women not as indicators of one's superiority of the other, but as indications of the value in both masculine and feminine humanity (p. x).

In her feminist critique of men and power, hooks (2004) is careful to disaggregate the experiences of poor and working class men from those of wealthy, upper-class men:

More than any other male group in the United States [poor and working class men are] constantly concerned about the contradiction between the notion of masculinity he was taught and his inability to live up to that notion. He is usually "hurt," emotionally scarred because he does not have the privilege or power society has taught him "real men" should possess. (p. 559)

In his renowned work, The Power Elite, C. Wright Mills, (1956/2000), describes the powerful as "those who are able to realize their will, even if others resist it" (p. 9). Furthermore, he contends that "American men of power tend, by convention, to deny that they are powerful." This denial he argues enables them to promulgate a Theory of Balance, 'Balance of Power' implies equality of power, and equality of power seems wholly fair and even honorable, but in fact what is one man's honorable balance is often another's unfair imbalance. Ascendant groups of course tend readily to proclaim a just balance of power and a true harmony of interest, for they prefer their domination to be uninterrupted and peaceful. (p. 246)

Whether men are oblivious to the power they are perceived to possess as a group or individually, whether they deny or intentionally avoid acknowledging experiences of power 
which position them for advantages denied to others, the collective contradictory nature of men's experiences of power, as Davis and Wagner (2005) have argued have direct implications on their attitudes toward and actions on behalf of social justice. Nevertheless, Davis and Wagner (2005) assert, there are ways to counteract these barriers. Regarding privilege, they contend that men can develop critical-consciousness (see Freire, 1993; Landreman et al., 2007). Regarding hegemonic masculinity, men can be encouraged to, or supported as they challenge traditional gender scripts. That is, just as they have been taught to "do" their gender (Ely \& Meyerson, 2010), men can "undo" aspects of their gender identity that are oppressive. Men "undoing" gender according to Ely and Meyerson’s study involves “disregarding conventional masculine scripts in their day-today interactions" (p. 8). Regarding contradictory experiences of power, men can be helped to see how they may not only enact or perpetuate oppression in subtle and obvious ways, but how the inequitable systems of power that privilege masculinity also oppress nonhegemonic or non-dominant expressions of masculinity causing many men pain. As hooks (2004) maintains, "the pain men experience can serve as a catalyst calling attention to the need for change" (p. 558).

In addition to the barriers outlined by Davis and Wagner (2005), researchers have identified other barriers to men allyship. In his study of the journey of White male allies to advocacy, Welp's (1998) participants identified several barriers which delayed their progress as advocates, these included: a tunnel-like focus on one's career advancement; the lack of an intellectual framework for understanding their social category as White men; the strong, negative influence of parental ideologies about race and difference; lack of firsthand experiences with discrimination; and the lack of White male social justice advocate role-models. Prime and MossRacusin (2009) identified three barriers to men in their study becoming "champions" (p. 11) of 
gender equity. The first barrier was apathy — that is, a general attitude of indifference toward the subject of gender inequity. The second barrier was fear- that is, worry over loss of status within the organization, making mistakes that expose one's incompetence on the subject, and other men's disapproval. The third, and final two-part barrier was real and perceived ignorance-the former reflects the lack of acknowledgement that a gender equity problem even exists, the latter reflects one's belief that they know too little about gender equity issues to make a meaningful contribution (p. 14). The multiplicity of barriers which inhibit some men from allyship have not prevented others from taking up the cause. The antecedents revealed in the literature which lead the latter group of men to allyship will be discussed next.

Antecedents. As discussed earlier in this literature review, several scholars have examined antecedents to allyship (Bishop, 2002; Broido, 2000; Broido \& Reason, 2005; Duhigg, Rostosky, Gray, \& Wimsatt, 2010; Edwards, 2006; Hardiman et al., 2013; Landreman et al., 2007; Messinger, 2010; Munin \& Speight, 2010; Reason \& Broido, 2005; Reason \& Davis, 2005). However, fewer scholars have focused specifically on the dynamics which lead men to engage as allies (Casey \& Ohler, 2012; Drury \& Kaiser, 2014; Fabiano, et al., 2003; Prime \& Moss-Racusin, 2009; Prime, Moss-Racusin, \& Foust-Cummings, 2009; Welp, 1998). In their examination of extant research on the roles men play as allies confronting sexism, Drury and Kaiser (2014) identified three major antecedents to men becoming allies. The first has to do with men's ability to recognize overt, subtle, and benevolent forms of sexism as well as the consequences of each for women. The second has to do with the extent to which men endorse legitimizing beliefs:

People who endorse legitimizing beliefs tend to believe that high status groups have earned their position in the social hierarchy whereas low status groups have simply not worked 
hard enough to rise in the hierarchy. ... In contrast, people who reject legitimizing beliefs understand status differences as a product of structural systems and biases that restrict low status group members' opportunities and access to resources. (p. 640)

The third and final antecedent identified by Drury and Kaiser is men's relationship orientation. That is, the more men demonstrated a sense of social responsibility and desire to help others, the more likely they are to develop an ally identity (p. 641). In their investigation of the impact of social norms on men's allyship behavior to end violence against women, Fabiano et al. (2003) found that men's willingness to act as allies was contingent upon their perceptions of other men's and women's social norms related to the importance of consent and the willingness to intervene. Employing a bystander effect framework for analysis, Casey and Ohler (2012) examined factors which motivated newly trained male allies to intervene in situations that were potentially victimizing to women. They found that in addition to the framework components: noticing a problem, determining that it is problematic, perceiving a social responsibility to do something, and identifying a viable course of action (Latane \& Darley, 1969), male study participants considered an array of factors which informed their decision to act or not. Three factors related to the situational context - the participant's relationship to the perpetrator and/or victim, whether either had been drinking, and the number of people present. Interestingly, however, there were no consistent patterns related to context. The findings also pointed to factors related to group and masculinity norms which either inhibited or promoted action. These included: an assessment of the power differential between the ally and the perpetrator — when allies occupied a higher social or formal rank they were more likely to take action; and explicit male group messaging which discouraged intervening in another man's business or “cockblock[ing]" (p. 75). Consideration of the consequences of action or inaction also influenced 
participant's willingness to act, as well as factors directly related to their personal identity. One factor in particular was associated with participants' unrevealed sexual identities and whether they perceived that ally action made them vulnerable to exposure. Another factor was allies' concern that their own personal past record of violence against women would be exposed and that they would be discredited for their hypocrisy. Prime and Moss-Racusin (2009) found that the strongest predictor of men serving as gender equity "champions" was a strong sense of fair-play. Other antecedents identified by these scholars included: a high awareness of gender bias, a belief that achieving gender equality is a worthy goal, demonstrated defiance of some masculine norms, and a strong commitment to helping others. In another study, which examined factors influencing men's willingness to participate in gender equity training, Prime et al. (2009) found that men's perceptions of other managers' willingness to participate in the trainings positively affected their willingness to participate. Additionally, the belief that the trainings would positively impact the communities the participants' businesses served increased men's willingness to participate. The researchers also found that perceptions of job relevance positively influenced men's willingness to participate in the trainings. Participants in Welp's (1998) exploration of men allies' journeys to advocacy identified several antecedents to their ally development. These included: religious underpinnings, the desire to convey the importance of helping others to their children, their own parents' negative and positive role modeling of behaviors related to diversity attitudes, experiences while engaged in diversity-related work, and the heightened awareness which came with their own ascendant shift in class membership.

Having reviewed the barriers to and antecedents of men allyship that emerged in the extant literature, an examination of the consequences or costs and/or benefits of men allyship will now be discussed. 
Consequences (i.e. Costs/Benefits). Thus far, this section of the literature review has focused on two of the three most researched aspects of men allyship: the socio-psychological barriers to men allyship, and the personal and situational factors (antecedents) which lead men to allyship. However, before discussing the third most researched aspect of men allyshipconsequences (i.e. costs/benefits) — I want to juxtapose and elaborate further on the expected role of allies and the traditional expectations of men in order to underscore how these conflicting expectations influence the consequences of men allyship.

In what she describes as an open letter to a would-be male ally who disrupted a gathering of women feminist memorializing the anniversary of the murders of women activists, Bishop (2002) reprimands the would-be ally while pointing out how his actions were the exact opposite of a true ally:

the role of an ally is to listen and learn and trust that the people who are central to the event know what they need. When they trust you and know you well enough, they will ask you to do something specific to support their efforts. (p. 124)

Bishop's passionate assessment of the ally role - to listen, to learn, to trust the people central to the cause, to wait until these people feel they know you well enough to not just ask you to do something, but a specific thing in order to support their efforts — stands in stark contrast to the traditional behavioral expectations of men. As men are expected to speak-not listenbecause they are presumed to already know, to trust their own intuition about the best course of action, not rely on or give deference to others - especially women, to move forward with the solution they have devised, not wait to be told (by women) the specific action they can take to help (Brannon \& David, 1976). 
Moss-Racusin (2014) points out that while women are expected to be nurturing, modest, and other-oriented (communal), men are expected to be dominant and self-promoting (agentic). Bishop (2002) highlights several characteristics ascribed to allies. The ones that follow align more closely to traditional female characteristics than male: a sense of connection with others, a sense of collective responsibility, a disdain for egoism yet a strong sense of self, a preference for shared power over domineering power, and a willingness to be open, honest and vulnerable (see p. 111 for comprehensive list). This discrepancy between behaviors expected of men and those expected of allies, suggests that men who aspire to ally must continually reconcile what being a man means to them as well as what becoming an ally means to them.

In his essay, Neely (2013) seems to address the challenge of reconciliation between being a man and being an ally:

being an ally cannot mean that I am working to paternalistically "save" others with my cismasculine power...I must work in honest solidarity (not charity) with gender injustice movements, become aware of how I'm positioned within systems of power... and then use my privileged access to power in coalition with women and trans folks to create change and liberate all of us from the poison of patriarchy. (p. 357)

Citing the work of Cheng (1996) and Schrock and Schwalbe (2009), Ely and Meyerson (2010) assert that: "Signifiers of manhood vary across demographic groups, geographies, jobs, and organizational cultures ... and men craft a masculine self strategically adapted to the local context" (p. 6). Neely's “masculine self" seems to be adapted to his awareness of his general location within a patriarchal society and his specific location within gender injustice movements. The notion that masculinity can be adapted in various contexts is echoed by Kimmel (2013): 
This idea that manhood is socially-constructed and historically shifting ... gives us a sense of something extraordinarily valuable - agency, the capacity to act. . . Our behaviors are not simply "just human nature," because "boys will be boys." From the materials we find around us in our culture - other people, ideas, objects - we actively create our worlds, our identities. (p. 329)

The power to create one's world and one's identities as expressed by Kimmel, appears, in some ways, to be an attempt to reclaim agency for men who wish to change. His entreaty, therefore, is a nice point from which to pivot to a discussion of the consequences of men allyship not as a static set of outcomes over which there is no control, but as manifestations collectively created and therefore when deemed necessary can be collectively transformed.

In the ensuing discussion, consequences refer to the costs and/or benefits of men allyship. While theoretically the costs and/or benefits of men allyship accrue to men who ally, men who don't, women and sexual minorities, organizations, and society, in general, this section of the literature review is focused on the specific costs and benefits which accrue to men who ally.

Costs. Moss-Racusin (2014) cites "four primary components of workplace masculine stereotypes that are typically enforced within Western professional cultures" and stem from earlier work by Brannon and David (1976):

(1) avoid behaving in any way that could be construed as feminine, or enacting female stereotypes,

(2) 'be a winner' by attaining status, power and professional prestige,

(3) show no weakness or 'chinks in the armor' by demonstrating constant vigilance and emotional and physical toughness, and 
(4) be a 'man's man' or 'one of the boys' by complying with masculine stereotypes and fitting in with other male peers who can provide career advancement. (Moss-Racusin, 2014, p. 249)

According to Moss-Racusin (2014), men who strictly comply with these prescriptions and those who don't pay a high price. Those who attempt to strictly comply with "stereotypes calling for men to demonstrate physical strength and toughness can paradoxically undermine their mental and physical health" (Levant \& Pollack, 1995; as cited by Moss-Racusin, 2014, p. 249), compromise their development of interpersonal skills (Pollack, 1999; Burn \& Ward, 2005; as cited by Moss-Racusin, 2014, p. 250), increase their likelihood of sexually harassing women (Berdahl, 2007; as cited by Moss-Racusin, 2014, p. 250), as well as their propensity to "enact violence against women" (Parrott \& Zeichner, 2003; Reidy, Shirk, Sloan \& Zeichner, 2009; as cited by Moss-Racusin, 2014, p. 250). On the other hand, men who do not strictly comply with these prescriptions, such as men allies whose ally work may be characterized as less manlyeven feminine, may suffer "backlash," or social and economic penalties in the form of "social ostracism" including loss of status, "lack of access to informal mentoring channels and social capital," "workplace bullying," "not being hired," "failure to advance," "inequitable pay," and “wrongful termination” (Rudman \& Phelan, 2008; Moss-Racusin, Phelan, \& Rudman, 2010; as cited in Moss-Racusin, 2014, p. 253). Moss-Racusin identifies several behavioral domains likely to incite backlash. The first is emotional self-disclosure/vulnerability which can incite workplace bullying:

backlash for emotional disclosure can serve as a powerful barrier to men's interpersonal communication in the workplace, particularly surrounding personal issues that may interfere with work but could be managed successfully with appropriate support. (p. 255) 
The second and third behavioral domains have to do with men being adept at skills typically expected of women (e.g. caring for children, homemaking), and being successful in a traditionally female role (e.g. relationship counselor). The forms of backlash these behavioral domains incite, respectively, include being sabotaged by peers (Rudman \& Fairchild, 2004), and being characterized as a wimp (Heilman \& Wallen, 2010). Even an act such as requesting family leave has led to backlash in the form of men being characterized as "poor workers," and men suffering "organizational penalties (such as salary reductions and demotions)", and the loss of eligibility for "raises and promotions" (Rudman \& Mescher, 2013; as cited by Moss-Racusin, 2014, p. 256).

Another cost men allies may perceive is harsh-critique from women and sexual minorities for presuming the title "ally" without a comprehensive understanding of allyship nor a demonstrated commitment to its tenets. An excerpt from Bishop's (2002) “open letter" may be perceived as such a critique:

I know you meant well when you took the microphone, uninvited, and spoke to us at the ... rally. . . Your "contribution" added the only sour note in an amazingly powerful and expressive series of events. ... You provided a crystal clear example of how not to be an ally. (p. 123)

Patton and Bondi (2015), two women activist researchers, provide another example of what might be perceived as harsh-critique when they summarize the work activities described by the self-proclaimed White men allies in their study as "what most nice people do": "[They] purposefully connected with marginalized persons on campus, helped students negotiate the system, and addressed issues of inequity in their courses/departments" (p. 509). These researchers argue that while these are important activities, they do not involve the personal 
sacrifice and risk-taking that characterizes allyship. Citing Kivel (2007), Patton and Bondi assert that "[A]llies should find themselves in contentious relationships with those in power...such as confronting powerful decision-makers and being questioned when they posed suggestions conflicting with the status quo" (p. 509). Instead, their study revealed that although their participants' understanding of allyship included "sacrifice, difficulties, and the inability to conveniently excuse oneself from conflict and pushback from others," overwhelmingly, they did not experience any negative consequences as a result of their ally efforts. As one participant shared:

I haven't been put into a position where it feels like a tremendous sacrifice, and there are times when I feel guilt about it because I know there are people who are taking a lot more risks than I do. (p. 502)

Another participant added, "Sometimes I feel as if I should be doing more, or at any point, I can just walk away from things and there are no negative consequences for me" (pp. 501-502).

Given the lack of risk experienced with his ally work, a separate participant lamented: I am probably not being a strong enough ally because if I was noticing negative impact . . . doing work as assertively as I feel that I should be, then I would have more people pissed off at me. (p. 502)

Interestingly, Patton and Bondi note that while "risk" was not a feature of their participants' descriptions of ally work, reward was as illustrated in the following reflections from two different men:

I think I probably get rewarded as much as I get any questions about my doing this work, and I don't know because I can't tell, but I don't think there have been any penalties or sacrifices yet. (p. 502) 
"I think at some level in ... student affairs we reward people in positions of privilege who get it [social justice] or at least purport to get it" (p. 503).

As discussed earlier, in the section on contexts, structural positioning and agency, the absence of perceived costs for the White male faculty and administrators in Patton and Bondi, raises questions about the ways in which contextual factors such as race, and positioning within an organization may shape men's experiences and effectiveness as allies. In a thought piece entitled, Privileged Social Identities and Diversity Leadership in Higher Education, David S. Owen (2009), a White male, assistant professor of philosophy and Coordinator of Diversity Programs argues that appointing White men to diversity leadership positions in higher education should not be summarily dismissed. He asserts that relegating White men to the sidelines of diversity efforts undermines the potential some possess to act as effective social justice change agents. He explains:

If White men undertake only supportive, behind-the-scenes roles, we can take credit and feel personally virtuous for working for diversity and social justice, while at the same time avoiding the risks of directly challenging a system that is deeply structured by race and gender inequalities. In these cases, we can avoid breaking publicly with White male peers over practices of Whiteness and White bonding, or maleness and male bonding, nor do we need to take a public oppositional stance against the racialized and gendered structures of the institution. ... In other words, we can be "good liberals' (or, perhaps more derogatorily, "politically correct") when it comes to diversity without taking on any of the burdens or risks. (p. 197)

Owen's analysis might be extrapolated to suggest that without a formal leadership appointment White men are likely to skirt the challenges of meaningful diversity work. However, with a 
recognized diversity leadership position they are more likely to assume the risks involved with taking bold action against power structures. The implication as it pertains to this discussion, then, is that White men who, for example, take on social justice work as uncompensated allies are unlikely to take the kinds of risks that lead to meaningful change without having formal responsibility for such efforts. Aspects of Patton and Bondi's (2015) findings seem to partially support Owen's argument. None of the participants who self-identified as allies perceived any substantial risks related to doing ally work. Furthermore, though each was formally employed in mid to high status faculty and administrative positions within the higher education academic department and student affairs, none held a formal diversity leadership role. Even Patton and Bondi's critique of the activities these self-proclaimed allies performed determined that while their work was important and helpful, it could not be distinguished from the work any other "nice" faculty member or administrator would do. The proposition that White men may be less likely to take or experience the risks associated with allyship, even when they identify as allies, unless they are in a formal diversity leadership role is fascinating because it undermines a fundamental tenet of allyship expressed by Bishop (2002):

Try to avoid the trap of "knowing what is good for them." Do not take leadership. They are the only ones who can figure out what is good for them, and developing their own leadership strengthens their organizations. (p. 117)

Although, Owen (2009) might argue that a White man with additional privileged identities assuming a diversity leadership position within a college or university is different from assuming leadership of a grassroots organization, the fact is that many of these offices aim to specifically address the needs of students from marginalized backgrounds. Therefore, although the contexts 
are different, given the similarity in mission, it does not seem likely that the effect of a White male leader with additional privileged identities would be very different.

While the proposed study does not limit men faculty participants by race, White men faculty dominate STEM. Therefore, findings may shed further light on the potential relationship between the quality of White men allyship and White men's formal and informal positions within the academic organization.

Having examined the consequences of men allyship as they relate to costs, this discussion will now turn to the consequences of men allyship as they relate to benefits.

Benefits. As a sparsely researched topic, there is limited empirical evidence on the specific benefits of men allyship. Drury and Kaiser (2014) highlight findings which indicate that, in general, allies experience "fewer negative reactions" when they confront discrimination than do target group members (Rasinski \& Czopp, 2010). As discussed earlier, research on Whites who confront racism revealed that "allies' confrontations may be viewed as more appropriate condemnations of prejudice compared to the same actions taken by members of the group targeted by discrimination" (Czopp, Monteith, \& Mark, 2006; Rasinski \& Czopp, 2010, as cited, in Drury \& Kaiser, 2014, p. 642). DeTurk (2011) found that allies in her study used a dialogic approach that may further explain this finding:

Allies noted that they wanted to avoid making others angry, uneasy, or embarrassedfeelings that can turn against the ally and entrench the person's original attitude; and some allies verbally validate others' prejudicial feelings while at the same time condemning discourse that stems from such feelings. . . Embedded in this approach is a certain reliance on empathy and perspective-taking. . . Allies' discourse, consequently, is influenced by 
their trust that most people, given the opportunity, would like to discard our racism and homophobia and welcome learning. (p. 580)

As discussed earlier, men have a clear advantage over women when it comes to confronting sexism (Eliezer \& Major, 2012; Drury, 2013):

The surprising nature of arguing in favor of outgroup interest should thus lead others to pay closer attention to the argument and, to the extent that a man makes a sound argument when confronting, observers should become more aware of the sexist nature of a confronted act. (Drury \& Kaiser, 2014, p. 644)

Davis and Wagner (2005) point out that in addition to the individual level benefits of men allyship which include challenging sexist behaviors and comments as they occur, there are institutional level benefits, "for example, serving as an advocate on issues related to pay equity, representation, promotion to leadership, and harassment-free environments" (p. 38).

Furthermore, the development of critical consciousness in men who ally translates into equityaffirming behaviors that role model for younger men an expression of masculinity not defined by "dominance and control" (p. 39). The need for White male role models was echoed in Welp (1998) who describes the lack of White male role models as "One of the strongest themes to emerge from his study" (p. 113). This theme also resonated in Owen (2009):

Role-modeling White antiracism and feminism is not a trivial matter. For young white male faculty, staff, and students to feel empowered to actively and publicly challenge unjust social structures requires the willingness to go against expectations, and the expectations for White men are that they will choose White and male bonding rather than undermine the sociocultural status quo. (p. 196) 
Prime and Moss-Racusin (2009) propose several practical gains for men in the workplace engaged in gender equity work. They include:

- Freedom to share financial responsibilities with one's spouse or partner

- More rewarding and intimate relationships with spouse or partner

- Freedom to parent more substantively; more rewarding relationships with children

- Freedom to define oneself according to one's own values rather than traditional gender norms, and

- Better psychological and physical health (p. 21)

Men allies in the literature share perspectives which suggest that another benefit of allyship is the way in which it decenters traditional notions of masculinity in favor of expressions of manhood that center on men's connectedness and concern for humanity. For example, Neely (2013) reflects,

It is time (well past time, actually) to write a new story where cisgender men are constant and committed allies in ending gender oppression, and, in the process, are able to come back to our true selves and reclaim our true humanity. (p. 358)

Reflecting on what it means to be a "champion" of gender equity, one of the participants in Prime and Moss-Racusin's (2009) study shared:

I'm in it to change the way we, as a global community, look at one another, for whatever the difference, and see fear when we're not looking at a mirror image of ourselves ... we have all of the capabilities, as a species, to solve that stuff and to have this world ... [be] equitable. ... I have a sense of privilege in having grown up middle-upper class, white, and male in the United States ... [and I want] to make a difference. (p. 12) 
Responding to a question regarding his motivation to act as a champion for gender equity, another of Prime \& Moss-Racusin's participants added this:

In some instances, it's a very personal investment in improving the lives of our daughters, making the world a freer and safer place for ourselves as men, for women we care about. I think there's something about creating models of masculinity that aren't as restrictive, that don't require that you only talk about sports. (p. 21)

This section has provided a thorough examination of the intricacies of men allyship and advocacy. It has also underscored pertinent theories and research which indicate the myriad ways men allyship is shaped by contextual factors, beliefs, and attitudes. It further illustrates the value of men allyship, despite the fact the opportunity to be an effective ally appears to be tied to the very oppressive, inequitable systems allyship seeks to disrupt. Additionally, this section has documented extant research purporting the value of men allyship, as well as, the specific barriers to, antecedents, and consequences (costs and benefits) of men allyship. Furthermore, the literature reviewed raises provocative questions about the ways in which White men within academia may or may not be effective in carrying out ally work as traditionally conceptualized.

Thus far, the review of literature has provided critical insight into the complexities of faculty work, the multidimensionality of faculty activism, the issues surrounding dominant group member activism, and the particular dynamics and challenges associated with men who ally. In the sections that follow, the review of literature will address the gendered academic organization as the context within which gender equity work occurs, and the roles faculty play in gender equity initiatives. 


\section{The Gendered Academic Organization}

\section{Gender Equity in the Academy}

The progress of women faculty in traditionally male-dominated fields is remarkable (National Center for Science \& Engineering Statistics, 2015). However, there remain areas of the academy where women are grossly underrepresented, and despite notable progress, the number of women in fields like the hard sciences continue to trail behind the number of men in terms of academic rank and tenure (Sturm, 2006). The reasons for this discrepancy are debated and range from assertions that women are just not as interested as men are in fields like the hard sciences (i.e. physics, math, engineering, computer science), to women who choose an academic career in the hard sciences often depart from the field to start a family (Bailyn, 2003; Blickenstaff, 2005; Maranto \& Griffin, 2011; McClelland \& Holland, 2014). Whatever the reason(s), gender inequities persist and are the target of various change initiatives which include strategies such as engaging men faculty in gender equity work.

Gender equity work is premised on understandings of what constitutes gender equity. Latimer, et al. (2014) define gender equity in academia as

[A] representation of women across all fields of inquiry, at all levels of rank and administrative appointments that is proportional to the availability of women candidates in those fields. (p. 334)

Bailyn (2003) calls for a revision of conceptions of gender equity which are satisfied with equality of opportunity for women based on male-constructed norms and/or conceptions of gender equity which tout the establishment of inclusionary policies and practices which acknowledge "an academic's outside life” as evidence gender equity has been achieved. Instead, she maintains that an "ideal image of gender equity," not only legitimates "the private sphere of 
family, community, and other personal involvements," but equalizes "the value placed on economic and noneconomic activity" (p. 140). Though Bailyn's (2003) admittedly idealistic conception of gender equity is easily contrasted with Latimer and colleagues' more succinct and measurable conception of gender equity, neither provide a blueprint for achieving gender equity. Indeed, scholars have theorized (Acker, 1990; Bailyn, 2003; Morahan, Rosen, Richman, \& Gleason, 2011; Ridgeway \& Correll, 2000; Roos, 2008; Rosser, 2007) and tested (Ely \& Meyerson, 2000; Latimer et al., 2014; Nolan, Jackson, Latimer, Tower, \& Borres, 2012; Sturm, 2006) myriad approaches to achieving gender equity in organizations and none have suggested that their approach offers a blueprint for every context and situation. Although a review of the various approaches to gender equity in organizations exceeds the objectives of this review, it is important to note that at the crux of each theorized and empirically tested approach is the implicit assumption that gender is entrenched in the structures and designs of organizations and in the cognitive schemata of the people who inhabit them. Taking this into consideration, a brief review of literature on the gendered academic organization has been included as it is the organizational context for this study.

\section{Gender and Academia}

The post-secondary academic organization, generally, and the academic department, specifically, represent the contexts within which gender equity work takes place. In addition to traditional notions of post-secondary institutions as slow changing bureaucracies (Kezar, 2014), it has also been suggested, that like other established organizations, institutions of higher education are gendered (Acker 1990; Britton, 2000; Parsons and Priola, 2013). Acker (1990) provides the following explanation of a gendered organization, 
To say that an organization ... is gendered means that advantage and disadvantage, exploitation and control, action and emotion, meaning and identity, are patterned through and in terms of a distinction between male and female, masculine and feminine...[and] men are almost always in the highest positions of organizational power. (Connell, 1987; West and Zimmerman, 1987; as cited in Acker, 1990, p. 146)

Citing, Ferguson (1984) and Leathwood (2005), Parsons and Priola (2013) explain the gendered nature of academic culture and its oppressive effects on academic women:

The traditional culture [of academia is] based on bureaucratic hierarchical systems . . . founded on sets of values that define and maintain a specific configuration of gender roles and relations ... these relations ... disadvantage women in both their research and managerial careers. (Park, 1996; Priola, 2007; Thomas \& Davies, 2002; as cited in Parsons \& Priola, 2013, p. 580)

Drawing on Acker (1990), Ely and Meyerson (2000) identify four categories of social practices through which gendered organizations are sustained. These include:

(1) Formal policies and procedures;

(2) informal work practices, norms, and patterns of work;

(3) narrative, rhetoric, language, and other symbolic expressions; and,

(4) informal patterns of everyday social interaction. (p. 114)

Maranto and Griffin (2011) describe the professoriate as "a highly gendered occupation" and point to formal and informal policies and practices as evidence. For example, a perceptible disdain for faculty with "non-work ... responsibilities," reinforced by a time-boundless work culture, and a tenure-clock inconveniently synced with many faculty women's reproductive 
clocks (p. 140). Acker's (1990) analysis of "the abstract worker" in gendered organizations supports Maranto and Griffin's assertion:

In organizational logic, filling the abstract job is a disembodied worker who exists only for the work. Such a hypothetical worker cannot have other imperatives of existence that impinge upon the job. At the very least, outside imperatives cannot be included within the definition of the job. Too many obligations outside the boundaries of the job would make a worker unsuited for the position. The closest the disembodied worker doing the abstract job comes to a real worker is the male worker whose life centers on his full-time, life-long job, while his wife or another woman takes care of his personal needs and his children.

(p. 149)

In her essay reflecting on lessons learned from the oft cited MIT (1999) report, Bailyn (2003) claims that senior faculty women at MIT "believe absolutely" in the notion of "the perfect academic...who gives total priority to work and has no outside interests and responsibilities." She alleges that these academic women "cannot conceive of any other way to be a first-rate scientist," which she suggests, "may explain why most of them are not married and have no children ... [while] men academics routinely have families" (p. 139). Van den Brink and Benschop (2012) make the point that despite the embeddedness of gendered processes at the institutional level, gendered dynamics vary in local institutional contexts (e.g. the academic department) because of differences in "core activities, financial resources, career patterns, epistemological issues and publishing strategies" (p. 72). Supporting their contention, Latimer et al. (2014) explain how gendered processes shape and privilege certain academic disciplines over others: 
The characteristics traditionally most valued in academia (i.e. rationality and objectivity) are linked with science and masculinity and thus are seen as in opposition to non-science and femininity. As a consequence, academic disciplines are gendered based on their methods of inquiry, and those perceived to be more objective and inherently masculine are privileged. (p. 335)

As this discussion has made clear gendered processes operate at all levels of the academic organization from the individual gendered position, to the gendered academic department and discipline, to the structures and processes which govern the larger institution. Considering this, strategic change for gender equity in the academic organization must be viewed as a multileveled process. At each level are faculty actors who play varying roles in gender equity change.

\section{Roles of Faculty Actors in Gender Equity Work}

Earlier in this literature review, I examined the multidimensionality of faculty activism and organized it into three categories: engaged scholarship (teaching, research, and service which aims to contribute to the betterment of the local/global community); protest; and, what I termed leadership for a just institution (LJI; which reflects activism aimed at matters of justice within an academic institution). I also drew two conclusions from the review of literature on faculty activism. The first is that although certain forms of faculty activism overlap into more than one of the three categories, other forms fit squarely under a single category. The second is that faculty engaged in activism use multiple identity labels (e.g. faculty activist, academic activist, activist academic, scholar activist, intellectual activist, practitioner-scholar, and/or scholarpractitioner) and although the literature revealed instances when clear distinctions could be discerned between some of these labels (e.g. practitioner-scholar and scholar-practitioner; academic activist and activist academic), it also revealed a tendency for these labels to be used 
interchangeably (e.g. faculty activist and academic activist, intellectual activist and scholar activist) creating a nagging inconsistency that increases the likelihood for conceptual confusion. In light of this, I decided to use faculty activism as an umbrella term and focus instead on the proposed categories of faculty activism which I suggest provide a clearer understanding of the specific types of activist work.

This section of the review turns to the literature on organizational change to explore the roles of faculty actors in gender equity initiatives. While the nature of the work performed by some of these faculty actors would fit squarely under the proposed faculty activism category leadership for a just institution (LJI), some faculty actors may not embrace an activist label (e.g. academic feminist, see Hart, 2008). In the organizational change literature less emphasis is placed on self-imposed activist labels and more emphasis is placed on position in the academic organization and the purpose, function, and outcomes of faculty actors' roles in change efforts.

Change agents, a term commonly used across the organizational change literature, is also used to describe faculty actors engaged in gender equity work. Drawing on the organizational transformation literature, Nolan, et al. (2012), define change agents as "individuals who are recognized as informal leaders in the targets of change" (p. 2). In the case of change efforts targeting faculty groups or departments, these change agents would be faculty perceived as informal leaders by their peers and administrators. However, organizational change literature also references individuals in positions of formal authority as "change agents" (see Kezar, 2014; Sturm, 2006). Whether formal or informal, these leaders are presumed to have the social capital necessary to influence target group members to act in the interest of change. Kezar (2014) warns, however, that to be effective, change agents must carefully assess their level of agency which exposes them to differential "power conditions" and "match strategies to available resources" 
accordingly (p. 118). She distinguishes between the leadership strategies common to those in positions of power and those primarily enacted by "bottom-up leaders" or those without formal leadership authority. She asserts that those in positions of authority (also called "top-down" leaders) employ the following strategies to promote change: establish core values/mission, utilize planning mechanisms, use resources and funding, use incentives to motivate others, create supportive administrative structures, and hire and train employees who will support change initiatives (pp. 111-113). On the other hand, bottom-up leaders use strategies which include creating intellectual opportunities to inform and build capacity, professional development aimed at heightening awareness and establishing a vision, using search committee service to advocate for the hiring of like-minded people, garnering resources, using the classroom as a forum to engage students, gathering data, joining existing networks, and partnering with influential stakeholders (pp. 113-117). Conceptualizing change agents as both formal and informal leaders who leverage varying levels of agency within an organization to promote change makes it a useful umbrella term under which other terms used to describe the role of faculty actors can be categorized.

Parsons and Priola (2013) cite Meyerson and Tompkins (2007) who, drawing on DiMaggio's (1988) terminology, describe “institutional entrepreneurs" as "those who can expose the contradictions between their identities, ideology and interests and the dominant logic of their organizations" (p. 582). In her proposed framework and methodology for designing more inclusive academic organizations, Sturm (2006) defines "organizational catalysts" as individuals who operate at the convergence of different domains and levels of activity. [They act as information entrepreneurs leveraging] knowledge, ongoing strategic relationships, and accountability across systems. This role places individuals with 
knowledge, influence, and credibility in positions where they can mobilize institutional change. (p. 287)

Whereas the emphasis in the definition of institutional entrepreneurs is on the change agent's ability to draw attention to contradictions between the "dominant logic of their organization" and their "identities, ideology, and interests," the defining feature of organizational catalysts is their legitimacy and strategic positioning within the organization as well as their capacity to exploit these features in the interest of change. While it is conceivable that a change agent could be both an institutional entrepreneur and an organizational catalyst, it is also possible a change agent could be described as one and not the other or neither. In fact, some faculty actors assume change agent roles specific to the gender equity initiatives on their campus. In her report on barriers to gender equity and "source-specific [gender equity] interventions," Holmes (2014) describes specific roles faculty actors (men and women) have played in gender equity change as mentors who "provide advice and counseling" and as "advocates [who] will stand up for a colleague and actively promote his or her advancement" (p. 33). She also describes the role of trained faculty who serve as "equity advisors" on search and evaluation committees. According to Holmes, these faculty actors serve as representatives of under-represented groups while not necessarily being from those underrepresented groups... This practice shares the responsibility of equity "eyes and ears" among all faculty and relieves faculty from under-represented groups from being the only voices to speak up for equity. (p. 34)

Conjuring imagery of faculty activists discussed earlier in this review, Meyerson and Scully (1995) use the term "tempered radicals" to describe 
individuals who identify with and are committed to their organizations, and are also committed to a cause, community or ideology that is fundamentally different from, and possibly at odds with the dominant culture of their organization. (p. 586)

Given this description, tempered radicals are likely to be faculty who embrace an activist identity. They could also be faculty actors who serve as institutional entrepreneurs, organizational catalysts, or in specific-situational roles such as 'mentors,' 'advocates,' and 'gender equity advisors.'

Parsons and Priola (2013) examined the roles of women faculty activists in the field of business attempting to change the "gender status quo" within their departments through microlevel forms of resistance such as raising awareness about gender equity "through every day talk in university departments" (p. 586), gender equity research, and using the classroom to "sneak gender issues in" through teaching (p. 588). Citing Meyerson and Tompkins (2007), Parsons and Priola note,

it is often marginalization that creates the motivation to change ... being on the margins of an organization generally corresponds to having insufficient power and resources to implement wide changes or to mobilize a broad base of support. For this reason, the localized, small-scale tactics used by dispersed actors . . . have also been widely debated and criticized for their individualist, rather than collectivist, focus. (p. 582)

The deference some scholars give to "collectivist" rather than "individualist" change strategies is illustrated by Nolan and colleagues (2012) who invoke Lewin's (1947) field theory which asserts that without a major strategic intervention "only small variations in the behavior of individuals and groups will be observed" (p. 2). In a similar vein, Roos (2008) argues that "[f]inding opportunities to change institutions as opposed to changing individuals to fit into static 
institutions, is the most effective way to move forward [with change]" (p. 196). Less aligned with traditional approaches which privilege organization-level strategies over those at the individual or group level of an organization are Sturm (2006) who suggests that a multileveled framework and methodology are necessary to successfully implement and sustain a change strategy, and Ely and Meyerson (2000) who promote a radical approach to change in which "any one intervention is an act of resistance, not intended by itself to transform the gender relations of the organization" but through "a series of interventions, each designed to subvert traditional gender arrangements, [increases] the possibility of organizational transformation” (p. 133). Ely and Meyerson's approach echoes the feminist ideology resonant in Parsons and Priola's conviction that,

the varieties of activism and strategies for change are multiple...ranging from radical activism to subtle resistance ... [furthermore,] . . Micro-changes initiated endogenously by organizational members are important in affecting organizational practices and can contribute to create a wider critical awareness antecedent to any transformation project. (p. 582)

Several findings support the significance of a "critical awareness antecedent" in faculty actors' engagement as change agents (Anicha et al., 2015; Bailyn, 2003; Prime et al., 2009; Roos, 2008; and Sturm, 2006). In fact, Bailyn's (2003) reflections on the incidents which led to the oft cited MIT (1999) report, not only lend credence to Parsons and Priola's (2013) assertion that "it is often marginalization that creates the motivation for change," but documents how a microlevel action such as "a single woman scientist out of frustration, anger, and despair about her situation" writing a letter of complaint to her university president ultimately led to the collection 
of data documenting gender inequities which upon being presented to the (male) Dean of the School of Science served as a "critical awareness antecedent." As Bailyn recounts,

As soon as the Dean became aware of these discrepancies, he began to make changes, and even before the women gave him the final report, salaries and space allocations had been adjusted. (p. 146)

Similarly, Roos (2008) describes how data documenting gender inequities in the Arts \& Sciences department of the public research university in her study served as a "critical awareness antecedent" for a (male) Dean who revised gender-discriminatory policies and practices which proved to result in "positive changes in the promotion and recruitment of [Arts \& Sciences] women to senior professor positions" (p. 196). According to the scant, but emergent research on men faculty allyship, “critical awareness antecedents” including presentation of data documenting gender inequities and personal experiences of discrimination have fueled men to increase their engagement in gender equity work (Anicha et al., 2015; Prime \& Moss-Racusin, 2009). In terms of the impact of personal experiences, Prime and Moss-Racusin (2009) found that some of the men participants in their study "described pivotal experiences where they suffered unfair penalties for breaking with masculine norms as turning points that prompted them to become more engaged advocates of change" (p. 6). Findings from Anicha and colleagues indicated that,

Learning about both overt manifestations of sexism and unconscious gender bias appeared to provide Advocates with an understanding of the challenges faced by women faculty as well as a deepened empathy for their gendered-female colleagues. (p. 31) While the aforementioned studies demonstrate the potential for a "critical awareness antecedent" to inspire change behaviors. Other studies have documented the dubious relationship 
between awareness of inequities/discrimination and perceived responsibility/accountability for change (Buttner, Lowe, \& Billings-Harris, 2006; McClelland \& Holland, 2014). In their study of academic leaders' perceptions of responsibility for gender equity initiatives in STEM departments, McClelland and Holland (2014) found that awareness of gender inequities inspired high personal responsibility leaders to initiate change, whereas low personal responsibility leaders either failed to perceive that gender equity change was needed or if there was a perceived need for change ascribed responsibility for enacting change to others-especially women. According to these researchers,

This group consistently ... described women as responsible for changing, whereas male colleagues were not as commonly included in these discourses of responsibility...the low responsibility group imagined gender diversity as something that would happen once women changed, by altering their family expectations and adapting to the more masculine behaviors expected in these departments. (p. 221)

Buttner and colleagues (2006) found that despite the positive effects of diversity awareness education on the attitudes of business school deans, the factor having the greatest effect on these deans' implementation of diversity initiatives was being assigned responsibility for them. Kalev, Dobbin, and Kelly's (2006) research findings support the proposition that the success of diversity initiatives depends on their integration into administrative structures and assignment of responsibility for diversity to a specific accountable party.

The critical role faculty actors play in gender equity change cannot be overstated. While extant literature provides a glimpse into the various functions of these roles, and highlights the complexities of the relationship between a faculty member's awareness of inequities, sense of responsibility for change and subsequent action; much remains unexplored. For example, the 
range of roles men faculty play in gender equity change, their pathways to those roles, the ways in which they reconcile their traditional faculty roles with their roles as faculty actors for gender equity change, and how men faculty engaged in gender equity work are perceived by their women colleagues engaged in the same efforts.

The summary that follows synthesizes key concepts from the literature, underscores prevalent gaps in the literature and delineates the emergent research questions.

\section{Summary}

The review of literature commenced with an examination of the complexities of faculty work. Major findings from this section of the review indicate that faculty work continues to be defined by uneven engagement in teaching, research, and service. Furthermore, while institutions tend to espouse their value of each of these components, their reward structures defy such proclamations. Ascendancy in the faculty ranks is unequivocally tied to research productivity and this reality has direct implications on faculty engagement in activities that may be described as faculty activism. Given the multidimensionality of faculty activism, there is the potential for faculty activities which fall under this category to be perceived as legitimate expressions of faculty work. This is especially true when faculty activism primarily involves activist research tied to one's academic discipline and is reflective of one's social justice commitments. Similarly, faculty activism that is enacted through critical pedagogical approaches may also qualify as bona fide faculty work. The issue however, tends to get slippery when faculty activism reflects activities that are best described as service. As the literature on faculty work makes clear, among the three - teaching, research, and service — when it comes to the factors which matter in relation to promotion and tenure, service is the least of these. Nevertheless, the literature on faculty activism suggests that activities such as men faculty engagement in gender equity work 
may be considered a vestige of faculty work which in combination with other efforts spanning the institution depict the institution favorably as an equity embracing organization. The literature on faculty activism also revealed that some faculty seem willing to risk job security in the interest of justice. However, a closer analysis of situational factors suggests that even when faculty engage in more radical forms of activism (e.g. sit-ins, marches), they have weighed the consequences of their actions and those who persist with such efforts are typically aware of protections stemming from union membership or from tenured faculty status. These factors are not unrelated to which faculty tend to be activist, and which faculty tend to steer clear of faculty activism. In the review of literature on gendered academic organizations the term "tempered radicals" was used to describe faculty who maintain an equal commitment to "their cause" and their scholarly identity. While such a term seems to capture many of the experiences of faculty activism described in the literature, it may be more ambitious than real faculty activism suggests. That is, the proposition that tempered radicals maintain an equal commitment to their scholarly work and their activism seems inconsistent with the tensions between the academic and the activist depicted in the literature. In nearly every case, such strivings gave in to more pressing, scholarly interests.

The review of literature on dominant group member activism drew attention to the challenges dominant group members are likely to face as they act as allies and advocates alongside members of empowered targeted groups. Key findings from this section revealed that social identities are not constructed by individuals, but by the existence of individuals in racialized, gendered, heteronormative, able-bodied, ageist contexts that are characterized by an oppressed-oppressor binary which assigns some individuals to privileged positions and others to disadvantaged positions. Additionally, findings from the literature in this section revealed the 
multiplicity of social group identities emphasizing the fact that some individuals occupy both dominant and marginalized identities so that in some instances one may be an oppressor, and in others someone who is oppressed. Other important findings from this section revealed a tension not so much related to dominant group members' embracing of an ally or advocate identity, but dominant group members' espousing such an identity irrespective of the principles and practices which inform the associated activist work. These findings are particularly important in a study exploring men faculty engagement in gender equity work. How men faculty negotiate faculty and activist identities may be indicative of their levels of commitment to gender equity work. Also, how they interpret the tensions and suspicions target group members may express in response to their efforts at advocacy or the assumption of an activist label may have important implications related to their sustained interests in gender equity work.

The specific discussion of literature on men allyship and advocacy underscored the ways in which men as an identity group are both privileged and disadvantaged by systems of patriarchy and notions of hegemonic masculinity. The literature reviewed also addressed the ways in which men's "contradictory experiences of power" can impede their understanding of gender equity issues as well as the likelihood that they will engage in these issues as advocates for gender justice. Several findings from extant literature on men allyship in settings within and outside of academia addressed the barriers to, antecedents and consequences of men allyship. The most obvious gaps in the literature on men allyship are related to contextual factors. Only two studies in the extant literature specifically focus on men faculty allyship: Anicha et. al (2015) and Patton and Bondi (2015). Furthermore, the latter derives its data from men faculty identified as allies, while the former analyzes documents and archival data to assess the theories and research which inform a new, men only gender equity advocacy program for faculty at a research 
university. All other studies of men allyship for gender or social justice equity focus on nonacademic men, and aside from those which gather data from college students, a significant portion of these studies occur in nonacademic contexts. This void in the literature limits current understandings of how academic contexts influence men faculty's involvement with the critical issue of gender equity. Given their dominance in the academy this gap in the research is not only regrettable but indicative of the urgent need for studies of this nature.

The review of literature on gendered academic organizations underscored the importance of multileveled approaches to gender inequities in organizations. Important research by Parsons and Priola (2013) demonstrates the ways in which micro-level forms of individual activism help to chip away at unjust structures. Other key findings from Ely and Myerson (2000), Roos (2008), and Sturm (2006) support the assertion that gender equity transformation relies on change strategies at every level of the organization.

Finally, the roles faculty play in gender equity work reflect the tenets expressed above. While some faculty are instrumental in making notable changes across facets of the organization, others may incite attention to discrimination by way of a passionate letter to the president which provokes subsequent actions that eventually lead to a movement (see Bailyn, 2003).

\section{Research Questions}

Findings from the review of literature and reflections on key themes and emergent categories from the pilot study, raise four critical research questions:

1. What drives men faculty to engage in gender equity work?

2. Given the centrality of the adapted concepts of allies and advocates in the A \& A program, how do men faculty talk about their ally identity development? 
3. What are men faculty's perceptions of gender equity work? What counts as gender equity work and what doesn't?

4. What are the implications of institutional context on gender equity work? 


\section{CHAPTER III: METHODOLOGY}

This chapter comprises six sections. The first explains the theoretical perspective underlying the choice of research methodology. The second section describes key components of the research methodology. The third section delineates the research procedures. The fourth and fifth sections outline the data collection and data analysis strategies. The sixth section addresses methodological limitations.

\section{Phenomenology as Philosophy Underlying Grounded Theory (GT)}

Patton (2002) makes the point that the term phenomenology is frequently "confused and diluted." In addition to it having varying forms, he asserts,

It can refer to a philosophy . . . an inquiry paradigm . . . an interpretive theory . . . a social science analytical perspective or orientation ... a major qualitative tradition . . . or a research methods framework. (p. 104)

Here, phenomenology refers to the 'philosophy' or "philosophical stance" (Crotty, 1998, p. 3) informing the selected research methodology for this study—GT. According to Zaner (1970), "Phenomenological philosophy is first of all philosophical criticism ... I disengage from a claim in order to criticize it...in the systematically adopted attitude of disengagement" (pp. 79-80).

The deliberate effort to 'disengage' from extant theories in order to allow new or more fully developed ones to emerge is a core objective of traditional GT approaches (Glaser, 1998) and remains a central feature of more progressive or flexible approaches in which "grounded theorists adopt a respectful yet critical stance towards extant theories" (Dunne, 2011, p. 114). As Crotty (1998) asserts, 
To take a fresh look at phenomena is, of course, to call into question the current meanings we attribute to phenomena. Phenomenology, it is often said, calls into question what is taken for granted. It is critique and grounds a critical methodology. (p. 82)

Charmaz (2006) suggests that GT is such a methodology as "Grounded theory methods foster seeing your data in fresh ways and exploring your ideas about the data through early analytic writing" (p. 4).

A critical methodology is necessary in a study such as this, which aims to understand a specific under-investigated phenomenon (i.e. men faculty engagement in gender equity work) contextually distinct from, yet closely related to more frequently investigated phenomena (i.e. social justice allyship, men's allyship for gender equity in nonacademic settings, and men's nonviolence ally work within and outside of academia), because of the tendency to extend theories applicable in one context to a seemingly similar, though distinct context without empirical evidence supporting their applicability. Patton and Bondi (2015) seem to allude to this dilemma when they argue that the White men in their study, though identified as allies, were not ultimately engaged in ally work, but instead in activities that were mere niceties. Whether the concept of ally work as understood by Patton and Bondi is sufficient or in need of expansion to include 'niceties' can be debated, but a phenomenological GT approach offers an opportunity to make either case. As Crotty (1998) admonishes,

We have a need to define and classify. Unfortunately, our definitions and classifications displace what they stand for in our experience of them so that, rather than concepts pointing us to realities, realities are relegated to being mere exemplifications of concepts. Yet a concept is never able to exhaust the richness of a phenomenon ... there is always so much that the concept fails to express. (p. 81) 
In light of this, GT, as a critical research methodology is befitting as it requires the suspension of preexisting concepts in order to generate new theory or extend existing theory from newly observed data (Strauss \& Corbin, 1998).

\section{Grounded Theory as a Research Methodology}

Unlike traditional research methodologies which adhere to preexisting theoretical frameworks and predetermined hypotheses, GT aims to build theory grounded in empirically generated data which is systematically collected and analyzed in an iterative fashion. As Walker and Myrick (2006) point out, the inception of GT was an attempt by Glaser and Strauss to combine "the depth and richness of qualitative interpretive traditions with the logic, rigor and systematic analysis inherent in quantitative research" (p. 548). While the core purpose of GT remains intact, Glaser and Strauss parted ways following their publication of The Discovery of Grounded Theory in 1967. Nevertheless, both men continued to develop their own versions of the theory's methodology resulting in what has come to be termed the 'Glaserian' or 'Straussian' approaches (Stern, 1994). At the center of the debate around GT is the use of preconceived theories or categories in the data analysis process. In the Glaserian or classical approach a purist ideology prevails which espouses delaying a review of extant theoretical literature until after core categories emerge from the data. In the Straussian approach an early, but not necessarily exhaustive review of the extant literature is "advocated". In this approach, "The literature can direct theoretical sampling, and help with concept development" (Yarwood-Ross \& Jack, 2015, p. 20). A third approach to GT proposed by Charmaz (2006) emphasizes the theory's "systematic, yet flexible guidelines for collecting and analyzing qualitative data." According to Charmaz, these "guidelines offer a set of general principles and heuristic devices rather than formulaic rules" (p. 2). 
Given the fact that the phenomenon this research explores - men faculty engagement in gender equity work — is closely related to preexisting phenomena (i.e. social justice allyship, men allyship), and the conventional practice of conducting a literature review prior to data collection in dissertation research, the present study embraces a GT approach most aligned with combined elements of the Straussian and Charmaz (constructivist) approaches. In both, there is flexibility about the use of extant theory provided "researchers maintain a critical and reflexive attitude towards the literature" (Yarwood-Ross \& Jack, 2015, p. 20).

Despite the different GT approaches, there are five elements common to each though the way in which each is carried out may still be debated. These elements are: (1) theoretical sampling, (2) constant comparative analysis, (3) coding and categorization of data, (4) memoing, and (5) theoretical development.

\section{Theoretical Sampling}

Glaser and Strauss (1967) describe theoretical sampling as, a process of data collection for generating theory, whereby the analyst jointly collects, codes and analyzes ... data and then decides what data to collect next and where to find them, in order to develop ... theory as it emerges. (p. 45)

Strauss and Corbin (1998) assert that, "The aim of theoretical sampling is to maximize opportunities to compare events incidents, or happenings to determine how a category varies in terms of its properties and dimensions" (p. 202). In the case of men faculty engaged in gender equity work, for example, it may be important to 'maximize opportunities' to compare the experiences of men faculty of different academic ranks, and or men faculty differentially engaged in aspects of gender equity work. 


\section{Constant Comparative Analysis}

Throughout the research process data is constantly compared for evidence of connections, consistencies/inconsistencies, and distinctions in what Creswell (1998) describes as a "zigzag process - out to the field to gather information, analyze the data, back to the field to gather more information, analyze the data, and so forth" (p. 57). Strauss and Corbin (1998) note key aspects of the data analysis process: They are the data-i.e. participants' recollection of events, texts, etc.; both the researcher's and participants' interpretation of data; and "the interplay that takes place between data and researcher in both gathering and analyzing data...Interplay, by its very nature, means that a researcher is actively reacting to and working with data" (p. 58). This process is considered complete when categories of data reflect what Dey (1999) has aptly called "theoretical sufficiency" (p. 257) or what Charmaz (2006) has referred to as the point when "categories are 'saturated' when gathering fresh data no longer sparks new theoretical insights" (p. 113).

\section{Coding and Categorizing Data}

According to Saldana (2013), coding is more than "labeling... it is linking" (p. 8). As Richards and Morse (2007) posit, coding "leads you from the data to the idea, and from the idea to all the data pertaining to that idea" (p. 137). Saldana (2013) asserts coding and categorizing are often used interchangeably although "they are in fact, two separate components of data analysis." Saldana adds,

I advocate that qualitative codes are essence-capturing and essential elements of the research story that, when clustered together according to similarity and regularity ... facilitate the development of categories and thus analysis of their connections. (p. 8) 
As Charmaz (2006) put it, coding "generates the bones of your analysis...integration will assemble those bones into a working skeleton" (p. 45). GT approaches typically follow a cyclical coding process which commences with a first cycle of coding sometimes referred to as open coding (Strauss \& Corbin, 1998) or initial coding (Charmaz, 2006). This initial coding involves a microanalysis of data that results in the application of an early set of codes which may be applied to a single word, sentence, or passage. Rather than a rigid, restrictive process, this initial phase is characterized by creativity, spontaneity, and intuition (Charmaz, 2006; Strauss \& Corbin, 1998). The second cycle of coding has also been described as focused coding (Charmaz, 2006) and "requires decisions about which initial codes make the most analytic sense to categorize your data incisively and completely" (p. 57). In this phase, data is compared and contrasted and conceptual categories determined. Charmaz (2006) specifies a third cycle of theoretical coding which reflects an exploration of the relationships between core categories. This phase of the coding process may lead to additional data collection when the emergent theory is rife with gaps, or represent the beginning of the articulation of a new or extended theory about the phenomena in question.

\section{Memoing}

According to Saldana (2013), "Coding and analytic memo writing are concurrent qualitative data analytic activities" (p. 42). McCann and Clark (2003) assert that memos "reflect the researcher's internal dialogue with the data at a point in time" (p. 15). Beck (1996) posits that memos help to "(a) raise data to a conceptual level, (b) develop the properties of each category, and (c) generate hypotheses about connections between categories" (p. 11). 


\section{Theoretical Development}

Kearney (1998) distinguishes between two types of theories: substantive and formal. Formal theories are "broader based and more generalized processes that occur in a variety of distinct, yet theoretically similar, social situations." Substantive theories, on the other hand, provide insight into "the basic social-psychological or social-structural processes that are used by persons or social groups in response to specific social problems" (p. 181). The latter, according to McCann and Clark (2003), represent the type of theories derived from GT. Also, relevant to the development of GT is what the theory is attempting to achieve. Some have argued that theoretical development is primarily concerned with "the identification of patterns and associations" and not causation (Coffey \& Atkinson, 1996, p. 144). While others have argued that rigorous GT analysis can lead to the identification of causal factors (Jeon, 2004; Miles \& Huberman, 1994).

\section{Presenting Grounded Theory at the End of the Study}

Two main strategies have been proposed for presenting GT findings at the end of a study. The first is to present the theory in narrative form explicating relationships between concepts (Strauss \& Corbin, 1990). The second is to depict the conceptual relationships in visual/graphic form (Charmaz, 2006; Coyne \& Cowley, 2006; McCann \& Clark, 2003). Orona (2002) has argued that the ability to coherently carryout the latter strategy is indicative of the researcher's clarity about the theory.

\section{Research Procedure}

\section{Site Selection}

Criteria. A critical preliminary step in the research process was identifying the ADVANCE sites where data would be collected. Two main criteria were used to select six sites: 
the first criterion was that a site had to be the recipient of an Institutional Transformation (IT) award; the second criterion was that the site had to have adopted the A \& A program. The first criterion was set because the comprehensiveness of IT initiatives increases the likelihood of various points of access to and levels of engagement in gender equity work. The second criterion was set because sites that have adopted the A \& A program not only have men who now participate in those programs, but also men whose engagement in the ADVANCE initiative predates the implementation of the A \& A program. Examining the perspectives of both groups of men creates the opportunity for critical comparative insights into the phenomenon of men faculty engagement in gender equity work.

Descriptions. In addition to the site criteria, other important contextual factors may have implications for the type and quality of data collected. Some of these include: site location, public/private status, mission (e.g. land grant or not), institutional size (and resources), and years in ADVANCE. Three of the six sites are in the Northeast region of the U.S., two are in the Midwest and one is in the Southeast. Although higher education institutions tend to be characterized as liberal-leaning or leftist, this is not always an accurate characterization of members of its community, as such there may be ways in which data are affected by regionrelated characteristics. In terms of institutional type, public or private, land-grant or not, the institutional mission may impact participant perspectives on and approaches to gender equity work. To the extent that the size of an institution may be correlated with an institution's resources, or the effectiveness of its communication processes, there may be ways in which as a contextual factor size of the institution influences perceptions of men faculty engagement in gender equity work. Another contextual factor which may bear upon perceptions of this phenomenon may be the number of years the institution has been engaged with the ADVANCE 
initiative. It might be expected that more experience would be correlated with more program success. Finally, the depth, breadth and perceived effectiveness of featured programs at each site may not only indicate critical points of access for engagement in gender equity work, but also shape perceptions about levels of engagement in gender equity work. Table 2 summarizes general data about each site and includes a column which lists study participants affiliated with that site by their participant ID \# to maintain anonymity:

Table 4. Site Descriptions

\begin{tabular}{|c|c|c|c|c|c|c|c|}
\hline $\begin{array}{l}\text { Site } \\
\#\end{array}$ & $\begin{array}{l}\text { U.S. } \\
\text { Region }\end{array}$ & $\begin{array}{l}\text { Carnegie } \\
\text { Classification }\end{array}$ & $\begin{array}{l}\text { Public/ } \\
\text { Private }\end{array}$ & $\begin{array}{l}\text { Land- } \\
\text { grant? }\end{array}$ & $\begin{array}{l}\text { Approx. } \\
\text { (population) }\end{array}$ & $\begin{array}{l}\text { Award } \\
\text { Year }\end{array}$ & $\begin{array}{l}\text { Study } \\
\text { Participants }\end{array}$ \\
\hline 1 & Southeast & $\mathrm{R} 1$ & Public & Yes & 30,000 & 2009 & $\begin{array}{l}9 / 20: 2,3,14,15,22,25 \\
32,33,34, \mathbf{3 5}\end{array}$ \\
\hline 2 & Northeast & $\mathrm{R} 2$ & Private & No & 8,000 & 2010 & $3 / 9: 16,23, \mathbf{2 4}, 26$ \\
\hline 3 & Northeast & $\mathrm{R} 2$ & Public & Yes & 12,000 & 2010 & $2 / 5: 7,13$ \\
\hline 4 & Midwest & $\mathrm{R} 1$ & Public & Yes & 65,000 & 2008 & $\begin{array}{l}\text { 6/16: } \\
9,10,11,12,18,19, \mathbf{2 1}, \mathbf{2 9}\end{array}$ \\
\hline 5 & Northeast & $\mathrm{R} 3$ & Private & No & 18,000 & 2012 & $\begin{array}{l}\text { 6/15: } \\
\mathbf{6}, 17,20,27,28,30,31\end{array}$ \\
\hline 6 & Midwest & $\mathrm{R} 2$ & Public & Yes & 14,000 & 2008 & $3 / 9: 1, \mathbf{4}, 5,8$ \\
\hline
\end{tabular}

R1-Highest Research Activity; R2-Higher Research Activity; R3-Moderate Research Activity; Women Leaders

\section{Purposive (Theoretical) Sampling}

Purposive sampling involves "selecting groups or categories to study on the basis of their relevance to your research questions" (Mason, 1996, pp. 93-94). In GT, purposive sampling is nearly synonymous with "theoretical sampling" which describes a strategy used to target study participants "based on their ability to contribute to an evolving theory" (Creswell, 1998, p. 118). In this study, men faculty engaged in gender equity work through ADVANCE-IT initiatives and ADVANCE-IT women faculty leaders on their home campuses are targeted because of their potential as "information rich cases ... those from which one can learn a great deal about issues of central importance to the research" (Patton, 1990, p. 169). Bong (2002) refers to such 
individuals as the "gatekeepers to local knowledge" (p. 4). Taylor and Bogdan (1984) have argued that rather than the number of 'cases' studied, "what is important is the potential of each 'case' to aid the researcher in developing theoretical insights into the area of life being studied" (p. 83).

\section{Participant Recruitment Strategy}

Data were collected from two sample groups-women who serve as leaders at selected ADVANCE sites, and men faculty who are engaged in gender equity work at the same sites. A shared criterion for both groups of participants is engagement with the ADVANCE initiative for at least one full year.

Given the importance of intersectionality as an emergent theme from the pilot study, and the attention the broader ADVANCE project gives to it in relation to gender, upon confirmation of IRB approval for this study a member of the researcher's dissertation committee who is also the leader of an ADVANCE site, reached out to colleagues at the selected sites on behalf of the researcher and asked that they support the researcher's efforts in two ways: one-consider participating in an interview with the researcher, and, two-identify (to the extent possible) men faculty and academic leaders of varying academic/administrative ranks, from different disciplines/units of the university, and with diverse social identity backgrounds (e.g. race, religion, sexual orientation, ability status). These efforts resulted in the initial recruitment of 30 study participants. Two of the 30 each recommended an individual I should interview for the study. Those individuals agreed to participate bringing the total number of study participants including the three pilot participants to 35 .

Study Participants. Study participants included 29 men faculty and/or administrators at the six sites in Table 2, and six women faculty who serve as ADVANCE leaders at five of the 
sites. Demographic data revealed that most study participants identified as White American/Caucasian (84.4\%), two (6.3\%) identified as Black American, and two (6.3\%) as Hispanic/Latino. Ninety-seven percent (97\%) of all study participants indicated they are married. Ninety-percent $(90 \%)$ of the men in the study indicated they are fathers. Of that percent, $72 \%$ have one or more daughters. Men participants ranged in age from 37 to 64 years with an average of 50.3 years. Sixty-five percent $(65 \%)$ of participants identified their political leaning as mostly liberal, $12.9 \%$ mostly moderate, and one (3.2\%) mostly conservative. Ninety-one percent (91\%) of participants indicated they have been at their current institution for more than 10 years. Only two participants indicated they had been at their institution for less than 6 years. Seventy-eight percent $(78 \%)$ of participants are tenured faculty.

Table 5. Men Faculty Participant Descriptions

\begin{tabular}{|c|c|c|c|c|c|c|}
\hline ID & $\begin{array}{l}\text { Interview } \\
\text { Time }\end{array}$ & $\begin{array}{l}\text { Interview } \\
\text { Format }\end{array}$ & $\begin{array}{l}\text { Acad. } \\
\text { Dept. Type }\end{array}$ & $\begin{array}{l}\text { Tenure } \\
y / n\end{array}$ & $\begin{array}{l}\text { Academic } \\
\text { Leader? }\end{array}$ & Site \\
\hline 1 & $65 \mathrm{~m}$ & video & Behavioral & $\mathrm{Y}$ & Associate Dean & 6 \\
\hline 2 & $45 \mathrm{~m}$ & In-p & $\begin{array}{l}\text { Natural \& } \\
\text { Physical Sci }\end{array}$ & $\mathrm{Y}$ & VP & 1 \\
\hline 3 & $73 \mathrm{~m}$ & In-p & Social Sciences & $\mathrm{N}$ & NA & 1 \\
\hline 5 & $91 \mathrm{~m}$ & video & Engineering & $\mathrm{Y}$ & Program Director & 6 \\
\hline 7 & $69 \mathrm{~m}$ & video & Education & NA & Program Director & 3 \\
\hline 8 & $53 \mathrm{~m}$ & video & Human Services & $\mathrm{Y}$ & Program Director & 6 \\
\hline 9 & $56 \mathrm{~m}$ & video & $\begin{array}{l}\text { Natural \& } \\
\text { Physical Sci }\end{array}$ & $\mathrm{N}$ & Program Director & 4 \\
\hline 10 & $48 \mathrm{~m}$ & video & $\begin{array}{l}\text { Natural \& } \\
\text { Physical Sci }\end{array}$ & $\mathrm{Y}$ & Chair & 4 \\
\hline 11 & $57 \mathrm{~m}$ & video & Engineering & $\mathrm{Y}$ & Chair & 4 \\
\hline 12 & $64 \mathrm{~m}$ & video & Life Sciences & $\mathrm{Y}$ & Chair & 4 \\
\hline 13 & $58 \mathrm{~m}$ & video & Life Sciences & $\mathrm{Y}$ & NA & 3 \\
\hline 14 & $65 \mathrm{~m}$ & In-p & $\begin{array}{l}\text { Natural \& } \\
\text { Physical Sci }\end{array}$ & $\mathrm{Y}$ & Associate Chair & 1 \\
\hline 15 & $68 \mathrm{~m}$ & In-p & Social Sciences & $\mathrm{Y}$ & NA & 1 \\
\hline 16 & $67 \mathrm{~m}$ & video & Engineering & $\mathrm{Y}$ & NA & 2 \\
\hline 17 & $62 \mathrm{~m}$ & video & $\begin{array}{l}\text { Business/ } \\
\text { Economics }\end{array}$ & $\mathrm{Y}$ & NA & 5 \\
\hline 18 & $51 \mathrm{~m}$ & video & $\begin{array}{l}\text { Biological } \\
\text { Sciences }\end{array}$ & $\mathrm{Y}$ & Program Director & 4 \\
\hline 19 & $25 \mathrm{~m}$ & phone & Engineering & $\mathrm{Y}$ & Dean & 4 \\
\hline
\end{tabular}




\begin{tabular}{|c|c|c|c|c|c|c|}
\hline 20 & $65 \mathrm{~m}$ & phone & $\begin{array}{l}\text { Business/ } \\
\text { Economics }\end{array}$ & Y & NA & 5 \\
\hline 22 & $43 m$ & phone & Engineering & $\mathrm{Y}$ & Associate Dean & 1 \\
\hline 23 & $62 \mathrm{~m}$ & phone & Engineering & $\mathrm{Y}$ & NA & 2 \\
\hline 24 & $48 \mathrm{~m}$ & phone & Humanities & $\mathrm{Y}$ & NA & 2 \\
\hline 25 & $60 \mathrm{~m}$ & phone & NA & NA & VP & 1 \\
\hline 27 & $75 \mathrm{~m}$ & phone & $\begin{array}{l}\text { Life } \\
\text { Sciences }\end{array}$ & $\mathrm{Y}$ & Chair, Dept. Head & 5 \\
\hline 28 & $68 \mathrm{~m}$ & phone & $\begin{array}{l}\text { Natural \& } \\
\text { Physical Sciences }\end{array}$ & $\mathrm{Y}$ & Program Director & 5 \\
\hline 30 & $28 \mathrm{~m}$ & phone & Engineering & Y & NA & 5 \\
\hline 31 & $50 \mathrm{~m}$ & phone & Social Sciences & NA & Program Director & 5 \\
\hline 32 & $48 m$ & focus & $\begin{array}{l}\text { Natural \& } \\
\text { Physical Sci }\end{array}$ & $\mathrm{Y}$ & $\mathrm{NA}$ & 1 \\
\hline 33 & $48 \mathrm{~m}$ & focus & Humanities & $\mathrm{Y}$ & Program Director. & 1 \\
\hline 34 & $48 m$ & focus & NA & NA & Program Director & 1 \\
\hline
\end{tabular}

Table 6. Women Leader Participant Descriptions

\begin{tabular}{llllll}
\hline ID & $\begin{array}{l}\text { Interview } \\
\text { Time }\end{array}$ & $\begin{array}{l}\text { Interview } \\
\text { Format }\end{array}$ & Academic & Tenure? & Site \\
\hline 4 & $41 \mathrm{~m}$ & Video & Engineering & $\mathrm{Y}$ & 6 \\
6 & $49 \mathrm{~m}$ & Video & Engineering & $\mathrm{Y}$ & 5 \\
21 & $93 \mathrm{~m}$ & Video & Engineering & $\mathrm{Y}$ & 4 \\
26 & $40 \mathrm{~m}$ & Phone & Engineering & $\mathrm{Y}$ & 2 \\
29 & $58 \mathrm{~m}$ & Phone & Engineering & $\mathrm{N}$ & 4 \\
35 & $57 \mathrm{~m}$ & Phone & Social & $\mathrm{Y}$ & 1 \\
& & & Sciences & & \\
\hline
\end{tabular}

Although this exempt research does not present any substantial threats to participant wellbeing, attempts to maintain participant anonymity resulted in the use of numbering to identify participants and to the extent possible, the removal of institutionally-identifiable data.

\section{Data Collection}

According to Strauss \& Corbin (1998) the decision about which data to use should be based on "which data has the greatest potential to capture the types of information desired..." (p. 204). Maxwell (2013) addresses the debate around "the extent to which you decide on your 
methods in advance," noting that some scholars believe "substantial prior structuring of the methods leads to a lack of flexibility to respond to emergent insights and can create methodological "tunnel vison."' On the other hand, he cites concerns that less structured methods can compromise "the comparability of data across individuals, times, settings, and researchers..." (p. 88). One-on-one interviews were the primary form of data collection in this study. Study participants also completed an electronic demographic questionnaire sent to them by email with an embedded link to the Google Form (see Demographic Questionnaire in APPENDIX). The interview style chosen was intensive. According to Charmaz (2006), The in-depth nature of an intensive interview fosters eliciting each participant's interpretation of his or her experience. The interviewer seeks to understand the topic and the interview participant has the relevant experiences to shed light on it...Thus, the interviewer's questions ask the participant to describe and reflect upon his or her experiences in ways that seldom occur in everyday life ... The structure of an intensive interview may range from a loosely guided exploration of topics to semi-structured focused questions. Although the intensive interview may be conversational, it follows a different etiquette... What might be rude to ask or be glossed over in friendly agreement in ordinary conversation...becomes grist for exploration. (p. 26)

As Lofland \& Lofland (1984) note, while initial GT interviews are more unstructured, given the interest in theory building core to GT methodology the structure of subsequent GT interviews increases (Coyne, 1997; Creswell, 1998; Knight, Nunkoosing, Vrij, \& Cherryman, 2003).

Using interviews as a method of data collection in research has clear benefits and challenges. In terms of benefits, skilled interviews can uncover the meaning people make of phenomena and how that meaning shapes their experiences (Seidman, 1998). In terms of 
practicality, interviews allow a degree of flexibility in the data collection process (Darlington \& Scott, 2002), and are a way to collect a substantive amount of data in a relatively expedient fashion that can be redressed and clarified (Marshall \& Rossman, 1999). In terms of challenges, throughout their text, Kvale and Brinkmann (2009) are explicit in their sentiments that a lack of interviewing skills compromises the use of interviews as a viable data collection method. In one instance, they state:

Some interview research can be characterized as 'tourist interviewing,' where the interviewer, without substantial prior training, meets the subject for a very brief period of time, records a conversation in snapshot mode, and subsequently tries to say something interesting about it. (p. 299)

To minimize a 'tourist' approach, the researcher revisited best practices in qualitative interviewing and designed an interview protocol with early inquiries designed to promote a measure of mutual sharing aimed at building rapport. The necessity of building trust and rapport in the interviewing process is an issue addressed by Charmaz (2006) and others (McCracken, 1988). Maxwell (2013) cautions that, it is the kind [emphasis in original] of rapport, as well as the amount, that is critical. A participant can be very engaged intellectually in an interview, but not be revealing anything deeply personal, and for some studies, this kind of relationship may be ideal. Conversely, someone may be very open about personal matters to a stranger whom they never expect to see again, but not willing to critically reflect on this material. (p. 91)

The Interviews. In this part of the study (details of the pilot are discussed in chapter one), I conducted 32 intensive interviews in three formats: by phone (13), by Skype or Webex video-conference (15), and, in-person (4). Each were recorded and the average interview length 
was 58 minutes. While researchers have argued for (Lofland \& Lofland, 1984; Rapley, 2004) and against (Glaser \& Holton, 2004) recording interviews, the researcher's past experiences demonstrated that the pros of recording interviews - capturing the verbal exchange, and being able to be an attentive listener-outweigh the cons of recording interviews - e.g. interviewees' nervousness about being recorded and the possibility of researcher error in recalling what was said. As Thomas, Nelson, and Silverman (2005) have acknowledged it is usually the case that as the interview progresses subjects become less anxious about being recorded. This held true in this study. The researcher used her kindle to record phone interviews and both her phone and her kindle to record in-person interviews using a voice recording application that she had used successfully in the past. Participants who were available to interview by video conference, were sent a link to join a Cisco Webex meeting. Some participants had trouble logging into Webex. When that occurred, the interview would move to Skype or phone. Both Webex and Skype enable recording. To minimize the risk of losing data, the researcher used an application called Hypercam 2 to back-up the video-recorded interviews. Hypercam 2 records screen and audio data

\section{Data Management}

I used Dedoose - a Computer-Assisted Qualitative Data Analysis Software (CAQDAS)— to manage and analyze my data. The use of such software is growing in popularity in qualitative studies (see Miles, Huberman, \& Saldana, 2014). An initial step in the data management process was uploading my audio and video files into Dedoose. This required converting my video AVI files into MP4 files which I accomplished by purchasing a program called, iSkySoft. This step was time consuming given the length of my videos, but efficient. Audio files created on the voice recording app on my Kindle and android were already in MP3 format and easy to upload into Dedoose. Once files were uploaded into my Dedoose "Media", I began working with them. 
Dedoose allows users to code directly from the audio/video files using its excerpt feature to which users can apply codes and create memos and transcriptions. As I got used to using these features. I would code excerpts, transcribe that excerpt, then cut and paste that excerpt into a memo. I found memos to be more user friendly and they were easy to organize as coded data, export into a word document and print.

Dedoose has plenty of drawbacks, however. There were too many instances where it booted me out of the system unexpectedly and if I had not saved a transcription or memo, it was gone. This is what prompted me to start hitting send after every few sentences and using the export feature for memos. Additionally, the Dedoose video-player could be temperamental taking an unreasonably long time to load and pausing intermittently throughout coding. A Dedoose technician assisted me by converting all the videos to MP3 files. This was a huge step in improving my coding experience. The original videos were backed-up on my hard drive and I could play them as needed.

\section{Data Analysis}

The First Level. Data analysis began with three critical themes emerging from the Pilot Study (discussed in detail in Chapter One): raising one's consciousness, developing an advocate/ally identity, and taking purposeful action which were conceptualized under the broad category, Components of Men Faculty Engagement in Gender Equity Work. These themes could be translated into answers to the critical question, what is this phenomenon of men faculty engagement in gender equity work?

- $\quad$ it is being more aware,

- $\quad$ it is becoming an ally,

- $\quad$ it is doing something to make a difference. 
What remained unknown from the emergent themes in the pilot was how does men faculty engagement in gender equity work look in context? That is, in academic departments, in A \& A facilitations, and in men advocates' and allies' interactions with others. What also remained unknown was the pivotal question, why do men faculty engage and stay engaged in gender equity work? That is, what drives men to this work and what keeps them committed.

Table 7. Results of First Level of Analysis (Pilot Study)

Results of First Level of Analysis of Pilot Study Findings

\begin{tabular}{|c|c|c|}
\hline $\begin{array}{l}\text { What is this phenomenon of } \\
\text { men faculty engagement in } \\
\text { gender equity? }\end{array}$ & $\begin{array}{l}\text { How does this phenomenon look } \\
\text { in context? }\end{array}$ & $\begin{array}{c}\text { Why do men get engaged and } \\
\text { stay engaged? }\end{array}$ \\
\hline $\begin{array}{l}\text { - It is becoming more } \\
\text { aware } \\
\text { - It is becoming an ally } \\
\text { - It is taking purposeful } \\
\text { action }\end{array}$ & 0 & 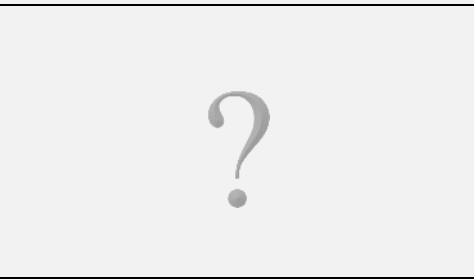 \\
\hline
\end{tabular}

The Second Level. The findings from the pilot were shaped by the types of questions asked (see Pilot Study Interview Protocol: APPENDIX). To generate the kind of data that would help address what remained unknown, I revised the interview protocol for this study (see Interview Protocol APPENDIX). The second level of analysis commenced with a review of memos taken during my first interview that helped to refine my thinking about the next interview and marking the beginning of an iterative constant comparative analysis of data throughout my investigation. I must also note, here, that I was strategic about the order of my interviews. I wanted to begin with participants who were instrumental in the architecture of the formal A \& A program and, for the most part, I achieved this objective. Key themes from the second level of analysis were infused with those from the pilot, but the revised interview questions were generating responses that not only put these themes in the pertinent contexts, but helped to identify drivers of initial engagement and apparent drivers of continuous engagement. Strauss 
and Corbin (1998) describe this aspect of the data analysis process as 'conceptualizing' or 'abstracting':

In conceptualizing, we are abstracting. Data are broken down into discrete incidents, ideas, events, and acts and are then given a name that represents or stands for these. The name may be one placed on the objects by the analyst because of the imagery or meaning they evoke when examined comparatively and in context, or the name may be taken from the words of respondents themselves. The latter often are referred to as "in vivo codes" (Glaser $\&$ Strauss, 1967). As we continue with our data analysis, if we come across another object, event, act, or happening that we identify through comparative analysis as sharing some common characteristics with an object or a happening, then we give it the same name, that is, place it into the same code. (p. 105)

Discrete data began to organize under the concepts: self-development work for action, preparing others for action, leveraging your power in practice, drivers of initial engagement and drivers of continuous engagement. These categories of data were beginning to address the questions that remained unanswered from the pilot and, thus are organized under these headings in Table 8 . Some of the subthemes which represent a composite of discrete codes are depicted under each category.

Table 8. Results of Second-Level Analysis "Conceptualizing"

\begin{tabular}{|c|c|c|}
\hline \multicolumn{3}{|c|}{ Results of the Second Level of Analysis "Conceptualizing" } \\
\hline $\begin{array}{c}\text { First Level Analysis: What is } \\
\text { men faculty engagement in } \\
\text { gender equity? }\end{array}$ & How does it look in context? & $\begin{array}{c}\text { Why do men engage and stay } \\
\text { engaged? }\end{array}$ \\
\hline $\begin{array}{l}\text { It is becoming more } \\
\text { aware } \\
\text { It is becoming an ally }\end{array}$ & $\begin{array}{l}\text { Self-development work for } \\
\text { action } \\
\text { - } \quad \begin{array}{l}\text { Be informed and } \\
\text { equipped with data }\end{array}\end{array}$ & $\begin{array}{l}\text { Drivers of Initial Engagement } \\
\text { - Recognition/Desire to } \\
\text { solve the problem } \\
\text { - Sense of Duty }\end{array}$ \\
\hline
\end{tabular}




\begin{tabular}{|c|c|c|c|}
\hline • & $\begin{array}{l}\text { It is taking purposeful } \\
\text { action }\end{array}$ & $\begin{array}{c}\text { - } \begin{array}{l}\text { Address implicit bias } \\
\text { privilege }\end{array} \\
\text { - } \quad \text { Test your own practices } \\
\text { Preparing others for action } \\
\text { - Note levels of readiness } \\
\text { - Assess \& address } \\
\text { resistance } \\
\text { - } \quad \text { Role-model } \\
\text { - Personal Relevance } \\
\text { Leveraging your power } \\
\text { - } \quad \text { Work the system: } \\
\text { challenge criteria } \\
\text { - Share Power } \\
\text { Peframe Issues } \\
\text { Practice "The No } \\
\text { Asshole Rule" }\end{array}$ & $\begin{array}{l}\text { - Pre-existing interest/ } \\
\text { involvement in issues } \\
\text { - Belief in ability to help } \\
\text { solve problem } \\
\text { Drivers of Continuous } \\
\text { Engagement } \\
\text { - Belief in importance of } \\
\text { A \& A work } \\
\text { - Continued Sense of duty } \\
\text { - Satisfaction w/ } \\
\text { experience } \\
\text { - Positive feedback from } \\
\text { significant others. }\end{array}$ \\
\hline
\end{tabular}

The Third Level of Analysis (Theoretical Development). The goal of GT research is to build or expand theory that is grounded in the data collected. As Charmaz (2006) explains, Through studying data, comparing them, and writing memos, we define ideas that best fit and interpret the data as tentative analytic categories... Our analytic categories and the relationships we draw between them provide a conceptual handle on the studied experience. Thus, we build levels of abstraction directly from the data and, subsequently, gather additional data to check and refine our emerging analytic categories. Our work culminates in a 'grounded theory,' or an abstract theoretical understanding of the studied experience. (p. 4) 
The theoretical relationships between the emergent analytic categories in this study are depicted below in Table 9.

Table 9. Theoretical Relationships between Emergent Analytic Categories

\begin{tabular}{|c|c|}
\hline Analytic Categories & Theoretical Relationships \\
\hline Initial + Continuous Drivers of Engagement & $\begin{array}{l}\text { Initial drivers are antecedents or precursors of } \\
\text { continuous drivers of engagement }\end{array}$ \\
\hline $\begin{array}{l}\text { Continuous Drivers }+ \text { Experience of } \\
\text { Engagement }\end{array}$ & $\begin{array}{l}\text { The experience of engagement in gender } \\
\text { equity work can continually drive engagement } \\
\text { in the work or debilitate it. }\end{array}$ \\
\hline $\begin{array}{l}\text { Ally Identity Development }+ \text { Gender Equity } \\
\text { Work + Drivers of Engagement (Initial \& } \\
\text { Continuous) }\end{array}$ & $\begin{array}{l}\text { Ally identity development is a process that is } \\
\text { simultaneously part of gender equity work } \\
\text { and a driver of engagement in gender equity } \\
\text { work. }\end{array}$ \\
\hline
\end{tabular}

These relationships are explored further in the research findings discussions in Chapters 4 and 5 and depicted in the framework for the proposed emergent GT in Chapter 6.

\section{Methodological Limitations}

The perfunctory researcher response regarding limitations in a qualitative study is that given the limited number of participants and/or the use of a purposive sample findings are not generalizable. However, qualitative research scholars have challenged this concession by reiterating the objectives of qualitative research and unpacking what is meant by generalizable. For example, Gobo (2004) and Yin (1994) distinguish between statistical and analytical generalizability and the relevance of the latter over the former in qualitative research.

Another limitation is related to the data collection methods. Interview data reflect an exchange between the interviewer and subject and are influenced by a series of textual factors 
not limited to but including the researcher's interview skills, subjects' willingness and/or ability to accurately recount the phenomenon in question, and the interpretations of questions and responses by subject, and interviewer, respectively.

Researcher bias presents limitations to any study. To minimize researcher bias in this study memoing is not only used as a strategy to aid in data analysis but the notes generated through memoing create an audit trail which can be used to reference researcher thinking at each stage of data analysis. Another strategy to reduce researcher bias is peer review of data coding and analysis. In this case, members of the local ADVANCE team on my campus reviewed data and emergent codes and provided feedback. Data triangulation is another strategy that will be used to minimize researcher bias by collecting and analyzing data from both men and women faculty engaged in the initiative.

GT research does not lead to conclusions, but often more questions and/or hypotheses generated from inductive data. Like other forms of research, it has its limitations and biases, but neither diminish its ultimate value as an explicit methodology that encourages us to ".... attend to what we hear, see, and sense" (Charmaz, 2006, p. 3) as reliable data from which we can better understand phenomena. 


\section{CHAPTER IV: FINDINGS (RQ 1 \& RQ 2)}

\section{What Drives Men Faculty to Engage in Gender Equity Work?}

An analysis of findings revealed two sets of factors drive men faculty to engage in gender equity work: initial drivers of engagement and continuous drivers of engagement. These are discussed below and summarized in Table 10.

\section{Initial Drivers of Engagement}

Initial drivers of engagement are forces that appear to influence a male faculty member's initial decision to get involved in gender equity work. While a single driver may be force enough to cause a male faculty member to engage, the combined force of multiple drivers may also lead a male faculty member to engagement in gender equity work. An analysis of findings revealed four primary initial drivers of engagement in gender equity work for men faculty: (1) interest/ prior involvement in social justice/gender equity work (2) recognition of and desire to solve the gender inequity problem, (3) belief in one's ability to help solve the problem, and (4) sense of duty to engage in efforts to address the problem.

Table 10. Initial \& Continuous Drivers of Engagement in Gender Equity Work

\begin{tabular}{lll}
\hline \multicolumn{1}{c}{ Initial Drivers } & \multicolumn{1}{c}{ Continuous Drivers } \\
\hline $\begin{array}{l}\text { 1. Interest/prior involvement in social } \\
\text { justice/gender equity work }\end{array}$ & $\begin{array}{l}\text { 1. } \text { Belief in importance of work carried } \\
\text { out by ADVANCE and/or A \& A }\end{array}$ \\
$\begin{array}{l}\text { 2. Recognition of and desire to solve the } \\
\text { gender inequity problem }\end{array}$ & $\begin{array}{l}\text { 2. Continued sense of duty to remain } \\
\text { engaged in these efforts }\end{array}$ \\
$\begin{array}{l}\text { 3. Belief in one's ability to help solve the } \\
\text { problem }\end{array}$ & $\begin{array}{l}\text { 3. Satisfaction with the engagement } \\
\text { experience, and, }\end{array}$ \\
4. Sense of duty to engage in efforts to & 4. Positive feedback/perceptions of \\
address the problem & support for engagement in this work
\end{tabular}


Interest/ Prior Involvement in Social Justice/Equity Work. This two-part initial driver is combined because of the tendency for these two factors to be linked in the data. That is, often within this study's data, men who were interested in social justice/equity work, were also men who had some level of prior involvement in this work.

Interest. The primary interest in social justice/equity work driving men faculty study participants seemed to stem from their concerns about the equitable treatment of women, generally, and the women in their lives (wives, daughters, friends/colleagues), particularly. As noted in the description of study participants, $97 \%$ of study participants included men married to women, and $72 \%$ of men in this study are the fathers of one or more daughters. The following excerpts reflect how men's interest in the equitable treatment of women contributed to their initial drive to engage in gender equity work:

I think for me the turning point was the birth of my daughter. and wanting to make sure that she had every opportunity that I had as a child and that her gender was not going to be an impediment to her. success. - P16

So, these issues were sort of on my mind anyway...My wife also works in academia. She and I are in the same department. Part of it also were just conversations we had. Like we would come out of a faculty meeting and I was very often unaware of dynamics — and she would say, 'oh did you notice what happened?' and it would amaze me-I didn't really notice or if I did, I didn't know what to make of it...So, I entered the trainings partly just to learn about that, right. I found the training experience very unique and I wanted to get involved. $-\mathrm{P} 1$

Even though in my (life-sciences) department, there is an equal representation of women, that doesn't translate into the equitable and inclusive treatment of women...Historically, 
there has been a tremendous amount of animosity from the senior male faculty toward the junior and senior female faculty...and among some men this attitude persists...The animosity manifests itself superficially in complaints about productivity or quality of scholarship...I don't share those values. I don't respect those positions...So, that's why when I was asked to be part of the ADVANCE grant, [I agreed], I certainly share more values with folk who support the principles of the ADVANCE grant. -P27

Prior involvement. Several men faculty study participants had been previously involved in social justice/equity work and this factor seemed to be an initial driver of their engagement in ADVANCE/A \& A. For study participants like P12, P19, and P23, prior involvement in campusbased women's centers and women policy and council groups had contributed to their initial drive to engage in ADVANCE A \& A. These organizations, described by P19 as "a critical resource," offered men opportunities to learn more about issues related to social justice and equity. And, as P12 shared, they also offered professional development opportunities like leadership development workshops and academic career coaching. P23 described his participation in the lunch and learn events hosted by his campus' women's center and his role as a volunteer referee in their powder-puff football games. For other participants, like P28, prior involvement was more directly linked to work role:

From the beginning of my time at my university, I have been very active with assisting efforts to promote gender equity in STEM... [In fact], I am the gateway to research for every female major that we have [in my department].

Recognition of and Desire to Solve the Gender Inequity Problem. Several men faculty seemed to be initially driven to engage in gender equity work due to their recognition of and 
desire to solve the gender inequity problem. The following selection from P3 is an example of this initial driver and includes indications of his prior involvement in this type of work:

I've never hesitated to use my voice and when I see something, I'm not afraid to question it whether that be in a hiring discussion or in a curricular discussion or that be in some kind of campus climate type situation...[among] a group of people who look like me.

In the following excerpt from P10, recognition of and desire to solve the gender inequity problem is a clear driver of initial engagement coupled with elements of the other initial drivers of engagement (interest in equity work, belief in ability to help solve problem, and a sense of duty to engage in the work):

After the first four years at [my institution] I was asked to became department chair of physics. And physics depts. as you know have serious issues with diversity. Physics is overwhelmingly a White and Asian male field. And, so that is something we are trying to fix. And, so I became interested in fixing that problem and became rather successful at it. I've actually hired more [women and minorities] in the 8 years I was chair, than the department had hired in the previous 156 years.

Belief in One's Ability to Help Solve the Problem. Men faculty's sense of self-efficacy about their ability to help solve the gender inequity problem presented as another initial driver of engagement in gender equity work. An excerpt from P18 is a helpful example:

I am one of them. I am the community - that entitled community that is not aware that it is entitled. If I say something, it is going to be heard differently than, for example, if a woman were to come down from the administration and try to say the same thing...And, [they] don't have to agree with me, but [they] can't deny the relevance of my position. 
The following selections from P1 and P20, respectively, illustrate very different ways in which belief in ability to help solve the problem was expressed in the data:

My thinking about how I could contribute to this effort evolved over time...Initially, I think I thought that I could help in the sense that anybody could help - that we are all part of the institution, so we should all be doing something to help. I think what I ended up realizing is that men had a particularly vital role to play here - and this is true of most institutionswe really have a male dominated institution and so I did come to realize that people who are part of the dominant group have a really vital role to play, cause the institution has been set up to benefit us. $-\mathrm{P} 1$

So, when I heard about this program, I thought, oh this is great, I'm good at kicking down doors and stomping people's faces, you know, and the women on campus are outnumbered and probably a lot of them just want to get their work done. They don't want to get involved with these issues and so the women...who are involved with these issues are severely outnumbered and need some allies and ...I'd make a pretty good ally. So, I came in with that attitude of 'Hey, I'm here to help. Here are my tools.' -P20

Sense of Duty to Engage in Efforts to Address the Problem. As was evident in some of the previous examples, a sense of duty to engage in gender equity work emerged as an initial driver of engagement. In the following excerpt from P23, the potential strength of this single initial driver is evident in relation to the other initial drivers present in this situation:

I always felt a responsibility to be aware of these activities, but I haven't always gotten involved. I wanted to know more about the issues ... how they affect the people I know, and the woman coordinating the effort was a colleague - we had been junior faculty members and climbed the ranks together. She thought I would be good at helping to get the 
word out. And, I'm an engineer so having a man in STEM helping to get other STEM men involved was a way I could help ... [However], The focal point became even more focused when we hired a woman in our department who is from my field and I was heavily engaged in recruiting her...So, when she came, they had this mentoring program on campus [and] they asked if I would be her mentor...And certainly, I felt even more responsibility, thena brand new woman faculty member, in our department, and I even feel responsible for bringing her here. I wanted to make sure that she had the most fair shake building her career here as possible. And, if I don't know all the issues—or, the challenges... I felt like I'm not going to be able to do that job justice. So, I got even more involved at that point.

All four initial drivers are at work in this excerpt. However, P23's increased sense of responsibility or duty to engage given his role in recruiting the new woman faculty member and his subsequent duties as her mentor seems to be the strongest of the driving forces. In this instance, the sense of duty to engage seems internally-driven. P23 expresses his desire to be an effective mentor. In other instances, the sense of duty to engage presented as the primary initial driving force, but was externally-driven. The following quote from P22, an associate dean, exemplifies this point: “I don't know how engaged I am with anything. I go to occasional meetings. I joined because of my dean saying, oh, the previous associate dean was a member of ADVANCE so you should [join], too." Quite differently from P23's seemingly internally-driven sense of duty to be an effective mentor, in this instance, P22's sense of duty to engage seems mostly externally-driven by an obligation based on his dean's expectation that he continues in a role his predecessor had assumed. In the following excerpt from P11, a department chair of engineering, sense of duty to engage seems to be driven by both an externally-driven obligation 
to participate at the urging of his associate dean and an internally-driven motivation to be effective in his new role as chair:

I was a faculty member in engineering. We have a lot of focus on doing research projects, procuring funding, and teaching classes and all that kind of stuff. So, I wasn't really involved too much — you know. I was more focused on my own individual group and its success for most of my career. But, got asked to serve as department chair the last three years, and in that role, you know, I have to take a wider, broader perspective and got pull- involved with the ADVANCE project through my associate dean, who formed the A \& A group [on my campus] and I signed up with him for about the last year.

While P11 seems to frame his reasoning for engaging in ADVANCE in his acknowledgement of the way in which his job role has changed from a faculty member to a department chair who needs 'to take a wider, broader perspective,' he follows that sentiment by stating he got 'pullinvolved' with ADVANCE through his associate dean who is coordinating the effort on his campus. His tone during the interview suggested he was going to say pulled-into ADVANCE, but then replaced it with involved with because it sounded better. The former sentiment, if accurate, reflects the same externally-driven, obligatory sense of duty to engage evident in P22's quote. Whereas getting involved with ADVANCE as a way 'to take a wider, broader perspective' suggests an internally-driven interest in doing a good job as chair. An analysis of my full interview with P11 suggests his sense of duty to engage is driven by both forces. Throughout our interview, he never expressed an explicit interest or deep belief in gender equity issues, but he did express commitment to meeting departmental and institutional objectives as they pertain to the A \& A program. For P11, it seems likely that as long as gender equity work is an expected 
part of his role, he'll engage in it, if his role expectations change, however, it may be unlikely that he will continue to engage in this work.

Examining the initial drivers of engagement is important because they are antecedents or precursors to continuous drivers of engagement. That is, there is no possibility of sustained or continuous engagement absent the initial drivers leading men faculty to engage in gender equity work. These initial drivers facilitate continuous drivers of engagement which are critical factors affecting the impact of gender equity initiatives. Following is a discussion of the continuous drivers of engagement identified in this study.

\section{Drivers of Continuous Engagement}

As the previous discussion suggests, the drivers of men's initial engagement in gender equity work via ADVANCE and/or A \& A may not be the same drivers of their continuous engagement. An analysis of findings reveal four apparent drivers of men's continuous engagement in ADVANCE and/or A \& A: (1) belief in the importance of the work carried out by ADVANCE/A \& A, (2) continued sense of duty to remain engaged, (3) satisfaction with the engagement experience, and (3) positive feedback/perceptions of support for engagement in the work. The selected excerpts for continuous drivers of engagement in gender equity work illustrate their interrelatedness.

Belief in Importance of ADVANCE/ A \& A Work. Not unexpectedly, men study participants were unanimous in their belief in the importance of gender equity work. In fact, P13 insisted that men should be fully engaged in this work and paraphrased what he described as an ancient philosopher's thought on these issues, "There will be justice in Athens, when those who are not offended are more outraged than those who are offended." He went on to share: 
I am convinced that you put women in a tough position to advocate for their rights...Whereas I can go out and talk to a male and say, 'What are you really doing here? Do you really think this is fair?' And, I'm not an immediate threat. I don't have an ulterior motive - that they can see . . . It's tough advocating for yourself and you shouldn't put people in that position.

Echoing this sentiment is P8:

Usually minority groups are responsible for any-and-all efforts to help create greater equity for themselves, and in a system that is imbalanced ... the burden of making change ought to fall on the dominant group.

Both P13 and P8 express strong core beliefs in the importance of the work the A \& A set out to do specifically as dominant group members advocating on behalf of those from disenfranchised backgrounds. They describe this work as the responsibility of dominant group members and share the sentiment that it is unfair to expect women/minority group members to carry the burden of this work. P13 is especially demonstrative in the specific ways in which he perceives he can be more effective than a woman in confronting his male peers about inappropriate behaviors. A strong belief in the importance of the work is also expressed by P14:

It is just a life-long idea that when we don't offer assistance to disadvantaged groups, it disadvantages us, because we don't get that breadth of experience. We don't get that different perspective that makes us go out of our intellectual or personal comfort zones where there is growth.

P14's selection reveals his belief in the importance of the work because of the reciprocal benefits of equity and inclusion. He perceives those from disadvantaged backgrounds in terms of their assets - their 'breadth of experience' that helps 'us go out of our...comfort zones.' His viewpoint 
is resonant with Edwards' (2006) conceptualization of allies for social justice who perceive that their liberation is tied to the liberation of others (Freire, 1970). That is, their engagement is not just about helping women or people of color but in so doing uplifting all of humanity.

Continued Sense of Duty. As an initial driver, sense of duty to engage in efforts to solve the gender inequity problem does not emanate from lived experience and insight gained as someone presently engaged in ADVANCE/ A \& A. However, continued sense of duty to engage in gender equity efforts via ADVANCE/ A \& A is informed by lived experience and insight gained as a result of present engagement in program work. While, theoretically, a continued sense of duty may be tied to external expectations related to one's position in an organization, the data revealed that a continued sense of duty stems from a strong commitment to the work that men carry out as advocates and allies. The following excerpt from P12, a department chair, illustrates this point:

I will frankly say, that I will be as disingenuous as the Trump administration in getting to my goals, if that's what it takes, I will get there somehow. And, if someone says well why are you pushing the minority faculty candidate, I'll say it's to maintain market-share when we are recruiting students, when we are competing with institutions who have the numbers ... I will work within the system ... within the climate I've been given.

In addition to showing the resolve that characterizes a male faculty member with a continued sense of duty to carry out gender equity work, this excerpt underscores a strategy enacted by advocates in positions of authority, that emerged as a recurring theme in this study—reframing. In this example, P12 describes how he will reframe issues to advance his agenda as an advocate for diversity, equity and inclusion in what he perceives as a hostile political climate-vowing that he will work 'within the climate that [he's been given].' The level of commitment to equity 
work expressed by $\mathrm{P} 12$ and in the previous excerpts from P13 and P8 demonstrates the interrelatedness of the continuous drivers of engagement: belief in the work and continued sense of duty to remain engaged in the work. It also exemplifies how these continuous drivers of engagement inspire determination to carry out the work despite challenges in the immediate academic and external environment.

Satisfaction with the Engagement Experience. Satisfaction with the engagement experience emerged as another driver of men's continuous engagement in gender equity work. A nonfactor at the point of initial engagement, men's experiences of engagement in gender equity work may dissuade or encourage continuous engagement in the work. Most participants in this study expressed a strong sense of satisfaction with their experiences of engagement in gender equity work via ADVANCE/A \& A. One of the aspects of the work with which they were most satisfied was the opportunity to work with likeminded men and women. During our interview, P27 noted this residual benefit, while highlighting another, "I've learned many amazing things just being you know peripherally involved in the ADVANCE grant. You know, like, gender bias is not gendered." P16 seemed to express satisfaction with how his A \& A group members interact:

It's not starting a march, right. And, it's not always drafting some policies type of thingsand, we do that - the men faculty advocates do that type of thing, but we do it in a very careful way. We don't want to be preachy. It's about steering a large ship slowly kind of thing...We are trying to have influence over better interactions, better campus culture, but it really happens at [the] grassroots [level]. So, when we meet with the allies...we don't talk about...the big things we do. We're talking about like, 'so, what happened to you last semester, where you wish you had said something or you wish... What kind of coping and 
what kinds of things can you do on the offense to support maintaining a climate that will make this better?'

Although P16 was not responding to a direct question about his satisfaction with his engagement experience, the tone of his comments makes clear an appreciation for how his A \& A group functions. Interestingly, and an unusual occurrence in this study, P16 focuses on how the advocates (typically, senior faculty who take on a more significant role in the program) engage allies (typically, tenure-track faculty who play a less significant role in the program) in dialogue about their experiences of engagement in the work. This is an important footnote as an analysis of study findings revealed an underlying subtheme related to the perceived insignificance or immateriality of allies within the A \& A program.

The importance of satisfaction with the engagement experience as a continuous driver of engagement in gender equity work is underscored by indicators of dissatisfaction with aspects of the engagement experience. For example, P28 described his dismay with what he perceived to be the unnecessarily slow pace of his A \& A group getting on to action items. As he put it, After a year of learning and heightening your awareness, at some point, you have to actually, do something... If you want something that is going to infuse your environment and just be present all the time, you need to have a lot of presence, and so the focus on sort of once a year we'll pull people together, that doesn't produce sustained change.

P8 shared a similar sentiment when describing his efforts as a facilitator in mobilizing advocates to meaningful action: "It can't just be about education or changing some minds, but it has to have a complete focus on [changing] the structure of the institution." Another emergent issue which seemed to impact satisfaction with the experience of engagement had to do with some advocates' 
perceptions of the replication of privilege within the program. P20 describes a pertinent incident, which led to his decision to minimize his involvement in A \& A:

So, I went out to talk to [the women] . . . they had no idea why I was doing this-advocates and allies, they'd never heard of that. There was not a lot of publicity. Anyway, but after talking to several women, they did come up with an issue that would be helpful to women if someone worked on it. Women who come back to work after having a baby need a place to pump milk. This never occurred to me. My wife went on leave after she had our child. If I had to pump milk, I would just go in my office and close the door. But, you know, I was talking to staff and they work at cubicles and they couldn't pump milk at their desks and they have no office and they said they have to go sit in the toilet to get privacy to pump their milk. And, I wouldn't want to be pumping milk for my six-week-old baby in the restroom-I got that. I felt like I really got that. And, so, I took that back to the higher ups and - nothing. I talked to the women who are the leaders in the program and these are highstatus women on campus - tenured, full-professors and they were like, 'Well, women faculty all have their own offices. If they want to pump milk, they can just go into their offices.' After pointing out that was not the situation for all women at the college, it became clear the attitude was 'It's not a problem for me or other women faculty, so.' Anyway, so these were high status women [we have a lot of female deans] and it was clear they were not being sensitive to issues facing women of lower status. So, that was a real challenge for me ... so I suggested they demote me to ally.

Contributing to this theme is the following excerpt from P7, at a separate site:

In many ways, I feel a big sense of disconnect between this situation where you have these relatively_very powerful women on campus leading this initiative and these relatively 
powerful men who are the $\mathrm{A} \& \mathrm{~A}$, both groups of whom can be described as 'The Untouchables.' They have a lot of power, a lot of whatever, you know, and the people that all of these things are directed to benefit seem like [an] almost silent receiving group that I'm not really sure...think this is good or bad or that this is what they would like to see or that they are even able to collectively or individually comment on that. That they, despite the fact that they are the ones in this situation, necessarily have an institutional perspective to really provide that sort of feedback and that it is even fair to put them on the spot with such things? But, I thought a lot about us as a working bunch of do-gooders ... I mean if you are trying to do things for a group who is essentially silent in being helped, it raises a lot of questions.

The replication of privilege within social justice movements is not new. However, for men faculty advocates this dynamic caused them to question their engagement in this work and, for P20, it resulted in his desire to minimize his role in A \& A. To proactively address these concerns, women leaders and A \& A at local sites might consider working with diversity educators on campus, and incorporating a reading of Freire (1970) followed by talks about pertinent issues he raises related to the oppressor and oppressed and the ways in which the oppressed can internalize oppressor consciousness. In addition to addressing concerns about the replication of privilege in $\mathrm{ADVANCE} / \mathrm{A} \& \mathrm{~A}$, such collaborations can create important partnerships across units while providing an outlet for advocates and allies to share their critiques in a constructive format where solutions that don't include minimizing involvement in or disengagement from the program are considered.

Positive Feedback/Perceptions of Support. Another factor that seems to drive the continuous engagement of advocates in this study is positive feedback and support from 
significant others. P7 spoke to this issue when I inquired about the impact of his work beyond the academy:

Well my wife and daughter just returned from the March on Washington a few weeks ago and my other daughter and her friend are staying at the house and they are both activists ... so I get a lot of positive encouragement about doing this sort of work.

When asked about the degree of support tenure-track faculty who might want to get involved in this work could expect, P12 described overwhelming support for the A \& A initiative among the leadership on his campus. While most men in this study, as in the broader A \& A initiative, are tenured faculty, it makes sense that irrespective of that status men faculty value the support and affirmation of significant others and are more inclined to take on the work if they perceive support from the leadership at their site.

\section{Implications}

Discerning the differences between drivers of initial engagement and drivers of continuous engagement is an important task for leaders to undertake when assessing the sustainability of programs like ADVANCE/A \& A. While the drivers of initial engagement may not dissipate entirely post-engagement, their force may be insufficient to maintain continuous significant engagement. The driver, sense of duty to engage is an interesting point of analysis. It appears as both an initial and continuous driver of engagement with hairline differences that may be easily overlooked. The most prevalent is that as a driver of continuous engagement, a continued sense of duty to engage, though it may be partly driven by external factors like one's position in an organization, is informed by knowledge of and lived experience enacting the work in question. Furthermore, it is grounded in a deep commitment to the work that stems from a belief in the importance of the work. On the other hand, as an initial driver of engagement, sense 
of duty to engage may stem from an obligatory, externally-driven force in the form of a boss or supervisor, or it may stem from an internally-driven force stemming from a core, though abstract, belief in a cause, and the role one will play to contribute to it. As an initial driver of engagement, there is limited knowledge about the nature of the work to be undertaken and beyond initial engagement its driving force may be minimal. Therefore, in the interest of continuous engagement, identifying factors which translate an initial sense of duty into a continued sense of duty is an important strategy

Other key strategies may involve leaders deliberately highlighting the strengths and skills of prospective advocates to increase their sense of self-efficacy as it pertains to their perceived ability to help solve the gender inequity problem. To promote continuous engagement, institutions might find appropriate ways to acknowledge presently engaged men to reinforce their perceptions of institutional support. To improve satisfaction with the engagement experience, A \& A organizers might work to increase the frequency and quality of their member development efforts and incorporate opportunities to discuss concerns members may have about program approaches and other emergent issues like perceptions of the replication of privilege within the program that can cause men faculty to question their engagement or ultimately disengage.

\section{How Do Men Faculty Talk About Their Ally Identity Development?}

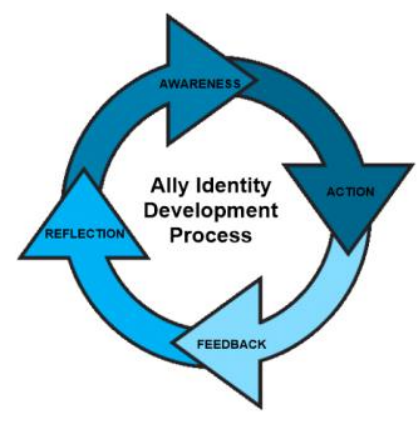

Figure 1 Ally Identity Development 
For nearly all men formally engaged in A \& A, a theme emerged around ally identity development as an ongoing process. Excerpts from my interviews with P30 and P23 exemplify this sentiment. As P30 explained,

I think the key is self-reflection, right. And so, I think as long as people are cognizant of the fact that this is real and that this needs attention and that in whatever ways you can you address it, because I recognize it's not always easy to deal with and even myself-I have been in situations where I was very disappointed in myself because I knew I should have acted and I didn't. I acted after the fact. So, I eventually did something, but you know I can beat myself up, but I also know some of my personality limitations and my style of interacting with people and those things aren't congruent. I'm not the type of person who is going to get in somebody's face or just—I've never been that way, but I will reflect, think, and find other ways to address things. I think that really, that's the main thing that's required. And, having an open mind, because you know, I mean - I know my worldview is continually changing and making updates and you know I'm never going to be done with this - is at least the conclusion that I've come to ... So, it comes down to having the openness to recognize and having the courage to act in some way.

Similarly, P23 discussed the continuous nature of ally development:

It's an ever-evolving kind of thing and it's ever-evolving both because you learn more and then other situations pop-up. So, our own identities in the process, we are all each going through our own path and people talk and say whatever and you know people who are new to the group, you know and I can say, 'oh man, I remember when I was thinking like that'you know kind of helping each other through the process. I mean you see everything so much through this lens now and it's very much like a Pandora's box and when you see it, 
you can't un-see it kind of thing and so that's the one thing. It's so ever evolving to me ... with two steps forward and one step back.

These reflections provide notable insight into how some men faculty experience ally identity development as an ongoing or "ever-evolving" process - comparable in many ways, P23 suggests, to opening Pandora's box — a particularly telling metaphor comparing the decision to ally to a regrettable decision to open one's self up to an inescapable cycle of confronting new problems and new vulnerabilities. The difference of course is that deciding to ally is a choice and men like P23 and P30 have elected not to opt-out-a critical decision upon which the transformative change the A \& A program hopes to bring about depends. Also, reflected in these excerpts are important themes around misstepping, pushing pass internal resistance, and selfforgiveness as elements of the ally identity development process.

Some advocates responded to the question about their ally identity development by providing, what I call, an ally-in-action clip - these are like clips from a movie, but instead of a fictional character, they depict an ally busy doing ally work. Following are examples from P12, a department chair and P27, a department head:

So, for example, right now, we are in the middle of a search for a faculty member and in a field (microbiology) where there has been a lot of progress in terms of balance over the last 15 years or so. And so, in recent hiring cycles, we've been hiring assistant professors. We never see a problem with diversity in the pool of candidates - diversity in the people we are making offers to. Now this year, we had funds to hire ... an endowed chair. Then, we suddenly see that what we are looking at is a pool of people that isn't diverse because they got into the academy 15-20 years ago. So, they are predominantly White men. And, there are far fewer women ... because there were far fewer women who came into the field at 
that point and you take that and you compound it with the fact of the nature of the search. So, ... what I did then, myself, was I discussed it with the dean — because I have to see the practical side of it—and said that we would informally invite in a few of the White men for interviews, but leave the search open. Then, I went to the women's center and asked if I could get their help as to how I could increase diversity in the search. And, they told me the challenges I face are that men--and this just made me laugh--will naturally apply for jobs that they're not quite qualified for. Whereas women have been told time and again that they're not qualified and they will generally apply for jobs that they're either completely or over-qualified for. Plus, women will not be as disingenuous as men—some will and some won't. It's just far less women are going to apply for jobs that they don't ever intend to take because they're looking for attention offers or they're just curious. So, this further erodes the pool. So, what we've done is to rewrite the add and take the advice from the women's center [and] not formally invite people in until we've exhausted different efforts to try and diversify the pool of candidates. And, my faculty have to buy into that because I'm not offering any choice ... So, that's trying to do something ... and, that's what my job should be. ... The other part of the message ... is that I'm not doing this because I was told to and I hate when people say to you, 'You're doing this because it's politically correct.' No, I'm doing it because it is the right thing to do and it will make us a better department. I think that is the key of what we pushed through the advocates is that this is not social guilt. This is how you will improve your research, your academics and everything, because you're just not representing fully, you're not reaching your potential. And so, that's the way I treat it. The rest is all benefit—-that it's right, that it's how it should be. But you have to tell people, "No, this is a hardnose decision, you want the place to be better? Diversify." -P12 
One of those male faculty I was telling you about got very angry with me — sent me very nasty emails, when I put several women on a search committee. He wanted a search committee that he chose with no women on it and I said, "Well, that just isn't going to happen. Fifty-percent of our faculty are women. What do you mean there are no womendon't be ridiculous." Well, [he says], 'you can pick certain ones,' and I said, "Well, listen that isn't going to be the way it is. So, I work with HR a lot and I'll pick who is going to be on this committee, if you're not capable of doing it." He said, 'Well, I don't want anyone else on it except me and a couple of buddies and I said, no, that's not going to be the way it is. ...' So, I will see it — and I give that example in advocates/allies' trainings — where we verbally have to stand up for structural things - for structural changes that represent a sensitivity to gender equity. (P27)

Defining one's ally identity development process in terms of ally actions taken reflects a core tenet of the A \& A program. That is, that the term ally should be conceptualized as a verb reflecting action, rather than as a noun reflecting a label. One's tendency to conceptualize their ally identity development in terms of actions taken, rather than as a process of internal transformation raises interesting which comes first-the chicken or the egg questions about academic men and allyship. For example, does taking ally action lead to ally identity integration? Or, does some degree of ally identity integration lead to ally action? Whichever is the case, it seems likely that as ally actions become more frequent and more impactful ally identity becomes more solidified and allies more emboldened to confront greater challenges. In the selection from P27, we see how he confronts one such challenge, something Sutton (2007) has described as assholes in the workplace. Sutton (2007) proposes "the no assholes" rule to protect organizations from "nasty" people. He advises, for example, not putting assholes on hiring 
committees due to their tendency to "hire other assholes" (p.88). Ally identity development as allies-in-action, then, reveals key themes that can also be interpreted as a list of action items which include: see the opportunity to act, question rationalizations and justifications that undergird inequitable policies and practices, go the extra mile, consult knowledgeable women, enforce "The No Asshole Rule", and tighten your message_-doing the right thing — not social guilt.

Table 11. Men Faculty Conceptualizations of Ally Identity Development

\begin{tabular}{|c|c|}
\hline $\begin{array}{l}\text { Ally Identity Development as } \\
\text { an “Ever-Evolving" Process } \\
\text { (Core Elements) }\end{array}$ & $\begin{array}{c}\text { Ally Identity Development as } \\
\text { Allies-In-Action } \\
\text { (Action Items) }\end{array}$ \\
\hline $\begin{array}{l}\text { - } \text { Continual Learning } \\
\text { - } \begin{array}{l}\text { Making mistakes/Self- } \\
\text { forgiveness }\end{array} \\
\text { - Pushing pass resistance } \\
\text { - No Opting Out }\end{array}$ & $\begin{array}{l}\text { - See the opportunity to act } \\
\text { - Question rationalizations/justifications } \\
\text { - Go the extra mile/ Consult w/knowledgeable women } \\
\text { - Enforce "The No Asshole Rule" } \\
\text { Reiterate message-Doing the right thing NOT social } \\
\text { guilt. }\end{array}$ \\
\hline
\end{tabular}

\section{Seasoned Social Justice Allies}

While ally identity development has been described as an ongoing process, there were notable distinctions between A \& A who were new to social justice work and conversations about allyship and those who presented as seasoned social justice allies. For these men ally identity development began many years before the A \& A program. For example, P28 traced the source of his ally identity to the influence of his "strongly" feminist mother who thought it was unfair that she had all boys and was resolved that "since she wasn't given any daughters, she would raise sons for feminist women to marry," and P3 who described how witnessing the emotional abuse 
his mother suffered at the hands of his father and her unwillingness or inability to stand up for herself led him to advocacy for women. In other examples, P14 described his sense of disconnect with the "backwards" politics and mores of the small rural town where he was raised as a factor shaping his interest in not only national but global issues of social justice. Similarly, P8 refers to the impact of his upbringing in an extremely progressive area of California as having contributed to his progressive worldview.

\section{The Appropriate Role of Men Allies in 'Women-Centered' Initiatives}

An important issue related to men allies and women-centered initiatives came to mind during my interviews with P28 and P3. In some of their non-ADVANCE related ally work—past and present — some tied to formal roles, some voluntary— both men have acted or are currently acting as leaders in primarily 'women-centered' initiatives. P28's activities are tied to his formal role as director of an initiative which aims to increase the success of women in STEM and P3 is an active member of his site's women's council and is considering a run as chair of that organization after being nominated for the position. I asked P3, an openly gay advocate, to share his thinking about the predominant views in the literature admonishing allies to essentially support, but not from the front (Bishop, 2002; Crowfoot \& Chesler, 2003; Hytten \& Warren, 2003):

You know, I don't buy it at all, you know it's something that's been particularly relevant in my life, you know I don't have any close LGBTQ friends, so allies have been very important to me, and you know, a lot of my work . . has been toward LGBTQ issues and I have found that it is my students who are allies and my colleagues who are allies who are more likely to show up, who are more likely to participate, and ... I've had many LGBTQ events and none of our LGBTQ faculty have joined in at any of these events, but some of 
the straight faculty have. . . And, on [another LGBTQ committee] where I serve, I've had a couple of blow-ups where the perception is that these allies should come and contribute their labor, then take a backseat. . It's like, 'hey we appreciate all your work, but it's time for you to sit down now' . . in sociology [there] is this idea of the freeloader program where these people will benefit through the work of what all these other people do, and they will act like, in the end, that they contributed. So, like with women, women will wait for other women to lead, then at the end, they'll act like they suffered through all of this struggle to get there and it's like, 'you didn't struggle, she did.' You know and so, I guess my opinion is that I don't believe that we should be exclusive to the possibility that other people can lead marginalized groups.

Owen (2009), also cited in my literature review, is a White male, assistant professor of philosophy and Coordinator of Diversity Programs on his campus. Like P3, he believes that White men should not be ruled out as leaders of diversity initiatives, but he frames his view of why they should be considered for these roles differently:

If White men undertake only supportive, behind-the-scenes roles, we can take credit and feel personally virtuous for working for diversity and social justice, while at the same time avoiding the risks of directly challenging a system that is deeply structured by race and gender inequalities. (p. 197)

While P3 contextualized his sentiment in terms of the way in which excluding majority people from leading initiatives can be unfair to them, Owen (2009) frames the issue around the way in which excluding dominant group people can effectively absolve them from having to take on the risks that come along with diversity work. This discussion is important because the central focus of the A \& A program is men. That is, recruiting, educating and mobilizing men to be A \& A for 
women, which requires them stepping into leadership roles among other men-but under the strategic counsel of women. Nevertheless, there were instances in the study, when participants talked about men advocates being challenged for trying to lead women-centered initiatives. P19 a dean at one site, and P26 a woman ADVANCE leader at another site, described similar situations in which gender studies' scholars challenged the authority of men to assume any sort of leadership position. In both instances, after learning more about program intentions, these scholars' concerns seemed to lessen. However, this remains an important issue for the A \& A program leadership to consider as the program expands on other campuses.

\section{The Intersectionality of Allies}

The NSF stipulates that ADVANCE grant applicants demonstrate the ways in which their proposed initiatives address how intersectionality impacts the experiences of women in STEM (NSF Program Solicitation Guidelines). This same level of analysis is warranted in explorations of the experiences of men allies. An intersectional analysis considers how simultaneous membership in privileged and disadvantaged groups shapes experience (Broido, 2000; Broido \& Reason, 2005; Burghardt, 2011; Davis \& Wagoner, 2005; Reason \& Broido, 2005). In the previous selection, the intersectional experiences of $\mathrm{P} 3$, a White, openly gay advocate, had a profound effect on his view of the appropriate role of dominant group members in social justice initiatives. In my interview with P9, an African-American advocate, he revealed something telling about the experience of intersectionality that he may not have intended:

I shared with the other advocates my experiences as a Black man in society-I mean people don't look at me and automatically think I have a $\mathrm{PhD}$, that I am a professor. So, I have had the experience of women clutching their purses or moving to the other side of the street. 
When asked whether people have been receptive to what he shared, P9 replied, "I mean, initially, they were surprised, but they seemed to respect the fact that I felt comfortable bringing it upYou know, but I was professional and didn't make them feel uncomfortable."

The tail end of P9's comments capture an emergent theme in the experiences of marginalized people at the intersections of academia (and corporate America) who may hold the same or more impressive credentials than their colleagues, but understand, somewhat intuitively, that part of their job not stated explicitly nor hidden in the fine print is keeping dominant group member's comfortable_-often euphemized as being professional. P17 and P30, both selfidentified Latino advocates, described how their White-skin appearance throughout most of their professional lives has granted them a sort of "immunity" from the type of discrimination other members of their families have experienced due, in part, to "heavy accents" which have acted as markers of their othered (non-majority) identities. Although issues of intersectionality were not a naturally emergent theme in this study — that is, I deliberately asked about them — what advocates shared about their experiences of intersectionality is important to consider. Men from a range of backgrounds are invited to participate in ADVANCE/A \& A - and with them come these interesting, instructive experiences that can enhance collective understandings of discrimination and marginalization. Jones and McEwen (2000), cited in the literature review, make the point that it is difficult to understand an individual with two primary intersecting identities from the perspective of just one of those identities. In their research, women who were also minority did not talk about being a woman separate from, for example, being a Black woman, or a lesbian woman. In this same way, it is probable that men like P3 who is White and gay, and P9 who is Black and a man, and P17 and P30 or are Latino and male view and understand the world through a more textured lens. 


\section{Wearing an Advocate/Ally or Feminist Label}

An unexpected theme arose in my interviews around openly wearing an ally, advocate, or feminist label. The issue was first revealed in my pilot study focus group when P34 reflected on another participant's easy embrace of the label, "feminist":

The idea that $[\ldots]$ is very comfortable about wearing the label that "I am a feminist." And although I think our orientation, in terms of wanting to see a world where women are treated equitably have all the same opportunities and everything, I think we're probably very much on the same page. I don't think of myself consciously often going out and wearing that label. I'm not saying that it's anything I have a problem with, but it's just maybe because of my journey being a little different, but I could see us being in the same room and advocating for the same issues. So, it's sort of interesting, we all come to these things in different ways, I guess, is what I'm trying to say. So, that I see it as a core part of my identity, but it's sort of funny to think about the fact that I haven't really, consciously put that label on it very frequently. But, if you were to kind of go down a list of this orientation - this attitude that makes you a feminist, I imagine, I'd be checking next to these boxes. So, it's just sort of interesting, how we think about or do identity.

While P34 suggests that his response to the idea of wearing a feminist label may be tied to his "journey being a little different," other men have framed the issue of wearing labels around context, as illustrated in the following excerpt from P33, and comfortability as demonstrated in the subsequent excerpt from P1:

I try to be as vocal about it as I can when the context is right. So, context is kind of important. So, I don't spend a lot of time at [my parent's] home talking about [these issues] . . .. My 
parents and my sister are both quite anti-feminist which that's the place where it creates conflict. They're sort of baffled by what it is that I do. (P33)

P1 reflects on his experience with this issue while conducting a facilitation with men on another campus who did not want others to know they were affiliated with the A \& A initiative:

I certainly do feel comfortable. But, I know that there are people who do not. We were at an ally institution, where the entire group of advocates was actually uncomfortable wearing the label. In fact, they kind of wanted to operate incognito. Like they kind of didn't want people to know that they were part of the group, which I guess is ok, but that discouraged us. It is important for people to know that there are advocates and allies on their campus. On our own campus, I know that we have colleagues in the Ag college who are definitely uncomfortable wearing the label-maybe engineering to some extent, too. So, in my college (behavioral sciences), it is something that is valued by the administration. I have a lot of colleagues who value it. I also have colleagues who don't.

P8, a seasoned A \& A facilitator, shares his take on the issue:

For us (advocates on his campus), Ally 101 is you have to identify yourself as an ally. People talk about something you need to say, "Hey I support gender equity, that's important to me. I support the ADVANCE movement." So, the difference between labeling yourself [an ally] and [being] an ally publicly and taking on the idea that ally is an action personally are two different things. So, if someone asked me whether I am an ally in the larger group in the university, I am not going to go into a discussion, 'Well, ally really isn't an identity it's an action.' . . . No, I'm going to say,' absolutely.' And, when I think that-when I say Ally 101 in our work when we bring men together or when we train people for the first time, that's the very first thing on the list is that you need to publicly identify as an ally for 
gender equity often. ... So, the reservation, then, that some men might experience ... I'm not sure if they are in a place to be an ally yet.

When I asked whether wearing the label is a core part of the work or if it should be a core part of the work, P8 responded:

I think it does need to be a core part. I think the label issue is the same reason some men don't feel comfortable calling themselves 'feminist.' And, unfortunately, it is a bias because of its association with women that is part of the struggle that is going on--not consciously, probably.

P8's assessment of the issue addresses the practical implications of wearing an advocate or ally label. That is, when men and more importantly groups of men identify themselves as allies it changes perceptions of the environment in positive ways. When men profess to be allies but operate incognito, it cripples the effect they can have on the environment. In many ways, P16's testimonial illustrates this point:

I feel that I do have such an identity. I proudly display a Break the Silence sticker on my door. I also happen to be an active ally in the LGBTQ organization on campus. ... There tend to be more lesbian and bi women in the student group than men who identify as gay or bi. So, I interact with women in that direction as well. ... So, in terms of both of those organizations, I'm a very active ally. I am visible at events that they have. In terms of this male advocate thing--this is fairly new. I just joined the organization last year. I've been going to semi-weekly meetings for the organization. But, that . . . is not as public in terms of what people perceive. My name is listed on the website. And, I attend the meetings that we have with allies, but other than that, I don't know how much, you know people know of this. But, in terms of internally, I identify very much as an ally. 
I asked if there are important distinctions, as you see it, between being an ally for advocates and being an ally for LGBTQ, to which he replied:

I am much more comfortable_ - or historically, I was much more comfortable being an ally of women than I was being publicly an ally for LGBTQ. I have become more comfortable being seen as an ally for the LGBTQ community. I have displayed a PRIDE sticker, right next to my Break the Silence sticker outside my office door for 5-6 years. But, I did not want to be seen with the LGBTQ community prior to getting tenure. It's amazing what tenure can do in terms of giving you the comfort to support causes that you are afraid might be seen negatively. ... Prior to me getting tenure [my institution] didn't even have an official office for LGBTQ affairs. That happened maybe a year or two years after [I got tenure], where they finally brought in a director for the program. And so clearly, prior to that, there wasn't any sort of sense that this was something that the campus cared about and of course when you have something like that, there's the question, 'Is it seen as a negative, if you [get involved in] that?' And so, finally getting a director, and starting to see programming on campus and things like that was important, you know, to me. [Because before that], there was a student organization at the time that I didn't know much about [that would host] some other activities. . I would sort of attend, but not make it publicly known that I was a part of that-you know, trying to show my support for students without necessarily claiming myself to be an ally in a public way... Tenure is such a subjective kind of process no matter what they try and tell you. And, all it takes is one person to have a negative opinion. And, they can pretty much torpedo a tenure case. And, so yeah, if you don't know, you don't want to take the risk. 
Whether the LGBTQ community ever considered P16 an ally is a question for another study. But, his fear of being outed as an ally to the community because of the potential negative impact on his tenure case illustrates the paradox of privileged systems like tenure in terms of their ability to at once thwart and facilitate social justice efforts. This scenario also underscores a sort of social-acceptability capital inherent in some social justice causes like gender equitywhen "gender" means cisgender women and absent from others like transgender rights.

\section{Implications}

How men faculty talk about their ally identity development may shed light on why some men become seasoned social justice allies, while other men try being an ally on and off at different moments in time. The extent to which A \& A engage in dialogue around this topic may have important implications for helping new and existing recruits think about their work. It may be that some men are more effective at rolling up their sleeves and doing as they learn, while other men may want to know all they can before they feel competent to act. As men consider their proclivities, they might also consider the extent to which their proclivities support desired outcomes. For example, if the desired outcome is more equitable departmental policies and practices, a proclivity toward taking action to transform identified inequitable policies and practices would seem to best contribute to this goal. Whereas a proclivity toward learning as much as one could about the ways in which existing policies and practices are determined to be oppressive, might delay attainment of this goal. On the other hand, acting without accurate knowledge about which aspects of policies and practices are effective, could obstruct desired outcomes. Another important implication of these findings is that ally identity is not constructed in a vacuum. Men who show up to serve as A \& A include men who have been and may currently be allies for women and other marginalized persons. In the door with these men comes lessons 
from those experiences and for some, experiences which stem from intersectional identities that have given them insights others may not have. It is important that A \& A coordinators pay attention to these realities and find ways to constructively integrate this intra-diversity into the fabric of their groups. Lessons learned from prior experiences as allies and advocates for social justice can enrich understanding about the various dynamics that influence these experiences. For example, the A \& A program can glean important insight from men faculty like P16 whose desire to be more fully engaged as an LGBT ally was inhibited by concerns related to his pretenure status and the lack of institutional indicators of support for members of this marginalized community. The assertion that concerns about one's pre-tenure status compromised actions or activities that would promote a more inclusive campus climate raises critical questions about the relevance and inherent value of promotion and tenure systems in an increasingly diverse society and academy. Senior men faculty advocates as powerful institutional stakeholders may be well positioned to address these issues. Additionally, these findings revealed that there is a fair amount of ideological discrepancy among men faculty advocates regarding the necessity of advocates/allies openly wearing the ally label. While core to the initial conceptualization of the formal men's advocates and allies group was building a visible coalition of influential academic men who openly support gender equity efforts to attract more likeminded men, the revelation that some of the men within these coalitions avoid wearing the label in certain academic contexts is surprisingly counterintuitive to the group's expressed mission and raises important questions like: Can advocates and allies function incognito? Are those who are uncomfortable wearing the label, equally uncomfortable advocating for gender equity causes? And, what, if any, are the specific benefits/disadvantages of avoiding openly wearing the label? A \& A coordinators need to unpack 
and dissect this peculiar dynamic. What contributes to it? And, what does its persistence or accommodation mean for the structure of the larger program?

Finally, evidence of ally identity integration, within some of the participants in this study, suggests the ways in which it is likely to act as both an initial and continuous driver of engagement in gender equity work. 
CHAPTER V: FINDINGS (RQ 3 \& RQ 4)

\section{What are Men Faculty Perceptions of Gender Equity Work?}

In this study, gender equity work was conceptualized as any effort which helps to promote equitable and inclusive environments within which all can thrive and reach their highest potential. Participants described gender equity work as a medley of micro (individual), meso (unit/departmental), and macro (institutional) level actions with gradations of significance relative to impact. P32, a full professor in astronomy and physics, describes gender equity work from an individual, self-development level:

My interest, and the reason I got into this group is to truly educate myself first and foremost and then ... just to try to-my goal going forward is to try to just change in small, but doable ways [the] daily working practices of [as] many people [as I can] so to try and spread that word.

P10, a former department chair, provides an example of how he carried out gender equity work at the departmental level:

Well, number one, changing the way we did recruiting. The rule was no matter how many wonderful white male candidates you had, you always brought in any minority candidates that were on paper reasonably close to the bar and at least two female candidates that were reasonably close to the bar. You bought in the best two and the best one at least. And, at a minimum, those people would knock your socks off occasionally and we would hire them. P6, one of the ADVANCE women leaders and a faculty member in engineering, describes the impact of a single intervention by her department chair:

He had just returned that week from an A \& A training and we were having a departmental meeting and the subject of course evaluations came up and a faculty member who is a 
woman of color brought up the issue of biases toward women and persons of color in course evaluations. ... He immediately, you know, jumps in and supports her comments by explaining that he had learned about this and that as a department we need to reconsider the amount of weight that we give to course evaluations. ...He could do that. . . If that had been me [speaking up], it would have shifted to 'Oh woe is me.'

An important point to note about P6's excerpt is that it had implications at the individual level in terms of legitimizing the concerns of women and people of color in the department, as well as implications at the departmental level in terms of moving the unit toward embracing more equitable policies/practices. It also exemplifies a gender equity strategy recently coined “amplification," by women in the Obama White House (Goff, 2016), which involves reiterating key ideas and giving due credit to their originator - usually a woman or other marginalized person whose contributions might otherwise be ignored or credited to a man. P27, a department head, shares an example of how gender equity work is played out at the broader institutional level, when he recounts an incident that occurred during a faculty senate meeting:

A male senator stood up and made some disparaging bias statements and the whole senate jumped down his throat. I mean male senators - I was amazed at that and the chair of the senate — when the senator who made the remarks said, 'I didn't mean anything by it'—said, 'Yeah, that's why they call it implicit bias.'

In addition to demonstrating the degree of impact a micro-action like speaking up to check someone can have within a broad institutional context, like a faculty senate meeting, with representatives from across the university, P27's excerpt also affirms the power of coalition building in bringing about social justice-oriented change - a key concept in the higher education change literature (Kezar, 2014). Participants also conceptualized gender equity work as strategic 
action or, in some instances, strategic inaction even in efforts to help women as evidenced in this excerpt from my interview with P14, an associate chair:

There are two things you have to be careful about and really think about [in terms of] being strategic with your female colleagues — especially if they're new colleagues. ... The first is you don't want to use the knowledge you have gained of the institution to shut down people who might be enthusiastic. It's very difficult, because sometimes you want to let that person experience it on their own, but then you don't want that person to become disillusioned because they experienced something you knew they were going to run into, but you don't want to sit there and say, this isn't going to work because of this, this and this. So, it's sort of a challenge to turn it into an opportunity and say, ok so I know this is what you want to do and here is an opportunity. Here, I think might be some roadblocks and let's talk about how you'll get around them. . But still it doesn't always work out because some people just want to do what they want to do. And some women [already] feel challenged in what are particularly hostile departments and they don't feel they can do anything... So how do you help provide some mentorship without either, you know, closing doors, because you know that door is [already] closed or over-guiding and then they don't feel empowered themselves?

The perceived importance of being strategic when attempting to help women, especially those who may be junior colleagues, reflects a sentiment expressed throughout my interviews about men not acting as knights in shining armor. As P6 joked during our interview, "we don't need them to save us, we're ok." While the challenge of providing strategic help to women is a core message, P14 also describes the need for strategic approaches when trying to advance causes like gender equity and other social justice issues within the structures of the institution: 
These institutions will not change unless you force them to change because people get too comfortable in their own ways. It's a cost. It is work. And, unless you demand that these institutions change, they will just replicate what they're doing. And, there's a lot of turnover administratively as administrators move up and out of their institution. So, you have an opportunity. It's not a constraint, but it's an opportunity. Sometimes my colleagues complain that we've had a lot of dean turnover. I don't see it as a challenge, I see it as an opportunity. Because once that new dean is in, I've got two months to get to that new dean and get a host of new things together, because they're all fresh and they all want to make their mark. . So, you have to look at institutions as sort of intersecting and parallel worlds of constraints and opportunities, and you've got to be keen and you've got to be quick to take advantage of the opportunities. But, unless you do, you can't wait for someone to come around and say it. . They're going to do it the way they want and it doesn't always jive with the way I want to do it [and] having worked here for 15 years, I know the roadblocks ... So, that's sort of the institutional challenge-you just get to know where you are and when ... you've got an opening.

Men consistently alluded to working the system as a key feature of gender equity work. P14's explicit response exemplifies this. Another critical feature of the work reflected in participant comments was seeking and receiving feedback from women colleagues about the work. P26, one of the ADVANCE women leaders on her campus, reflected on how the A \& A group on her campus seeks feedback on their gender equity work:

So, they've created these workshops and they are constantly updating them based on the issues that are currently important to the women STEM faculty, and, along with that, they 
regularly meet with our women STEM faculty — and by regularly, I mean once or twice per academic year.

In my interview with P21, she shares feedback the men in her A \& A program received from their women's advisory council about developing their personal development plans:

Men saw the task of putting together a personal development plan as picking out topics that each would study and then come back to the group and share what they learned. But, we were telling them, no, that's not a personal development plan. You need to reflect on your feelings about this... What do you feel when a woman comes into an interview dressed a certain way? That's about a feeling, it's in your gut, and you need to be able to talk about that, to figure out what that's about. . . And, so, if they can't do that work, they can't facilitate that work in other men. ... It really comes down to men wanting to think—not feel.

There is an important, though subtle, distinction between men seeking feedback as P26 describes and men receiving feedback as in P21's example. The seeking — asking women to provide feedback about their work — may be easier than the receiving — that is considering the possibility that the feedback warrants a change in behavior. This supports an A \& A program tenet that a critical part of the work is listening to and trusting women. Another recurring theme around gender equity work had to do with comfort. P7 expressed frustration with how comfortable and safe his site's work was at the expense of being effective:

Everything we did was kind of safe, very milk toasty kinds of things and honestly, I don't think anyone learned anything. . . You know, I know that the whole theater-based roleplaying piece can be pretty threatening for folks and [that] it can be pretty difficult to get folk to be involved, but I think that kind of experiential learning is where we need to go. 
P7 perceives the way in which experiential learning activities can serve as "critical incidents"concept in the multicultural education literature (Landreman et. al, 2007, p. 281) used to describe experiences that trigger cognitive dissonance. Kezar (2014) identifies cognitive dissonance as a critical turning point in transformative thinking (p. 30) that may not be comfortable, but is effective in helping people see the world with a different lens.

Finally, men faculty perceived gender equity work as boundless. In my interview with P1, he shared how his son questioned him about cheering-on the only all girl Legos team in their competition, when he was supposed to be focused on coaching them. He recounts explaining to his son the importance of girls getting involved in this sort of activity, how they are underrepresented in those sorts of competitions, then, assuring his son that he was rooting for both teams. This was only one of many examples of how men faculty advocates counted gender equity work as actions not only occurring within the academy, but beyond it.

\section{Academic Leader Perceptions of In-Role Behavior (IRB)}

The sample for this study included two administrative Vice-Presidents — one of whom is a senior faculty member in a life-science department, the other, the administrative head of a diversity program division at his university; two associate deans in departments of engineering; two current department chairs-both in engineering, a recently-former department chair in physics; a current department head in a life science; and one associate chair in the social sciences. Between them, all but one, an associate dean of engineering, perceived their gender equity efforts as part of their work or doing their job. This is demonstrated in the subsequent passages from $\mathrm{P} 12$ and $\mathrm{P} 2$, respectively: 
[At my institution], it is seen as part of your job as a chair to be an advocate. And, I think it's one of those things, you can take it or leave it as a chair. It's not a requirement, but if you want to be a high performing chair, this is an expected part of what you do.

When I asked how that expectation as communicated to him, he replied,

It's not, but it is very much something that is clear - that the college will, as an afterthought, be grateful that you're doing something for them because they're going to be asked from above, "What's your college doing?" ... I think the college could be doing a better job, but the fact that they need to be seen as doing something, I could take advantage of that and push things. (P12)

Likewise, P2 described the expectation for this work in his role:

I don't think about [being an advocate] so much. I just think about doing these things. It's like some of it seems like common sense-natural almost. It's like I am proud that [the woman who recommended me to you] would view me that way, but it's like you know, I don't think about that. That's not how I self-perceive. I think that I am doing a job and I am just trying to get things going, which is really what I do across the board and [the efforts I have made within the context of ADVANCE] are just one aspect of my work.

The overwhelming perception of academic leaders, in this study, that gender equity work is part of their job seems to enrich and extend extant research. Buttner et al. (2006) and McClelland and Holland (2014), both discussed in the literature review, found, in the latter case, a notable difference between high personal responsibility leaders whose awareness would consistently lead to action and low responsibility leaders who perceived gender equity issues as a problem women should address; and relatedly, in the former case, findings which revealed that assignment of responsibility for diversity was a greater driver of leader promotive diversity actions than 
awareness. The specific dynamic unfolding among leaders in this study is that although they perceive this work as their job, technically, it is not "assigned." That is, being an advocate is voluntary, yet overwhelmingly, in this study, these men perceive that advocate or gender equity work aligns with their duties. Working to achieve gender equity outcomes through one's traditional academic work without the weight or connotations of calling it gender equity work may also neutralize resistance. That is, it is easier to attack one's politics than it is one's reinforcement of organizational policies and practices designed to promote equity. It is also challenging for detractors to push back against diversity issues that have been purposely reframed as broader concerns of the institution. Both P2 and P12 described how they employ this tactic as they carry out their work. For example, P2 explains,

I don't say, oh we need to hire more women and minorities when I am talking to the provost or the college deans, I say we need to focus on workforce development [and making this] a place where students want to come.

I asked how he held those in his charge accountable to these values and he shared his efforts to facilitate "aha" moments, where he uses an occasion to point out why paying attention to these issues is important. He also described his effort to role-model the behavior he wants to see, rather than telling people what they need to do.

\section{Gender Equity Work \& Traditional Faculty Work Fit}

Overwhelmingly, men faculty advocates indicated that they situated their gender equity work within the service category of their faculty files. Those who conduct gender equity related research indicated that they situated that activity within the scholarship category of their faculty files. None of the men faculty advocates indicated situating any of their ADVANCE/A \& A work within the Teaching category of their faculty files. The way in which men in this study make 
sense of their gender equity work within the broader context of their traditional faculty work seems to support Kuntz's (2007) assertion, in the literature review, that faculty work is a construction of daily practices (p. 185) which create meaning and shape, faculty identity. Given gender equity work includes the ally identity development process, this suggests the interesting possibility—maybe likelihood that gender equity work can not only transform men, but through their participation in it, conceptualizations of traditional faculty work.

\section{Time Spent on Gender Equity Work}

Men assessed time spent on gender equity work in three primary ways: time spent on ADVANCE/A \& A program tasks like outreach, program-prepping, and conducting/assisting with facilitations; their infusion of an ally/advocate ethic into their overall approach to workincluding interactions and encounters with colleagues and students; and as time spent beyond academia making a deliberate effort to be more mindful and conscientious husbands/partners, fathers, and citizens. When describing their time expenditure in quantitative terms, men indicated that they spent as little as one hour to as much as five hours a week on gender equity work.

\section{Implications}

Findings revealed that the predominant perspective of participants in this study is that gender equity work encompasses a range of actions and activities that are intentional and aimed at creating more equitable environments for all. Therefore, both micro and macro actions have value as well as the potential to impact an academic organization at every level. Within these findings, too, were important emergent themes, which shed light on some of the key objectives of gender equity work within the academy and the strategies used to accomplish them. These are summarized in Table 12 below: 
Table 12. Key Objectives of Gender Equity Work \& Strategies Used to Accomplish Them

\begin{tabular}{ll}
\hline Key Objectives of Gender Equity Work & Strategies Used \\
\hline Conscientious Leadership & Education/Awareness \\
& Critical Incidents \\
Inclusive Recruiting Practices & Exercise of Advocate-Leader Authority \\
Fair Use of Teaching and Course Evaluations & \\
Supporting the Voice \& Concerns of & Amplification \\
Marginalized Faculty & Strategic Helping \\
Transformed Departments \& Institutions & Strategic Maneuvering w/in Institutions \\
& Supportive Coalitions of A \& A \\
Effective \& Appropriate Gender Equity Action/Activities & Recurring Feedback \& Self-Reflection \\
& Role-modeling desired behaviors
\end{tabular}

Finally, understanding how men faculty and academic leaders conceptualize gender equity work in relation to traditional faculty work seems to be an important factor in the ultimate quality or significance of that work. For example, the extent to which men faculty can situate aspects of their gender equity work within the context of their traditional faculty work may be an indicator of how likely they are to continuously engage in gender equity work. Other factors that may influence continuous engagement are institutional or site dynamics over which men faculty may have little to no control. Those that emerged in this study are discussed in the next section.

\section{What are the Implications of Institutional Context/Site Dynamics on the Work?}

The goal of this study has been to explore the phenomenon of men faculty engagement in gender equity work. For each study participant that work unfolds within the context of one of the six ADVANCE Institutional Transformation (IT) sites selected for this study. Thus, each site's A \& A program is a subcomponent of the larger ADVANCE-IT initiative. However, even with that 
factor in common, differences in site dynamics seemed to shape men's ADVANCE/A \& A engagement experience. Three site dynamics that seemed to impact men faculty's experiences of engagement in these findings include: Institutional Disposition Toward Data and New Research Mission, Institutional Support, and Perceptions of the Pre-Existing ADVANCE-IT Project. Given the sensitive nature of these data, I deliberately omit both institutional and participant identifiers of any sort where it seems pertinent.

\section{Institutional Disposition Toward Data \& New Research Mission}

Institutional disposition toward data and new research mission seemed to influence at least two issues at one of the private sites in the study: the institution's reluctance to share institutional data and the faculty's focus on shifting promotion and tenure requirements given the institution's efforts to increase its research productivity. As a participant from the site explained, the latter issue may have impacted some faculty members' sense of time available to support "extra" initiatives like A \& A. The former issue, was thought to have limited the level of understanding potential men faculty advocates had about their campus' local gender inequity issues. The impact of these dynamics on engaged men faculty member's experiences of engagement are unclear. However, it is not inconceivable that these dynamics can have implications in terms of A \& A efforts to recruit other men faculty as well as their ability to keep presently engaged men continuously significantly engaged.

\section{Institutional Support}

The importance of perceived institutional and departmental support remained a persistent theme throughout this study and not because study participants indicated a lack of it in their personal experiences of engagement, but because their perception of support seemed to be a primary driver of their commitment to engagement. This fact is not revelatory as the broader 
ADVANCE initiative and the A \& A program deliberately target faculty whose risk of involvement factors are low. For example, on the website of one A \& A program, nontenured faculty who are interested in the program's objectives are explicitly invited to engage as allies with the possibility of becoming advocates within the subsequent 5 to 6 years. At another site, the institution's provost sent the following memo to the university community announcing the initiative and explicating in a textbook top-down fashion exactly how the program would be executed, which units of the campus would be involved in order of their priority, and with a request that those in leadership positions within their colleges plan for the A \& A program leadership to visit their colleges. I have omitted identifying information from the document:

Date:

To: $\quad$ University Community

From: Provost

Re: $\quad$ Advocates and Allies for Equity Initiative

Dear Colleagues:

As part of the President's 2020 Vision of inclusive excellence, we are proud to announce the launch this month of the Advocates \& Allies for Equity initiative. The original purpose of this NSF-funded program is to engage male colleagues as advocates and allies for the advancement of women faculty. [Our Institution's] participation and long-range goal is to institutionalize and expand this program as part of our approach to support a more inclusive and equitable environment.

Senior male faculty and administrators who already have a substantial record of supporting women staff and faculty will lead the program. To begin with, these Advocates will lead facilitated conversations with other men, Allies, and offer awareness, reflection, action and 
engagement to improve our own university culture and to become a national leader of other institutions.

[Another pre-existing gender equity seeking initiative] will lead implementation and institutionalization of the Advocates \& Allies, along with the College of Engineering and the Advocates \& Allies Women's Advisory Council.

We hope that you will support this initiative by facilitating the engagement of your respective departments and promoting the dissemination of Advocates and Allies for Equity. Please contact [person-in-charge], for additional information.

The language and tone of this memo seem to reflect the institution's unequivocal support of the A \& A initiative. The leadership has been rallied and the administrative structure delineated, with unambiguous checks and balances, as well as cross-disciplinary and interprogram collaborations to ensure the program is not only successful at that site, but becomes "a national leader of other institutions." In analyzing study data two things were intriguing about this site: first its advocates consistently matched the resolve expressed in this letter from the provost. Not one expressed perceptions of wavering institutional support for their role in the program. And, although they were frank about the challenges they faced with getting other men faculty on board, as one put it, "our greatest challenge is not getting men involved, but enthusiastic." The second thing I find intriguing is that the original A \& A model is predicated on a bottom-up organizational change strategy. P8 who was instrumental in the development of the original framework for the program asserts that academic leaders are not usually positioned to think critically about their departments and have a "hard time taking a critical look at what they can do better and instead promote what they are doing well." He says he's seen this dynamic unfold "time and time again" in his trainings. He concedes that these leaders might be effective as "allies" (the lower-level of participation) in the program, but argues that being an advocate (the higher level of participation) is "a hard space to occupy." He points out that the original 
model had as a requirement that you could not be an ally/advocate if you were a department chair or associate/dean. He also describes such leaders as "protectors of the system" given their formal responsibility to the institution. Following is an excerpt from our interview:

Being in a position to change and create a movement...that is what ADVANCE is trying to do and that is what advocate work is about — it doesn't mean the person in power-it doesn't mean the person like the department chair-because systemic change or institutional change often operates behind the scenes outside of the awareness of those who are in positions of power-sometimes — not always. There are other efforts going on, but [this is] what we call a "bottom-up" approach. Advocates is a bottom up approach. So, if you get the department chairs and associate deans involved it becomes a "top-down" approach and then it can't create a movement. Our goal is to bring as many people on board that are already on board and organize them so they can have influence on people close to them and they join, and we build a critical mass of people and eventually the system changes itself ... That's our effort. The larger ADVANCE project has "top-down" approaches by changing policies and those kinds of things, too, but they're both working simultaneously one from the top and one from the bottom.

P8 seems ideological about the effectiveness of bottom-up change strategies. This problematizes the issue of which approach ought to be taken for sites considering an A \& A program. In my interview with P5, he expressed the need for "a measure of flexibility" in thinking about program structure. Unlike P8 whose background is in human development, a field that welcomes engagement in gender equity issues, P5 is in a STEM field, as are many of the advocates from the site that has digressed from the original model. This fact raises questions about the extent to which hardcore "bottom-up" approaches are perceived as viable in certain academic contexts. It 
may be that in the hard sciences, initiatives like A \& A require a strong leadership mandate to convince their faculty that taking time to engage in this work will not be penalized or frowned upon. Adapting the A \& A model to accommodate this sort of organizational dynamic seems appropriate.

\section{Perceptions of the Pre-existing ADVANCE-IT Project}

At one site, the pre-existing ADVANCE-IT project had an image problem. An advocate from the site asserted that two major missteps were crippling ADVANCE and "seemed to be trickling into the advocates." The first was that the larger initiative had not proved to be a strong partner to pre-existing gender equity initiatives on campus. The second was that ADVANCE had "relied on the skills it took to write the grant and secure the award to [also] manage the award effectively" and a different set of skills was required for the latter. This advocate was convinced that the same incompetence which characterized the broader project was now impacting the effective administration of A \& A.

The extent to which the A \& A program is conceptualized as a part of the broader ADVANCE initiative has implications for how the two can either positively or negatively impact each other. In this scenario, there are implications on one advocate's experience of engagement in the program which suggests this sort of dynamic can affect the experiences of other advocates.

\section{Implications}

Findings from this investigation revealed three interesting site dynamics which may have directly or indirectly shaped the engagement experience for some of the men faculty participants. Although only three are highlighted here, it is clear the number of site dynamics which have the potential to shape men's experiences of engagement in gender equity work may be difficult to count. While some dynamics may be evident across institutions, others may be unique to a given 
institution or particular types of institutions. Whichever is the case, the important point is that these dynamics matter. Kezar (2014) cautions higher education change agents about the tendency to "ignore context" (p. xiv). She argues that the success of any new initiative in academia depends on the extent to which its implementation strategies reflect an intricate analysis of the organization's culture and context. This may occur intuitively on some campuses, and deliberately on others, but it seems certain that to be successful a given change process must be "customized to suit a particular organizational challenge and moment" (p. xv).

Based on these findings, I further contend that the reason awareness of these dynamics is critical is because they are typically variables institutional leaders can manipulate to either enhance or diminish the effectiveness of social justice/equity initiatives, as well as the experiences of faculty engaged in equity-related work.

Table 13. Site Dynamics \& Their Implications

\begin{tabular}{|c|c|}
\hline Site Dynamic & Implications \\
\hline $\begin{array}{l}\text { Institutional Disposition Toward Data } \\
\& \text { New Research Mission }\end{array}$ & $\begin{array}{l}\text { - Reluctance to share local gender equity } \\
\text { data w/prospective A \& A may } \\
\text { compromise perceptions of problem } \\
\text { relevance }\end{array}$ \\
\hline & $\begin{array}{l}\text { - Shifting Promotion and Tenure } \\
\text { Requirements: Faculty less inclined } \\
\text { toward "extra" activities like A \& A }\end{array}$ \\
\hline Institutional Support & $\begin{array}{l}\text { - Recruitment of faculty with low-risk of } \\
\text { involvement factors. }\end{array}$ \\
\hline & $\begin{array}{l}\text { Explicit Top-Down Approach- } \\
\text { Integration into Broader Objectives }\end{array}$ \\
\hline
\end{tabular}


- Provost's Expression of Unequivocal Support

Perceptions of the Pre-Existing

ADVANCE-IT Project
- Image problem-incompetent, poor partners, unreliable

- A \& A Inheriting Image Problem

At the end of my interview with P18, he responded to the question I asked all participants as we concluded - Is there anything that we didn't talk about that you think may be important for me to consider? "I think it is important that you capture the complexity of the landscape." It is a thought that remained with me throughout my remaining interviews and as I worked through my analysis of data and the preparation of my findings. The landscape is indeed complex. The phenomenon that I elected to study is multifaceted, but not as complex as the myriad contexts in which it unfolds. Thus, my objective in highlighting these site dynamics is not to generate a list of all the factors that could influence men faculty's experiences of engagement, but to underscore the complexities of context related to the exploration of this phenomenon.

In the proceeding and final Chapter of this dissertation, the emergent grounded theory (GT) is presented, followed by conclusions and future directions for research. 


\section{CHAPTER VI: GROUNDED THEORY \& CONCLUSIONS \\ Presentation of Grounded Theory}

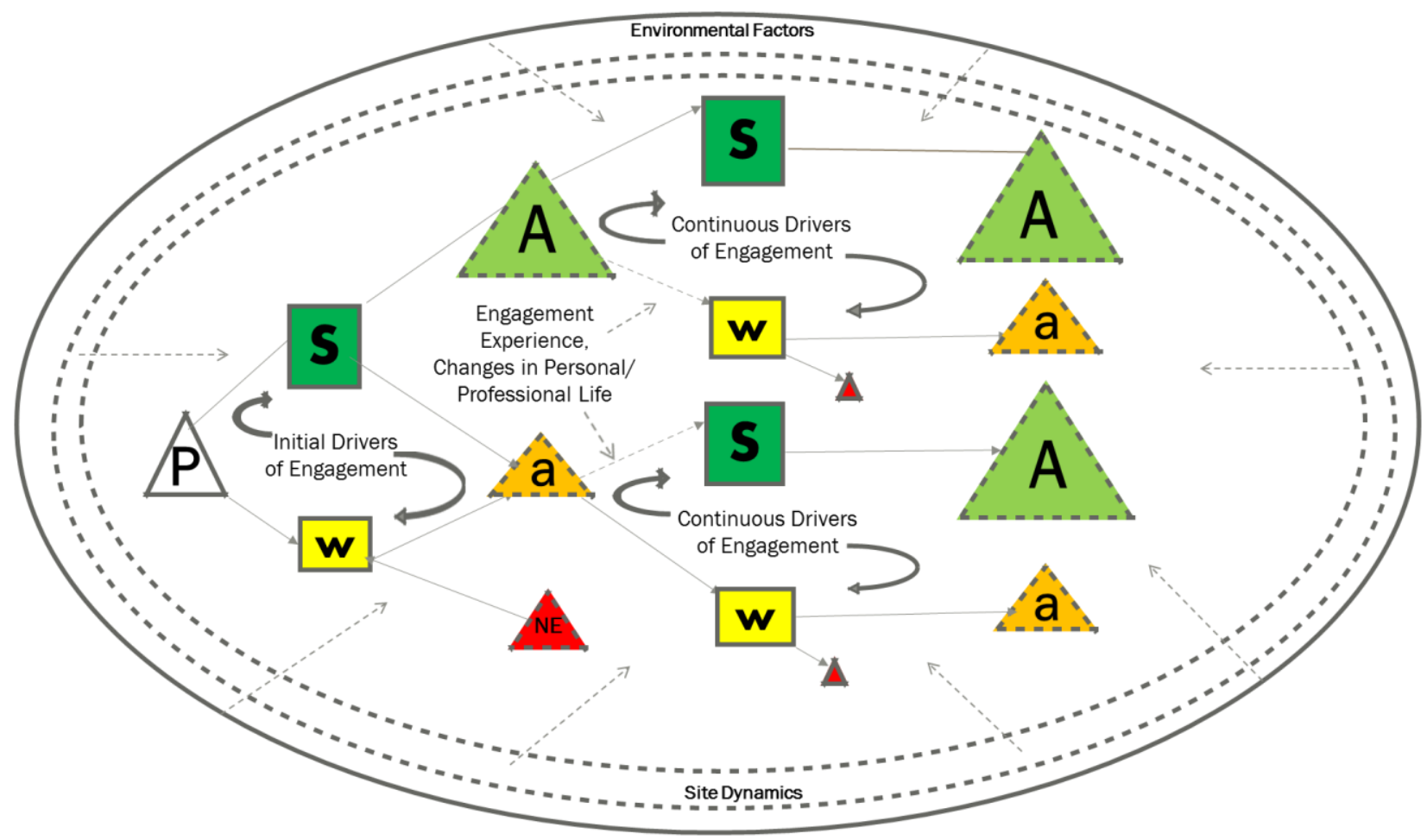

Figure 2. Presentation of Theory of Academic Men's Pathways to Significant \& Continuous Engagement

The theoretical relationships identified between the emergent analytic categories of data discussed in the findings, lead to the proposition of a Theory of Academic Men's Pathways to Significant Continuous Engagement. This substantive grounded theory underscores the process which drives academic men to initially engage in gender equity work and proposes, based on the analysis of data collected from academic men presently engaged in this work, the factors likely to drive their continuous engagement.

\section{Explanation of the Theoretical Model}

The core process depicted in the theoretical model is encompassed by layered concentric circles. Moving from the inside outward, the first circle represents the immediate or personal 
context within which a decision to engage unfolds. The dashed lines illustrate the permeability of this personal context by site dynamics (second layer) — examples from study findings include: institutional disposition toward the sharing of data, a new research-focused mission, degree of institutional support for A \& A, and negative perceptions of the effectiveness of the pre-existing ADVANCE initiative; as well as environmental factors (third layer) — an example from study findings is the perception of a social climate hostile to diversity and equity work post-Election 2016. Faint dashed arrows illustrate the way these elements may penetrate the core process central to the model.

Explanation of Symbols. Two symbols dominate the model: triangles represent a single academic man or professor, represented by a capital " $\mathrm{P}$ " at the starting point of the model at the far left of the diagram. Green triangles marked with a capital "A" represent a professor whose engagement significance is high. Within the context of the A \& A program, this professor would be an advocate. Orange triangles marked with a lowercase "a" represent a professor whose engagement significance is low. Within the context of the A \& A program, this professor would be an ally. Red triangles represent a professor with no engagement or "NE." Theoretically, this professor drops out of the model. Squares within the model represent the collective force of sets of drivers of engagement. Green squares marked with a capital "S" represent a set of drivers whose collective force is strong. Yellow squares marked with a lowercase "w" represent a set of drivers whose collective force is weak. Curved arrows indicate whether the collective force of a set of drivers is mostly strong or mostly weak.

Explanation of Key Relationships. It is proposed that when the collective force of initial drivers of engagement (depicted at the far-left side of the diagram) is mostly strong an unengaged "P" will likely pursue a path of high engagement significance. Within the context of A 
\& A, that would be exemplified by "P" becoming an "A." It is proposed that when the collective force of initial drivers is mostly weak an un-engaged "P" will likely pursue a path of low engagement significance exemplified by " $\mathrm{a}$ " (becoming an ally) within the context of A \& A, or no engagement represented by a red triangle " $\Delta$ ".

Once engaged, the model depicts the vulnerability of " $\mathrm{A}$ " and " $\mathrm{a}$ " to intervening factors such as the impact of the experience of engagement in gender equity work, changes in personal/professional life, site dynamics, and environmental factors which influence the force of proposed drivers of continuous engagement.

It is proposed that when the collective force of continuous drivers of engagement is mostly strong a presently engaged "A" will likely continue to engage with a high level of significance, whereas a presently engaged "a" may consider engaging at a higher level of significance, or choose to maintain their present lower-level of engagement. It is proposed that when the collective force of continuous drivers of engagement is mostly weak a presently engaged "A" will likely pursue a path of less significant engagement or disengage altogether, while a presently engaged "a" will either maintain their lower-level of engagement or disengage altogether.

Intervening Factors \& Alternate Pathways. The alternate pathways depicted in the model reflect the ways in which intervening factors such as the impact of the experience of engagement in gender equity work, changes in personal/professional life, site dynamics, and environmental factors can alter seemingly predictable outcomes. Within the micro or personal layer of the model, for example, an "A" whose proposed continuous drivers of engagement seem mostly strong could be in an academic department that has lost a full-time faculty member resulting in an increased teaching and advising load for " $\mathrm{A}$ " and consequently less time to 
maintain a high level of engagement in A \& A. In another example, an "a" may be asked by a dean to take on a greater role in A \& A given his prior involvement in social justice work and to ensure his tenure goals are not compromised the dean may affirm the weight potential research he may produce around the program will have in his promotion and tenure file. Moving outward, to the meso or site-dynamic layer of the model, factors like those discussed in chapter five may alter a seemingly predictable pathway. For example, “A,” an associate professor of engineering, may reconsider his intention to serve as coordinator of A \& A, given increased time demands related to new promotion requirements resulting from his institution's research-oriented mission-shift. In another example, "a," a tenure track faculty member may be feeling inspired to increase his involvement in social justice/equity initiatives despite perceived career risks to pushback against a political climate that seems increasingly hostile toward diversity initiatives.

The Continuous Nature of the Model. A critical feature of the model is its continuity. Theoretically, unless the opportunity to engage ceases to exist or an academic is no longer capable of engagement, the decision cycle recurs. This quality captures the reality faced by academics engaged in what may be described as nonessential or volunteer service activities. At various point in an academic calendar - e.g. the beginning or end of a semester — academics are likely to assess the viability of their continued engagement in activities that may not be an explicit part of their job description. Thus, it is interesting, that findings from this study revealed that most of the men faculty who also serve as academic leaders perceive their gender equity work as part of their formal role. This suggests that within the context of this study, academic leaders are likely to continually engage in gender equity work for at least as long as they hold their leadership positions. 
The Complexity of the Model. It is also important to note that while the model, on face value, seems to simplify a process that leads to continuous engagement, each case within a given context is complex. In fact, the collective force of a given set of initial or continuous drivers would be expected to vary significantly from one case to the next. That is, in theory, each driver whether initial or continuous has its own degree of force based on the individual. The collective force reflects the sum of each of the driving forces. Ideally, the sum of the collective force would strongly indicate the pathway an individual would follow, however, it is more likely that there would be degrees of ambiguity related to which pathway an individual will follow. Ensuring this complexity are the intervening factors previously discussed. In a study of sociological phenomena, it is impossible to account for all the factors that may affect expected outcomes. And, the goal of this grounded theory study was not to proffer a predictive model reflecting objective facts, but to depict a model that reflects the phenomenon of men faculty engagement in gender equity work as it was described and interpreted through interactions between the participants and the researcher. Thus, the Theory of Academic Men's Pathways to Significant, Continuous Engagement is useful in that it proposes an empirically-theorized process of significant, continuous engagement, while signaling the varying possibilities that may obstruct it.

\section{Conclusions}

Engaging powerful stakeholders in efforts to promote institutional diversity is a critical strategy that should be thoughtfully considered. While women and other marginalized persons often lead gender and other equity and inclusion seeking initiatives in academia, accomplishing these objectives requires not only the initial, but the continuous engagement of powerful stakeholders, like academic men, who can not only influence equity and inclusion promoting policies and practices, but also other powerful men who may join in this important effort. 
Findings from this study of the nearly unexamined phenomenon of men faculty engagement in gender equity work contribute empirical knowledge to extant research of interest to higher education scholars who focus on social justice change strategies at multiple levels of the academic organization, gender studies scholars interested in how men support equity initiatives in varying contexts, and data-driven practitioners interested in the implementation and sustainability of social justice change strategies.

\section{Future Directions for Research}

Although there was diversity in terms of the degree and type of engagement among men faculty study participants, the voices of men faculty described as allies within the context of the A \& A program are mostly absent from this analysis. What is important about this fact, upon reflection, is the sort of immateriality of allies that I consistently noted as I gathered and analyzed data. The "ally" designation within the context of the Men Faculty A \& A program represents a lower category of involvement in the larger program and arguably for good reasonthese are men who are mostly tenure-track faculty whose primary focus should be attaining tenure. However, I observed and adapted a way of thinking about allies that infused the discourse around the A \& A initiative. That way of thinking is that within A \& A, allies don't really do anything. It is a nominal category. Examples from the data reinforce this sentiment. Following unpleasant experiences as an advocate, P20 requests to be "demoted to ally." During our interview, P24, remarks with wonder, "We just attended this one training. They asked us to sign this certificate—and, we were allies!" In an earlier excerpt P28 describes the futility of bringing allies together only once a year if the goal is to effect meaningful change. The issue problematized here is the weakening of the conceptualization of "allies" in the minds of men faculty who are new to social justice work and the potential implications beyond the A \& A 
program. As P19 cautioned at the end of our interview, "Just remember that while this is your area of expertise, for most of us, this is Diversity 101." Given the powerful connotations of the terms "ally" or "allies" within social justice discourse, it is almost offensive to promulgate a notion of allies as individuals who are inconsequential within a given social justice/equity movement. And, if a desired outcome of heightening men's awareness of social inequities is that they will develop an increased commitment to equity-related causes, it is short-sighted to think that their social justice engagement would be limited to their engagement in a singular program. Therefore, future research should focus on this peculiar dynamic within the A \& A program. How do men who are allies think about their engagement in gender equity work? What does the designation "ally" mean to them? How does this aspect of the program model promote sustainability? In addition to these questions, future research should include a follow up with participants in this study a year or two from now. Will these study participants still be engaged in the program? Will there be evidence that the proposed drivers of continuous engagement were accurate? Will former allies from the selected sites now be tenured advocates? What about this issue of openly wearing an advocate or ally label? Has it dissipated? Or has the climate shifted in such a way that even more men allies seem to be driven into the closet? Future research might also investigate the voices of men faculty who opt-out of engagement in initiatives like A \& A. What drives their decisions? Within the context of STEM, where there are populations of influential men faculty from countries less advanced than our own regarding issues of gender equity are there surmountable cultural barriers that may transform stalwarts into engaged advocates? If the answer is, no, how is it proposed that gender equity goals will be attained in every area of STEM? Finally, future research should explore the way in which A \& A serves as a mechanism for organizational learning and sense-making about matters of social justice. It is not 
insignificant that most men in this study_-scientists and engineers - talked about how much they learned about implicit bias, privileged identities, and structural discrimination. This type of learning has important implications for the fields these men represent, their institutions, departments, and classrooms. 


\section{References}

Acker, J. (1990). Hierarchies, jobs, bodies: A theory of gendered organizations. Gender and Society, 4, 139-158. doi:10.1177/089124390004002002

Acker, J. (2012). Gendered organizations and intersectionality: Problems and possibilities. Equality, Diversity and Inclusion, 31, 214-224. doi:10.1108/02610151211209072

ADVANCE: Increasing the participation and advancement of women in academic science and engineering careers (ADVANCE). (n.d.). Retrieved December 14, 2015, from National Science Foundation: http://www.nsf.gov/funding/pgm_summ.jsp?pims_id=5383

Altheide, D. L., \& Gilmore, R. P. (1972). The credibility of protest. American Sociological Review, 37, 99-108. doi:10.2307/2093497

Anicha, C. L., Burnett, A., \& Bilen-Green, C. (2015). Men faculty gender equity advocates: A qualitative analysis of theory and praxis. Journal of Men's Studies, 23, 21-43. doi: $10.1177 / 1060826514561974$

Astin, A. W. (1993). Assessment for excellence: The philosophy and practice of assessment and evaluation in higher education. New York, NY: American Council on Education and Macmillan.

Baber, A. (1992). Naked at the gender gap: A man's view of the war between the sexes. New York, NY: Birch Lane Press.

Bailyn, L. (2003). Academic careers and gender equity: Lessons learned from MIT. Gender, Work and Organization, 10, 137-153. doi:10.1111/1468-0432.00008

Bateman, T. S., \& Organ, D. W. (1983). Job satisfaction and the good soldier: The relationship between affect and employee "citizenship". Academy of Management Journal, 26, 587595. doi: $10.2307 / 255908$ 
Beck, C. T. (1996). Grounded theory: Overview aand application in pediatric nursing. Issues in Comprehensive Pediatric Nursing, 19, 1-15. doi:10.3109/01460869609026851

Bellas, M., \& Toutkoushian, R. (1999). Faculty time allocations and research productivity: Gender, race and family effects. Review of Higher Education, 22, 367. doi:10.1353/rhe.1999.014

Berdahl, J. L. (2007). Harassment based on sex: Protecting social status in the context of gender hierarchy. Academy of Management Review, 32, 641-658. doi:10.5465/AMR.2007.24351879

Berkowitz, A. D. (2002). Fostering men's responsibility fo preventing sexual assault. In A. Schewe (Ed.), Preventing violence in relationships: Interventions across the lifespan (pp. 163-196). Washington, DC: American Psychological Association.

Bess, J. L., \& Dee, J. R. . (2012). Understanding college and university organization: Theories for effective policy and practice. Sterling, VA: Stylus.

Bilen-Green, C., Green, R. A., McGeorge, C., Anicha, C. L., \& Burnett, A. (2013). Engaging male faculty in institutional transformation. ASEE Annual Conference \& Exposition, 111. Atlanta, GA: ASEE.

Birk, T. (2014). Critical Cosmopolitan Teaching and Learning: A New Answer to the Global Imperative. Retrieved March 3, 2016, from Association of American Colleges \& Universities: https://www.aacu.org/diversitydemocracy/2014/spring/birk

Bishop, A. (2002). Becoming an ally: Breaking the cycle of oppression in people. Halifax, Nova Scotia, Canada: Fernwood.

Blackburn, R. T., \& Lawrence, J. H. (1995). Faculty at work: Motivation, expectation, satisfaction. Baltimore, MD: The Johns Hopkins University Press. 
Blickenstaff, J. C. (2005). Women and science careers: Leaky pipeline or gender filter? Gender and Education, 17, 369-386. doi:10.1080/09540250500145072

Bolman, L. G., \& Gallos, J. V. . (2011). Reframing academic leadership. San Francisco, CA: Jossey-Bass.

Bong, S. A. (2002). Debunking myths in qualitative data analysis. Forum: Qualitative social research, 3. Retrieved April 27, 2016, from http://www.qualitativeresearch.net/index.php/fqs/article/view/849/1845

Boulding, K. (2014). Towards a theory of protest. ETC: A review of general semantics, 71, 165172.

Boyer, E. (1990). Scholarship reconsidered: Priorities of the professoriate. Princeton, NJ: The Carnegie Foundation for the Advancement of Teaching.

Boyer, E. (1996). The scholarship of engagement. Journal of Public Service \& Outreach, 1, 1120.

Brannon, R., \& David, D. (1976). The forty-nine percent majority: The male sex role. Reading, MA: Addison-Wesley.

The Charlotte Observer (2015). Bree Newsome, James Tyson talk about SC Confederate flag grab. (2015, July 6). The Charlotte Observer. Charlotte, NC, USA. Retrieved November 18, 2015, from www.charlotteobserver.com/news/local/article26578984.html

Brescoll, V. L., Uhlmann, E. L., Moss-Racusin, C. A., \& Sarnell, L. (2012). Masculinity, status and subordination: Why working for a stereotype violator causes men to lose status. Journal of Experimental Social Psychology, 48, 354-357. doi: $10.1177 / 1368430212461160$ 
Brief, A. P., \& Motowidlo, S. J. (1986). Prosocial organizational behaviors. Academy of Management Review, 11, 710-725. doi:10.2307/258391

Britton, D. M. (2000). The epistemology of the gendered organization. Gender and Society, 14, 418-434. doi:10.1177/089124300014003004

Broido, E. M. (2000). The development of social justice allies during college: A phenomenological investigation. Jouranal of College Student Development, 41, 3-18.

Broido, E. M., \& Reason, R. D. (2005). The development of social justice attitudes and actions: An overview of current understandings. New Directions for Student Services, 17-28. doi:10.1002/ss. 162

Burke, R. J., \& Black, S. (1997). Save the males: Backlash in organizations. Journal of Business Ethics, 16, 933-942. doi:10.1023/A:1017991421416

Burn, S. M., \& Ward, Z. A. (2005). Men's conformity to traditional masculinity and relationship satisfaction. Psychology of Men and Masculinity, 6, 254-263. doi:10.1037/15249220.6 .4 .254

Burnett, A., Bilen-Green, C., McGeorge, C. R., \& Anicha, C. L. (2012). Examining the complexities of faculty attrition: An analysis of STEM and non-STEM faculty who remain and faculty who leave the institution. Journal of Women and Minorities in Science and Engineering, 18, 1-19. doi:10.1615/JWomenMinorScienEng.2012003100

Buttner, E. H., Lowe, K. B., \& Billings-Harris, L. (2006). The influence of organizational diversity orientation and leader attitudes on diversity activities. Journal of Managerial Issues, $18,356-371$.

Carlson, M. (2008). I'd rather go along and be considered a man: Masculinity and bystander intervention. journal of Men's Studies, 16, 3-17. doi:10.3149/jms.1601.3 
Carnegie Community Engagement Classification. (2015). Retrieved March 1, 2016, from New England Resource Center for Higher Education: A Resource Center at the College of Education and Human Development University of Massachusetts Boston: http://nerche.org/index.php?option=com_content\&view=article\&id=\&itemid=92

Carrigan, T., Connell, B., \& Lee, J. (1985). Toward a new sociology of masculinity. Theory and Society, 14, 551-604. doi:10.1007/BF00160017

Casey, E. A., \& Ohler, K. (2012). Being a positive bystander: Male antiviolence allies' experiences of "stepping up". Journal of Interpersonal Violence, 27, 62-83. doi: $10.1177 / 0886260511416479$

Catlett, B.S., Toews, M. L., \& Walilko, V. (2010). Men's gendered constructions of intimate partner violence as predictors of court-mandated batterer treatment drop-out. American Journal of Community Psychology, 45, 107-123. doi:10.1007/s10464-0099292-2

Charmaz, K. (2006). Constructing grounded theory: A practical guide through qualitative analysis. Thousands Oak, CA: Sage.

Checker, M. (2005). Polluted promises: Environmental racism and the search for justice in a southern town. New York, NY: New York University Press.

Checker, M. (2014). Anthropological superheroes and the consequences of activist ethnography. American Anthropologist, 116, 416-420. doi:10.1111/aman.12110

Cheng, C. (1996). Men and masculinities are not necessarily synonymous: Thoughts on organizational behavior and occupational sociology. In C. Cheng (Ed.), Masculinities in organizations (pp. xi-xix). Thousand Oaks, CA: Sage.

Chiovitti, R. F., \& Piran, N. (2003). Rigour and grounded theory research. Journal of Advanced Nursing, 44, 427-435. doi:10.1046/j.0309-2402.2003.02822.x 
Churchill, M. (2011). The sciences vs. humanities divide is false and ideologically driven. Chronicle of Higher Education. Retrieved August 5, 2016, from http://chronicle.com/blogs/old-new/the-sciences-vs-humanities-divide-is-false-andideoogically-driven/343

Coffey, A., \& Atkinson, P. (1996). Making sense of qualitative data: Complementary research strategies. Thousand Oaks, CA: Sage.

Coles, R., \& Scarnati, B. . (2015). Dynamics of faculty engagement in the movement for Democracy's Education at Northern Arizona University: Backgrounds, practices, and future horizons. Kettering Foundation Working [2015: 2].

Collins, D. E. (2005). The ivory tower and scholar activism. Academe, 91, 26-28. doi: $10.2307 / 40252830$

Collins, P. H. (2013). Toward a new vison: Race, class, and gender. In M. Adams, W. J. Blumenfeld, C. Castaneda, H. W. Hackman, M. L. Peters, \& X. Zuniga, Readings for diversity and social justice (pp. 606-611). New York, NY: Routledge.

Committee on maximizing the potential of women in academic science and engineering. (2007). National Academy of Sciences, National Academy of Engineering, and Institute of Medicine. Retrieved August 1, 2016, from http://www.nap.edu/catalog/11741.html Connell, R. (1987). Gender \& power. Stanford, CA: Stanford University Press.

Connor, D. J., \& Gabel, S. L. (2013). "Cripping" the curriculum through academic activism: Working toward increasing global exchanges to reframe (dis)ability and education. Equity \& Excellence in Education, 46, 100-118. doi:10.1080/10665684.2013.750186 
Coyne, I. (1997). Sampling in qualitative research: Purposeful and theoretical sampling; merging or clear boundaries? Journal of Advanced Nursing, 26, 623-630. doi:10.1046/j.13652648.1997.t01-25-00999.x

Coyne, I., \& Cowley, S. (2006). Using grounded theory to research parent participation. Journal of Research in Nursing, 11, 501-515. doi:10.1177/1744987106065831

Creswell, J. (1998). Qualitative inquiry and research design: Choosing among five traditions. Thousand Oaks, CA: Sage.

Croteau, D., Hoynes, W., \& Ryan, C. (Eds.). (2005). Rhyming hope and history: Activists, academics, and social movement scholarship (Vol. 24). University of Minnesota Press.

Crotty, M. (1998). The foundations of social research: Meaning and perspective in the research process. Thousand Oaks, CA: Sage.

Crowfoot, J., \& Chesler, M. (2003). "White men's roles in multicultural coalitions". In M. S. Kimmel, \& A. L. Ferber (Eds.), Privilege: A reader (pp. 349-380). Boulder, CO: Westview Press.

Czopp, A. M., Monteith, M. J., \& Mark, A. Y. (2006). Standing up for a change: Reducing bias through interpersonal confrontation. Journal of Personality and Social Psychology, 90, 784-803. doi:10.1037/0022-3514.90.5.784

Darlington, Y., \& Scott, D. . (2002). Qualitative research in practice: Stories from the field. Buckingham: Open University Press.

Davis, D.-A. (2014). What is a feminist activist ethnographer to do? American Anthropologist, 116, 413-415. doi:10.1111/aman.12110

Davis, T. L. (2002). Voices of gender role conflict: The social construction of college men's identity. Journal of College Student Development, 43, 508-521. 
Davis, T. L., \& Wagner, R. (2005). Increasing men's development of social justice attitudes and actions. New Directions for Student Services, 29-41. doi:10.1002/ss.163

Demb, A., \& Wade, A. (2012). Reality check: Faculty involvement in outreach \& engagement. The Journal of Higher Education, 83, 337-366. doi:10.1353/jhe.2012.0019

Dempsey, S. E., \& Barge, J. K. (2014). Engaged scholarship and democracy. In L. L. Putnam, \& D. K. Mumby (Eds.), The SAGE handbook of organizational communication: Advances in theory, research, and methods (pp. 665-688). Thousand Oaks, CA: Sage.

DeTurk, S. (2011). Allies in action: The communicative experiences of people who challenge social justice on behalf of others. Communication Quarterly, 59, 569-590. doi:10.1080/01463373.2011.614209

Dey, I. (1999). Grounding grounded theory. San Diego, CA: Academic Press.

DiMaggio, P. (1988). Interest and agency in institutional theory. In L. Zucker (Ed.), Institutional patterns and organizations: Culture and environment (pp. 3-21). Cambridge, MA: Ballinger.

Dozier, J. B., \& Miceli, M. P. (1985). Potential predictors of whistle-blowing: A prosocial behavioral perspective. Academy of Management Journal, 10, 823-836.

Drury, B. J. (2013). Confronting for the greater good: Are confrontations that address the broad benefits of prejudice reduction taken seriously? Doctoral Dissertation. Seattle, WA: University of Washington. Unpublished.

Drury, B. J., \& Kaiser, C. R. (2014). Allies against sexism: The role of men in confronting sexism. Journal of social issues, 70, 637-652. doi:10.1111/josi.12083 
Duehren, A. M. (2015, December 11). Law school faculty and staff commend student activism. The Harvard Crimson. Retrieved February 10, 2016, from http://www.thecrimson.com/article/2015/12/11/law-school-staff-activism/

Duhigg, J. M., Rostosky, S. S., Gray, B. E., \& Wimsatt, M. K. (2010). Development of heterosexuals into sexual-minority allies: A qualitative exploration. Sexuality Research and Social Policy, 7, 2-14. doi:10.1007/s13178-010-0005-2

Dunne, C. (2011). The place of the literature review in grounded theory research. International Journal of Social Research Methodology, 14, 111-124. doi:10.1080/13645579.2010.494930

Edwards, K. E. (2006). Aspiring social justice ally identity development: A conceptual model. NASPA Journal, 43, 39-60.

Eliezer, D., \& Major, B. (2012). It's not your fault: The social costs of claiming discriminationon behalf of someone else. Group Processes and Intergroup Relations, 15, 487-502. doi: $10.1177 / 1368430211432894$

Ely, R. J., \& Meyerson, D. E. (2000). Theories of gender in organizations: A new approach to organizational analysis and change. Research in Organizational Behaviour, 22, 103-151. doi:10.1016/50191-3085(00)22004-2

Ely, R. J., \& Meyerson, D. E. (2010). An organizational approach to undoing gender: The unlikely case of offshore oil platforms. Research in Organizational Behavior, 30, 3-34. doi:10.1016/j.riob.2010.09.002

Fabiano, P. M., Perkins, H. W., Berkowitz, A., Linkenbach, J., \& Stark, C. (2003). Engaging men as social justice allies in ending violence against women: Evidence for a social norms 
approach. Journal of American College Health, 52, 112.

doi: $10.1080 / 07448480309595732$

Fairweather, J. S. (1993). The nature of tradeoffs. Change, 25, 44-49.

doi:10.1080/00091383.1993.9939889

Fairweather, J. S. (1997). The relative value of teaching and research. In T. N. (Ed.), The NEA 1997 Almanac of Higher Education (pp. 44-62). Washington, DC: National Education Association.

Fairweather, J. S. (2002). The mythologies of faculty productivity: Implications for institutional policy and decision making. The Journal of Higher Education, 73, $26-48$. doi:10.1353/jhe. 2002.0005

Fairweather, J. S. (2005). Beyond the rhetoric: Trends in the relative value of teaching and research in faculty salaries. The Journal of Higher Education, 76, 401-422. doi:10.1353/jhe.2005.0027

Fairweather, J. S., \& Beach, A. L. (2002). Variations in faculty work at research universities: Implications for state and institutional policy. The Review of Higher Education, 26, 97115. doi: $10.1353 /$ rhe. 2002.0024

Farrell, W. (1993). The myth of male power. New York, NY: Simon \& Schuster.

Ferguson, K. E. (1984). The feminist case against bureaucracy. Philadelphia, PA: Temple University Press.

Few, A. L., Piercy, F. P., \& Stremmel, A. (2007). Balancing the passion for activism with the demands of tenure: One professional's story from three perspectives. NWSA Journal, 19, 47-66. 
Flood, M. (2005). Men's collective struggles for gender justice: The case of antiviolence activism. In M. S. Kimmel, J. Hearn, \& R. W. Connell, Handbook of Studies on Men \& Masculinities. Thousand Oaks, CA: Sage.

Flood, M., Martin, B., \& Dreher, T. (2013). Combining academia and activism: Common obstacles and useful tools. Australian Universities Review, 55, 17-26.

Foucault, M. (1991). Questions of method. In G. Burchell, C. Gordon \& P. Miller (Eds.), The Foucault effect: Studies in governmentality (pp. 87-104). Chicago, IL: The University of Chicago Press.

Freire, P. (1993). Pedagogy of the oppressed (30th anniversary edition). New York, NY: Bloomsbury Publishing Inc.

Frizell, S. (2015, November 9). University of Missouri faculty stages walkout as racism protests widen. TIME. Retrieved March 7, 2016, from http://time.com/4104562/missouri-mizzoufaculty-walkout-racism/

Gappa, J. M., Austin, A. E., \& Trice, A. G. (2007). Rethinking faculty work: Higher education's strategic imperative. San Francisco, CA: Jossey-Bass.

George, J. M. (1990). Personality, affect, and behavior in groups. Journal of Applied Psychology, 75, 107-116. doi:10.1037/0021-9010.75.2.107

George, J. M. (1991). State of trait: Effects of positive mood on prosocial behaviors at work. Journal of Applied Psychology, 76, 299-307. doi:10.1037/0021-9010-76.2.299

Gibson, R., \& Hartman, J. . (2014). Rediscovering grounded theory. London: Sage Publications. Giles, T., King, L., deLacey, S. (2013). The timining of the literature review in grounded theory research: An open mind versus an empty head. Advances in Nursing Science, 36, E29E40. doi:10.1097/ANS.0b013e3182902035 
Giroux, H. (2010, October 17). Lessons from Paulo Freire. Chronicle of Higher Education, 57(9). Retrieved February 3, 2016, from http://chronicle.com/articles/Lessons-FromPaulo-Freire/124910

Glaser, B. G. (1998). Doing grounded theory: Issues and discussions. Mill Valley, CA: Sociology Press.

Glaser, B. G., \& Holton, J. (2004). Remodeling grounded theory. Forum: Qualitative Social Research, 5. Retrieved July 3, 2016 from http://www.qualitative-research.net/fqs-texte/2-04glaser-e.htm

Glaser, B. G., \& Strauss, A. L. (1967). The discovery of grounded theory. Chicago, IL: Aldine. Gobo, G. (2004). Sampling, representativeness and generalizability. In C. Seale, G. Gobo, J. F. Gubrium, \& D. Silverman (Eds.), Qualitative research practice (pp. 435-456). London: Sage.

Goff, K. (2016). How the women of the Obama White House fought gender inequality-and we can too. The Daily Beast. Retrieved March 3, 2017 from http://www.thedailybeast.com/articles/2016/09/23/how-the-women-of-the-obama-whitehouse-fought-gender-inequality-and-we-can-too.html

Goodman, D. J. (2011). Promoting diversity and social justice. Florence, SC: Routledge.

Graham, J. W. (1983). Principled organizational dissent. Unpublished doctoral dissertation, Northwestern University, Evanston, IL.

Graham, J. W. (1986). Principled organizational dissent: A theoretical essay. In B. M. Staw, \& L. L. Cummings, Research in organizational behavior (Vol. 8, pp. 1-52). Greenwich, CT: JAI Press. 
Guckenheimer, D. (2009). Insider activism: Faculty as institutional change agents (Order No. 3379971). University of California, Santa Barbara. Ann Arbor: ProQuest LLC.

Hackman, H. W. (2013). Sexism: Introduction. In M. Adams, W. J. Blumenfeld, C. Castaneda, H. W. Hackman, M. L. Peters, \& X. Zuniga, Readings for diversity and social justice (pp. 317-323). New York, NY: Routledge.

Hallberg, L.-M. (2010). Some thoughts about the literature review in grounded theory studies. International Journal of Qualitative Studies on Health and Well-being, 5, 1. doi:10.3402/qhw.v5i3.5387

Hardiman, R., Jackson, B. W., \& Griffin, P. (2013). Conceptual foundations. In C. Castaneda, M. Adams, W. J. Blumenfeld, H. W. Hackman, M. L. Peters, \& X. Zuniga, Readings for diversity and social jusitice (pp. 26-35). New York, N. Y.: Routledge.

Hart, J. (2008). Mobilization among women academics: The interplay between feminism and professionalization. NWSA Journal, 20, 184-208.

Hartley, M. (2009). Leading grassroots change in the academy: Strategic and ideological adaptation in the civic engagement movement. Journal of Change Management, 9, 323338. doi:10.1080/14697010903125571

Heath, H., \& Cowley, S. (2004). Developing a grounded theory approach: A comparison of Glaser and Strauss. International Jouranl of Nursing Studies, 41, 141-150. doi:10.1016/S0020-7489(03)001135

Heilman, M. E., \& Wallen, A. S. (2010). Wimpy and undeserving of respect: Penalties for men's gender-inconsistent success. Journal of Experimental Social Psychology, 46, 664-667. doi:10.1016/j.jesp.2010.01.008 
Henwood, K., \& Pidgeon, N. (2006). Grounded theory. In G. M. Breakwell, S. Hammond, C. Fife-Shaw, \& J. A. Smith, Research methods in psychology. 3 rd edition (pp. 342-365). Thousand Oaks, CA: Sage.

Hillard, A. L., Schneider, T. R., Jackson, S. M., \& LaHuis, D. (2014). Critical mass or incremental change? The effects of faculty gender composition in STEM. Gender Transformation in the Academy, 19, 355-374. doi:10.1108/S1529-212620140000019016

Holmes, M. A. (2014). Advancing women in oceanography: How NSF's ADVANCE program promotes gender equity in academia. Oceanography, 27, 30-38. doi:10.5670/oceanog.2014.112

Hong, L. (2000). Toward a transformed approach to prevention: Breaking the link between masculinity and violence. Journal of American College Health, 48, 269=279. doi: $10.1080 / 07448480009596268$

hooks, b. (1994). Teaching to transgress: Education as the practice of freedom. New York, NY: Routledge.

hooks, b. (2004). The will to change: Men, masculinity, and love. New York, NY: Washington Square Press.

Houston, D., Meyer, L. H., \& Paewais, S. (2006). Academic staff workloads and job satisfaction: Expectations and values in academe. Journal of Higher Education, 28, 17-30.

Hytten, K., \& Warren, J. (2003). Engaging whiteness: How racial power gets reified in education. International Journal of Qualitative Studies, 16, 65-89. doi:10.1080/0951839032000033509a 
Jeon, Y.-H. (2004). The application of grounded theory and symbolic interactionism. Scandinavian Journal of Caring Science, 18, 249-256. doi:10.1111/j.14716712.2004.00287.x

Jepperson, R. L. (1991). Institutions, institutional effects, and institutionalism. In W. W. Powell, \& P. J. DiMaggio (Eds.), The new instiutionalism in organizational analysis (pp. 143163). Chicago, IL: University of Chicago Press.

Johnson, A. G. (1997/2005). The gender knot: Unraveling our patriarchal legacy. Philadelphia, PA: Temple University Press.

Johnson, A. G. (2006). Privilege, power, and difference. New York, NY: McGraw Hill.

Johnson, A. G. (2013a). Patriarchy, the system: An it, not a he, a them, or an us. In M. Adams, W. J. Blumenfeld, C. Castaneda, H. W. Hackman, M. L. Peters, \& X. Zuniga, Readings for diversity and social justice (pp. 334-339). New York, NY: Routledge.

Johnson, A. G. (2013b). The social construction of difference. In M. Adams, W. J. Blumenfeld, C. Castaneda, H. W. Hackman, M. L. Peters, \& X. Zuniga, Readings for diversity and social justice (pp. 15-21). New York, NY: Routledge.

Johnson, A. G. (2013c). What can we do? In M. Adams, W. J. Blumenfeld, C. Castaneda, H. W. Hackman, M. L. Peters, \& X. Zuniga, Readings for diversiy and social justice (pp. $612-$ 618). New York, NY: Routledge.

Johnson, S. (2013, July 11-17). CUNY faculty protest hiring of David Petraeus. The New York Amsterdam News, p. 10.

Jones, S. R., \& McEwen, M. K. (2000). A conceptual model of multiple dimensions of identity. Journal of College Student Development, 41, 405-413. 
June, A. W. (2015). When activism is worth the risk. Chronicle of Higher Education, 61(41), pp. A18-A21.

Kalev, A., Dobbin, F., \& Kelly, E. (2006). Best practices or best guesses? Assessing the efficacy of corporate affirmative action and diversity policies. American Sociological Review, 71, 589-617. doi:10.1177/000312240607100404

Katz, D., \& Kahn, R. (1978). The social psychology of organizations (2nd edition). New York, NY: John Wiley \& Sons.

Kaufman, M. (1999). Men, feminism, and men's contradictory experiences of power. In J. A. Kuypers (Ed.), Men and power (pp. 59-83). Halifax, Nova Scotia: Fernwood Books.

Kearney, M. H. (1998). Focus on qualitative methods. Ready-to-wear: Discovery grounded formal theory. Research in Nursing \& Health, 21, 179-186. doi:10.1002/(SICI)1098240X(199804)21:2\%3C179::AID-NUR8\%3E3.3.CO;2-9

Kellogg Commission on the Future of State and Land-Grant Universities, \& National Association of State Universities and Land-Grant Colleges. (1999) Returning to our roots: The engaged institution. (1999). Retrieved December 4, 2015, from www.aplu.org/library/returning-to-our-roots-the-engaged-institution/file

Kezar, A. (2014). How colleges change: Understanding, leading, and enacting change. New York, N.Y. : Routledge.

Kezar, A., Lester, J., Carducci, R., Gallant, T. B., \& McGavin, M. C. (2007). Where are the faculty leaders? Liberal Education, 14-21.

Kimmel, M. S. (1994). Masculinity and homophobia: Fear, shame and silence in the construction of gender identity. In H. Brod, \& M. Kaufman (Eds.), Theorizing masculinities (pp. 119141). Thousand Oaks, CA: Sage. 
Kimmel, M. S. (2013). Masculinity as homophobia: Fear, shame, and silence in the construction of gender identity. In M. Adams, W. J. Blumenfeld, C. Castaneda, H. W. Hackman, M. L. Peters, \& X. Zuniga, Readings for diversity and social justice (pp. 329-334). New York, NY: Routledge.

Kirk, G., \& Okazawa-Rey, M. (2013). Identities and social locations: Who am I? Who are my people? In M. Adams, W. J. Blumenfeld, C. Castaneda, H. W. Hackman, M. L. Peters, \& X. Zuniga (Eds.), Readings for diversity and social justice (pp. 9-15). New York, NY: Routledge.

Kivel, P. (2002). Uprooting racism: How White people can work for racial justice. Gabriola, BC: New Society Publishers.

Kivel, P. (2007). Social service or social change. In INCITE! (Ed.), Women of color against violence (pp. 129-149). Cambridge, MA: South End Press.

Knight, S., Nunkoosing, K., Vrij, A., \& Cherryman, J. (2003). Using grounded theory to examine people's attitudes toward how animals are used. Society and Animals, 11, 307-327. doi:10.1163/156853003322796064

Kuecker, G. D. (2010). Academic activism and the socially just academy. In K. Skubikowski, C. Wright, \& R. (. Graf, Social justice education: Inviting faculty to transform their institutions (pp. 42-55). Sterling, VA: Stylus Publishing.

Kuntz, A. M. (2007). Placing academic activism: Constraints and possibilities of faculty work. University of Massachusetts Amherst. Ann Arbor: ProQuest Dissertations \& Theses Full Text (304847347). Retrieved December 15, 2015, from http://search.proquest.com/docview/304847347?accountid=2837 
Kvale, S. \& Brinkmann, S. (2009). Interviews: Learning the craft of qualitative research interviewing. Thousand Oaks, CA: Sage.

Laberge, S., \& Albert, M. (1999). Conceptions of masculinity and of gender transgressions in sport among adolescent boys. Men and Masculinities, 1, 243-267. doi:10.1177/1097184X99001003001

Landreman, C. J., Rasmussen, P. M., King, C. , Xinquan, J. (2007). A phenomenological study of the development of university educators' critical consciousness. Journal of College Student Development, 48, 275-296. doi:10.1353/csd.2007.0027

Latane, B., \& Darley, J. (1969). Bystander "apathy". American Scientist, 57, 244-268.

Latimer, M., Jackson, K., Dilks, L., Nolan, J., \& Tower, L. (2014). Using dialogical change to promote positiv departmental climates. Gender Transformation in the Academy Advances in Gender Research, 19, 333-353. doi:10.1108/51527-212620140000019015

Laube, H., Massoni, K., Sprague, J., \& Ferber, A. L. (2007). The impact of gender on the evaluation of teaching: What we know and what we can do. NWSA Journal, 19, 87-104.

Leathwood, C. (2005). Treat me as a human being--don't look at me as a woman: Femininities and professional identities in further education. Gender and Education, 17, 387-409. doi:10.1080/0950250500145221

Levant, R. F., \& Pollack, W. S. (1995). A new psychology of men. New York, NY: Basic Books.

Lewin, K. (1947). Frontiers in group dynamics: Concept, method and reality in social science; social equilibria and social change. Human Relations, 1, 5-41. doi:10.1177/001872674700100103

Locke, K. (2001). Grounded theory in management research. London: Sage. 
Lofland, J., \& Lofland, L. H. (1984). Analyzing social settings: A guide to qualitative observation and analysis (2nd ed.). Belmont, CA: Wadsworth.

London, M. (2010). Understanding social advocacy: An integrative model of motivation, strategy, and persistence in support of corporate social responsibility and social entrepreneurship. Journal of Management Development, 29, 224-245.

doi: $10.1108 / 02621711011025768$

Maher, F. A., \& Thompson Tetreault, M. K. (2007). Privilege and diversity in the academy. . New York, NY: Routledge.

Mamiseishvili, K., \& Rosser, V. J. (2011). Examining the relationship between faculty productivity and job satisfaction. The Journal of the Professoriate, 5, 100-132.

Manning, K. (2013). Organizational theory in higher education. New York, NY: Routledge.

Maranto, C. L., \& Griffin, A. E. C. (2011). The antecedents of a 'chilly climate' for women faculty in higher education. human relations, 64, 139-159. doi:10.1177/0018726710377932

Marshall, C., \& Rossman, G. (1999). Designing qualitative research (3rd ed.). Newbury Park, CA: Sage.

Mason, J. (1996). Qualitative researching. London: Sage.

Maxey, I. (1999). Beyond boundaries? Activism, academia, reflexivity and research. Area, 31, 199-208. doi:10.1111/j.1475-4762.1999.tb00084.x

Maxwell, J. A. (2013). Qualitative research design: An interactive approach (3rd ed.). Thousand Oaks, CA: Sage.

McCann, T., \& Clark, E. (2003). Grounded theory in nursing research: Part I-Methodology. Nurse Researcher, 11, 7-18. doi:10.7748/nr2004.01.11.2.7.c5918 
McClelland, S. I., \& Holland, K. J. (2014). You, me, or her: Leaders' perceptions of responsibility for increasing gender diversity in STEM departments. Psychology of Women Quarterly, 39, 210-225. doi:10.1177/0361684314537997

McCracken, G. (1988). The long interview: Qualitative research methods. Newbury Park, CA: Sage.

McGhee, G., Marland, G. R., \& Atkinson, J. (2007). Grounded theory research: Literature reviewing and reflexivity. Journal of Advanced Nursing, 60, 334-342. doi:10.1111/j.13652648.2007.04436.x

Messinger, L. (2011). A qualitative analysis of faculty advocacy on LGBT issues on campus. Journal of Homosexuality, 58, 1281-1305. doi:10.1080/00918369.2011. 605740

Meyer, D. S., \& Whittier, N. (1994). Social movement spillover. Social Problems, 41, 277-298. doi: $10.2307 / 3096934$

Meyerson, D. E., \& Scully, M. A. (1995). Tempered radicalism and the politics of ambivalence and change. Organization Science, 6, 585-600. doi:10.1287/orsc.6.5.585

Meyerson, D. E., \& Tompkins, M. (2007). Tempered radicals as institutional change agents: The case of advancing gender equity at the university of Michigan. Harvard Journal of Law and Gender, 30, 303-322.

Miles, M. B., \& Huberman, A. M. (1994). Qualitative data analysis: An expanded sourcebook. (2nd ed.). Thousand Oaks, CA: Sage.

Miles, M. B., Huberman, A. M., \& Saldana, J. (2014). Qualitative data analysis: A methods sourcebook (3rd ed.). Thousand Oaks, CA: Sage.

Mills, C. W. (1956). The power elite. New York, NY: Oxford University Press, Inc. 
MIT. (1999). A study on the status of women faculty in science at MIT. Massachussetts Institute of Technology. Retrieved March 26, 2016, from web.mit.edu/fnl/women/women/.pdf

Morahan, P. S., Rosen, S. E., Richman, R. C., \& Gleason, K. A. (2011). The leadership continuum: A framework for organizational and individual assessment relative to the advancement of women physicians and scientists. Journal of Women's Health, 20, 387396. doi:10.1089/jwh.2010.2055

Moss-Racusin, C. A. (2014). Male backlash: Penalties for men who violate gender stereotypes. In R. J. Burke, \& D. A. Major (Eds.), Gender in Organizations (pp. 247-269). Cheltenham, GBR: Edward Elgar Publishing.

Moss-Racusin, C. A., Phelan, J. E., \& Rudman, L. A. (2010). When men break the gender rules: Status incongruity and backlash against modest men. Psychology of Men and Masculinity, 11, 140-151. doi:10.1037/a0018093

Munin, A., \& Speight, S.L. (2010). Factors influencing the ally development of college students. Excellence in Education, 43, 249-264. doi:10.1080/10665681003704337

Murphy, C. F. (1995). Beyond feminism: Toward a dialogue on difference. Washington, DC: The Catholic University of America Press.

National Center for Science and Engineering Statistics, D. f. (2015). Women, minorities, and persons with disabilities in science and engineering. Washington, D.C.: National Science Foundation.

Near, J. P., \& Miceli, M. P. (1987). Whistle-blowers in organizations: Dissidents or reformers? In L. L. Cummings, \& B. M. Staw, Research in organiztional behavior (Vol. 9, pp. 321368). Greenwich, CT: JAI Press. 
Neel, A. (2014, September 16). Princeton is the final ivy leaguer to lower burden of proof for sexual assault. The Washingon Post. Retrieved December 4, 2015, from https://www.washingtonpost.com/blogs/she-the-people/wp/2014/09/16/princeton-is-thefinal-ivy-leaguer-to-lower-burden-of-proof-for-sexual-assault/

Neely, R. (2013). Promises made. In M. Adams, W. J. Blumenfeld, C. Castaneda, H. W. Hackman, M. L. Peters, \& X. Zuniga, Readings for diversity and social justice (pp. 356358). New York, NY: Routledge.

New, J. (2013). Academics honor open-access activist who committed suicide. Chronicle of Higher Education, 59(20), p. A7.

Nolan, J., Jackson, J. K., Latimer, M., Tower, L., \& Borres, A. (2012). A dialogical change process for strategic planning to diversity academic departments. Retrieved March 3, 2015, from http://ocs.sfu.ca/wepan/index.php/wepan2012/wepan2012/paper/view/331

O'Reilly, C., \& Chatman, J. (1986). Organiztional commitment and psychological attachment: The effects of compliance, identification, and internalization on prosocial behavior. Journal of Applied Psychology, 71, 492-499. doi:10.1037/0021-9010-71.3.492

Organ, D. W. (1988). Organizational citizenship behavior: The good soldier syndrome. Lexington, MA: Lexington Books.

Organ, D. W. (1990). The motivational basis of organizational citizenship behavior. In B. M. Staw, \& L. L. Cummings, Research in organizational behavior (Vol. 12, pp. 43-72). Greenwich, CT: JAI Press.

Orona, C. J. (2002). Temporality and identity loss due to Alzheimer's disease. In A. M. Huberman, \& B. M. Miles (Eds.), The qualitative researcher's companion (pp. 367-392). Thousand Oaks, CA: Sage. 
Owen, D. S. (2009). Privileged social identities and diversity leadership in higher education. The Review of Higher Education, 32, 185-207. doi:10.1353/rhe.0.0048

Owney, C. S. (2010). Moments of realization: The experiences, development, motivations, and actions of student social justice allies. Ann Arbor, MI: ProQuest LLC.

Park, S. M. (1996). Research, teaching, and service: Why shouldn't women's work count. Journal of Higher Education, 67, 46-84.

Parrott, D. J., \& Zeichner, A. (2003). Effects of hypermasculinity on physical aggression against women. Psychology of Men and Masculinity, 4, 70-78. doi:10.1037/1524-9220.4.1.70

Parsons, E., \& Priola, V. (2013). Agents for change and changed agents: The micro-politics of change and feminism in the academy. Gender, Work and Organization, 20, 580-598. doi:10.1111/j.1468-0432.2012.00605.x

Patton, L. D., \& Bondi, S. (2015). Nice white men or social justice allies? Using critical race tehory to examine how white male faculty and administrators engage in ally work. Race, Ethnicity and Education, 18, 488-514. doi:10.1080/13613324.2014.1000289

Patton, M. Q. (1990). Qualitative evaluation and research methods. (2nd ed.). Newbury Park, CA: Sage.

Patton, M. Q. (2002). Qualitative research \& evaluation methods. (3rd ed.). Thousand Oaks, CA: Sage.

Paye, A. (2013, September 5-11). War college: Students, faculty protest militarization of CUNY. The New York Amsterdam News, pp. 33, 47.

Picower, B. (2015). Tools of inaction: The impasse between teaching social issues and creating social change. Teachers and Teaching: Theory and Practice, 21, 908-922. doi:10.1080/13540602.2014.995488 
Pollack, W. S. (1999). Real boys. New York, NY: Henry Holt andCompany.

Porter, S. R., \& Umbach, P. D. (2001). Analyzing faculty workload data using multilevel modeling. Research in Higher Education, 42, 171-196. doi:10.1023/A:1017579415737

Pratt, T. (2014, February 3). Faculty protest reforms they say "Dumb Down" higher education. Community College Week, p. 8. Retrieved March 2, 2016, from http://hechingerreport.org/faculty-protest-reforms-they-say-dumb-down-higher-ed-2/

Prime, J., \& Moss-Racusin, C. A. (2009). Engaging men in gender initiatives: What change agents need to know. Catalyst. Retrieved November 11, 2015 from http://www.catalyst.org/knowledge/engaging-men-gender-initiatives-what-chang-agentsneed-to-know

Prime, J., Moss-Racusin, C. A., \& Foust-Cummings, H. (2009). Engaging men in gender initiatives: Stacking the desk for success. Retrieved November 11, 2015 from http://www.catalyst.org/knowledge/engaging-men-in-gender-initiatives-stacking-thedeck-for-success

Priola, V. (2007). Being female doing gender: Narratives of women in education management. Gender and Education, 19, 21-40. doi:10.1080/09540250601087728

Rapley, T. (2004). Interviews. In C. Seale, G. Gobo, J. F. Gubrium, \& D. Silverman (Eds.), Qualitative research practice (pp. 15-33). London: Sage.

Rasinski, H. M., \& Czopp, A. M. (2010). The effect of target status on witnesses' reactions to confrontations of bias. Basic and Applied Social Psychology, 32, 8-16. doi:10.1080/01973530903539754 
Reason, R. D., \& Broido, E. M. (2005). Issues and strategies for social justice allies (and the student affairs professionals who hope to encourage them). New Directions for Student Services, 81-89. doi:10.1002/ss.167

Reason, R. D. \& Davis, T. L. (2005). Antecedents, precursors, and concurrent concepts in the development of social justice attitudes and actions. New Directions for Student Services, 5-15. doi:10.1002/ss. 161

Reidy, D. E., Shirk, S. D., Sloan, S. A., \& Zeichner, A. (2009). Men who aggress against women: Effects of feminine gender role violation on physical aggression in hypermasculine men. Psychology of Men and Masculinity, 10, 1-12. doi:10.1037/a0014794

Rice, P. J. (2009). Development of male social justice allies of women in college: A case study investigation of possibilities for change. Dissertation . ProQuest UMI \#3389143.

Richards, L., \& Morse, J. M. . (2007). Readme first for a user's guide to qualitative methods (2nd ed.). Thousand Oaks, CA: Sage.

Ridgeway, C. L. (1991). The social construction of status value: Gender and other nominal characteristics. Social Forces, 70, 367-386. doi:10.2307/2580244

Ridgeway, C. L., \& Correll, S. J. (2000). Limiting gender inequality through interaction: The end(s) of gender. Contemporary Sociology, 29, 110-120. doi:10.2307/2654936

Roos, P. (2008). Together but unequal: Combating gender inequity in the academy. Journal of Workplace Rights, 13, 185-199. doi:10.2190/WR.13.2.f

Rosser, S. V. (2007). Leveling the playing field for women in tenure and promotion. NWSA Journal, 19, 190-198. 
Rudman, L. A., \& Fairchild, K. (2004). Reactions to counterstereotypic behavior: The role of backlash in cultural stereotype maintenance. Journal of Personality and Social Psychology, 87, 157-176. doi:10.1037/0022-3514.87.2.157

Rudman, L. A., \& Mescher, K. (2013). Penalizing men who request a family leave: Is flexibility stigma a femininity stigma? Journal of Social Issues, 69, 322-340. doi:10.1111/josi.12017

Rudman, L. A., \& Phelan, J. E. (2008). Backlash effects for disconfirming gender stereotypes in organizations. In A. P. Brief, \& B. M. Staw (Eds.), Research in organizational behavior (Vol. 4, pp. 61-79). New York, NY: Elsevier.

Rudman, L. A., Mescher, K., \& Moss-Racusin, C. A. (2013). Reactions to gender egalitarian men: Perceived feminization due to stigma-by-association. Group Processes \& Intergroup Relations, 16, 572-599. doi:10.1177/1368430212461160

Saldana, J. (2013). The coding manual for qualitative researchers. Thousand Oaks, CA: Sage.

Sandler, B. (1986). The chilly climate revisited: Chilly for women faculty, administrators and graduate students. Washington, DC: Association of American Colleges.

Schmidt, P. (2011, October 14). Faculty unions in Ohio and Wis. Hunker Down. Chronicle of Higher Education, 58(8).

Schrock, D., \& Schwalbe, M. (2009). Men, masculinity, and manhood acts. Annual Review of Sociology, 35, 277-295. doi:10.1146/annurev-soc-070308-115933

Schuller, M. (2014). Being an insider without: Activist anthropological engagement in Haiti after the earthquake. American Anthropologist, 116, 409-412. doi:10.1111/aman.12110

Schuster, J. H., \& Finkelstein, M. J. (2006). The American faculty: The restructuring of academic work and careers. Baltimore, MD: The John Hopkins University Press. 
Science, technology, engineering, and mathematics: Equality narrows the achievement gap. (n.d.). Retrieved April 13, 2014, from www. ncwgc.org/TitleIX40/STEM.pdf

Seidman, I. (1998). Interviewing as qualitative research: A guide for researchers in education and the social sciences (2nd ed.). New York, NY: College Press.

Seo, M-G., \& Creed, W. E. D. (2002). Institutional contradictions, praxis, and institutional change: A dialectical perspective. The Academy of Management Review, 27, 222-247. doi:10.2307/4134353

Smith, C. A., Organ, D. W., \& Near, J. P. (1983). Organizational citizenship behavior: Its nature and antecedents. Journal of Applied Psychology, 68, 653-663. doi:10.1037/00219010.68.4.653

Smith, P. (1990). Killing the spirit: Higher education in America. New York, NY: Viking Press.

Stern, P. N. (1994). Eroding grounded theory. In J. M. (Ed.), Critical issues in qualitative research methods. Thousand Oaks, CA: Sage Publications.

Strauss, A., \& Corbin, J. . (1998). Basics of qualitative research: Grounded theory procedures and techniques (2nd ed.). Thousand Oaks, CA: Sage.

Sturm, S. (2006). The architecture of inclusion: Advancing workplace equity in higher education. Harvard Journal of Law \& Gender, 29, 247-334.

Su, X., Johnson, J., \& Bozeman, B. (2015). Gender diversity strategy in academic departments: Exploring organizational determinants. Higher Education, 69, 839-858. doi:10.1007/s10734-014-9808-z

Sutton, R. I. (2007). The no asshole rule. New York, NY: Business Plus.

Sykes, C. (1989). Profscam: Professors and the demise of higher education. New York, NY: St. Martin's Press. 
Tatum, B. D. (2013). The complexity of identity: "Who am I?". In M. Adams, W. J. Blumenfeld, C. Castaneda, H. W. Hackman, M. L. Peters, \& X. Zuniga, Readings for diversity and social justice (pp. 6-9). New York, NY: Routledge.

Taylor, K. (2015, November 4). CUNY Faculty members arrested after staging protest. The New York Times. Retrieved March 7, 2016, from http://www.nytimes.com/2015/11/05/nyregion/cuny-faculty-members-arrested-afterstaging-protest.html?_r $=0$

Taylor, S., \& Bogdan, R. (1984). Introduction to qualitative research methods (2nd ed.). New York, NY: John Wiley and Sons.

Thomas, J. R., Nelson, J. K., \& Silverman, S. J. (2005). Research methods in physical activity. Champaign, IL: Human Kinetics.

Thomas, R., \& Davies, A. (2002). Gender and new public management: Reconstituting academic subjectivities. Gender, Work \& Organization, 9, 372-397. doi:10.1111/1468-0432.00165

Tribune. (2015, November 9). Deans, faculty members call for Loftin's dismissal. Columbia Daily Tribune. Retrieved March 7, 2016, from http://www.columbiatribune.com/news/education/deans-faculty-members-call-for-loftins-dismissal/article_3b3c56d7-f432-573b-b02d-6787228c5369.html

Turner, R. H. (1969). The public perception of protest. American Sociological Review, 34, 815831. doi:10.2307/2095975

Van den Brink, M., \& Benschop, Y. (2012). Slaying the seven-headed dragon: The quest for gender change in academia. Gender, Work and Organization, 19, 71-92. doi:10.1111/j.1468-0432.2011.00566.x 
Van Dyne, L. V., Cummings, L. L., \& Parks, J. M. (1995). Extra-role behaviors: In pursuit of construct and definitional clarity (A bridge over muddied waters). Research in Organizational Behavior, 17, 215-285.

Van Dyne, L., Graham, J. W., \& Dienesch, R. M. (1994). Organizational citizenship behavior: Construct redefinition, measurement, and validation. Academy of Management Journal, 37, 765-802. doi:10.2307/256600

Wade, A., \& Demb, A. . (2009). A conceptual model to explore faculty community engagement. Michigan Journal of Communiity Service Learning, 5-16.

Wagner, K. C., Yates, D., \& Walcott, Q. (2012). Engaging men and women as allies: A workplace curriculum module to challenge gender norms about domestic violence, male bullying and workplace violence and encourage ally behavior. Work, 42, 107-113. doi:10.3233/wor-2012-1334

Walker, D., \& Myrick, F. (2006). Grounded theory: An exploration of process and procedure. Qualitative Health Research, 16, 547-559. doi:10.1177/1049732305285972

Welp, M. G. (1998). Pathways to diversity for White males: A study of White males' learning experiences on the path toward advocating for inclusion and equity (Order No. AAM9811592). The Fielding Institute. Ann Arbor, MI: ProQuest LLC.

West, C., \& Zimmerman, D. H. (1983). Small insults: A study of interruptions in conversations between unacquainted persons. In B. Thorne, C. Kramerae, \& N. Henley (Eds.), Language, gender and society. Rowley, MA: Newbury House.

Williams, J. C. \& Norton, D. L. (2008). Building academic excellence through gender equity. Journal of American Academic Research, 4, 185-208. 
Williams, R. L. (1989). Finding voice: The transition from individualism to social advocacy (Order No. 9010086). Ann Arbor, MI: ProQuest LLC.

Women in the sciences. (2013, June 26). Retrieved November 3, 2015, from Catalyst: http://www.catalyst.org/knowledge/women-sciences

Yarwood-Ross, L., Jack, K. (2015). Using extant literature in a grounded theory study: A personal account. Nurse Researcher, 22, 18-24. doi:10.7748/nr.22.4.18.e1316

Yin, R. K. (1994). Case study research: Design and methods. Thousand Oaks, CA: Sage.

Zaner, R. M. (1970). The way of phenomenology: Criticism as a philosophical discipline. New York, NY: Pegasus. 
APPENDIX A--Letter to ADVANCE Women Leaders

Dear ADVANCE-IT Leader,

My name is Amena Oliver Anderson. And, I am a doctoral candidate in the Interdisciplinary $\mathrm{PhD}$ in Education program at West Virginia University. My dissertation committee member, Dr. Melissa Latimer, director of WVU ADVANCE suggested that I reach out to you to ask if you would support my dissertation research project, Men Faculty Engagement in Gender Equity Work in STEM, in two major ways:

- One, agree to a one-on-one, face-to-face interview with me in person or via secure videoconference software, and

- Two, recommend to me a diverse contingent of 5-6 men faculty/administrators from your site who have been involved in the ADVANCE initiative for more than a year that I may interview.

To be clear, by diverse, I mean, in addition to, White, heterosexual men faculty, to the extent possible, I'd like recommended men to include

- men of color from within or beyond the U.S.,

- men who may openly identify as GBT

- men from different disciplinary fields, academic departments/administrative units, and

- men on the tenure-track as well as those who are tenured.

Prior to the interview, I am requesting that both men and women study participants complete a quick online, 16-item demographic questionnaire easily accessible by clicking the following link: https://docs.google.com/forms/d/e/1FAIpQLSfO2SKszuSc_A4RwPJlQ5IHBO4cjJs3YpIu9paGJ x dMe7jpA/viewform

Acknowledgement of this exempt research is on file with the West Virginia University Institutional Review Board. To ensure participant anonymity, to the extent possible, all institutional and personally identifiable information will be removed from reports of findings.

It is my hope that this research will help to illuminate the intricacies of a phenomenon that has only recently begun to receive empirical attention. I thank you for your attention and consideration and am hopeful that you will see the value in this endeavor and lend your support by making the requested recommendations and agreeing to be interviewed. At your earliest convenience, please reply to this request at aoliver1@mix.wvu.edu or call 304.312.8144.

Sincerely,

Amena

Amena Oliver Anderson

WVU Doctoral Candidate

Interdisciplinary $\mathrm{PhD}$ in Education 


\section{APPENDIX B-Letter to Men Faculty}

\section{Dear Prospective Participant,}

You were recommended to me as a possible participant in my study by one of your campus' ADVANCE_IT leaders. My name is Amena Oliver Anderson. And, I am a doctoral candidate in the Interdisciplinary $\mathrm{PhD}$ in Education program at West Virginia University. Under the supervision of my dissertation chair, Dr. Erin McHenry-Sorber, I am conducting a study to explore men faculty engagement in gender equity work in STEM. I am seeking men faculty/administrators who have been involved in some aspect of the ADVANCE-IT initiative on their campus for more than one year. Assuming you meet these criteria, I am hopeful that you will support this study by agreeing to participate in a one-on-one, face-to-face recorded interview with me, either in-person, or online via secure videoconference software for 45-60 minutes.

Prior to the interview, I am requesting that participants complete a quick online, 16 -item demographic questionnaire easily accessible by clicking the following link: https://docs.google.com/forms/d/e/1FAIpQLSfO2SKszuSc_A4RwPJ1Q5IHBO4cjJs3YpIu9paGJ x_dMe7jpA/viewform

West Virginia University's Institutional Review Board acknowledgement of this exempt research project is on file. While this research does not present any foreseeable risks to participants' well-being, an effort to ensure participant anonymity will be made by removing, to the extent possible, all institutional and personally identifiable information.

It is my hope that this research will help to illuminate the intricacies of a phenomenon that has only recently begun to receive empirical attention. I am hopeful that you will see the value in this endeavor and agree to participate in this study. I appreciate your attention and consideration and ask that you reply to this email request at aoliver1@mix.wvu.edu indicating whether I can reach you to arrange an interview within the coming weeks. I can also be reached by phone at 304.312.8144.

Thank you so much for considering my request and I look forward to the prospect of your participation.

Sincerely,

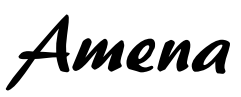

Amena Oliver Anderson

WVU Doctoral Candidate

Interdisciplinary $\mathrm{PhD}$ in Education 


\section{APPENDIX C—Demographic Questionnaire}

Participants in the dissertation study Exploring Men Faculty Engagement in Gender Equity Work are asked to complete this form prior to their interview with the researcher. Please forward any questions or concerns about this form to Amena Anderson at aoliver1@ mix.wvu.edu. THANK YOU!

1. Full name

2. Current Institution

3. Years at Current Institution

$0-5$

$5-10$

more than 10

4. Where did you grow up (U.S. city \& state or other country and region)?

5. Age

6. Gender

man

woman

Prefer not to say

Other...

7. How do you identify racially/ethnically?

African-American or Black American

Hispanic or Latinx (non-White)

Hispanic or Latinx (White)

Mexican-American or Chicano/a

Asian/Pacific-Islander

White American or Caucasian

Native American or American Indian

Other...

8. My immediate family includes... (check all that apply)

my opposite sex partner/spouse

my same sex partner/spouse

one or more sons 
one or more daughters

other relatives, e. g. parents, grandchildren, cousins, siblings

one or more pets

9. Political leaning

mostly liberal

mostly moderate

mostly conservative

Other...

10. How would you describe your religious affiliation?

11 . What is your faculty rank?

tenured

tenure track

clinical/teaching (non-tenure track)

instructor/adjunct (non-tenure track)

Not applicable

12. What is your administrative rank?

Program Director

Department Chair

Dean

Not applicable

Other...

13. What is the name of your academic department?

14 . What is your specific disciplinary field?

15. What are your major areas of research?

16. Please list all degrees earned and awarding institutions. 


\section{APPENDIX D-Interview Protocol (Men)}

1. I'd like us to start by getting to know a little bit about each other. I am.... Now, tell me something interesting about you. (Goal: Build Rapport)

2. How did you come to be involved in the ADVANCE initiative on your campus? (Goal: Build Rapport, Identify Points of Access for Engaging in Gender Equity Work)

3. (a)What were your initial thoughts about this initiative and the idea of promoting gender equity in general? (Goal: Explore Thinking about Gender Equity Initiatives) (b) What about the ROLE you would play in this effort, as a man, as the gender dominant group member who is engaging in an effort to promote the interests of women ALONGSIDE women? Talk about what you understand about the advantages and challenges of including men in this work and then, more specifically, talk about the advantage of specifically including you in this work. What is it that you bring to the table in terms of power and influence that is useful in advancing this cause? (Goal: Explore Thinking About Ally Role Perceptions of One's Power/Influence)

4. (a) To what extent would you say, you have cultivated an advocate/ally identity? (b) How comfortable are you with openly wearing the label—advocate? ally? feminist? activist? (Goals for $3 \&$ 4: Explore Thinking about Ally Identity, Comfort w/Wearing Labels)

5. (a) What is the specific work we are talking about when we say "gender equity work"? What does it look like? what activities/tasks characterize it? (Goal: Define/Capture actual perceptions of the work) (b) Talk about some of the specific forms of this work that you carry out through ADVANCE. (Possible follow-up: How is the work you described different from what you ordinarily do as a faculty member?) (Goal: Locate Evidence of Actual Gender Equity—Identified Work Performed, Participants' Assessment of that Work in Relation to Traditional Faculty Work).

6. (a) What percentage of your time is spent engaged in gender equity work? How do you reconcile that expenditure of time with your other faculty work responsibilities? (b) How easily does gender equity work fit into your disciplinary tradition/the work you carry out as a professor and scholar? (Goal: Assess Participant Investment in Gender Equity Work, Assess Participants' Rationalizations/Explanations Regarding How/Where this Work fits)

7. (a) Talk about factors that promote your engagement in this work, as well as those that discourage your engagement in this work? (Goal: Explore the Extent to which Participants identify textual factors and those relate to intersectionality) (b) How would you assess the costs/benefits of engaging in this work? (Goal: Explore the Extent to which Participants are explicit about real costs—risks, and real benefits--advantages)8. 
8. (a) How do you think about "being an academic" now, versus how you thought about it before your engagement in ADVANCE? (b) How do you think about "gender or being a man" now versus how you thought about it before your engagement in ADVANCE? (Goal: Explore how engaging in gender equity work may have affected perceptions about academic and gender identities/roles/requirements/expectations)

9. Talk about the ways in which intersectionality influences your experiences as a male ally/advocate as it relates to issues such as risks and rewards associated with doing this work, the type of gender equity work you undertake and your level of engagement in that work, as well as your perception of how this work fits in relation to the work that is expected of you as a faculty member. (Goal: Explore perceptions of Impact of Intersectionality on the experience of Men Faculty Engagement in Gender Equity Work).

10. So, we've had a really enlightening discussion, before we conclude is there anything we haven't discussed that you'd like to share related to the phenomenon of men faculty engagement in gender equity work - things you may have experienced, observed, contemplated, that you believe in an important component of any meaningful discourse around these issues? 


\section{APPENDIX E—-Interview Protocol (Women)}

1. I'd like to begin by asking you to tell me about yourself and how you came to be involved in ADVANCE.

2. Talk to me about men faculty engagement in ADVANCE. What are your thoughts about it? What do you think it is important to know or consider about engaging men in gender equity work?

3. In your experiences as an ADVANCE leader on your campus, what challenges or opportunities have you observed as they pertain to engaging men in gender equity work?

4. What do you perceive to be the drivers that lead men faculty to engage in projects like ADVANCE?

5. In your opinion, what constitutes men doing gender equity work and what does not?

6. What do you believe is important for a study like this one to address? 
